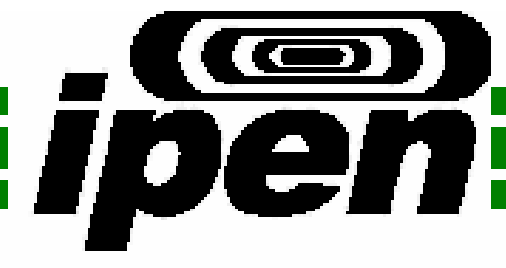

AUTARQUIA ASSOCIAD A A UIIVERSIDADE DE SÃo PAULO

\title{
ELABORAÇÃO DE UM PROCEDIMENTO PARA CONTROLE DE QUALIDADE EM SISTEMAS DE RADIODIAGNÓSTICO ODONTOLÓGICO
}

\author{
PAULA SERRA SASAKI ANDRADE
}

Dissertação apresentada como parte dos requisitos para obtenção do Grau de Mestre em Ciências na Área de Tecnologia Nuclear - Aplicações.

Orientadora:

Dra. Maria da Penha Albuquerque Potiens 
INSTITUTO DE PESQUISAS ENERGÉTICAS E NUCLEARES

Autarquia associada à Universidade de São Paulo

\title{
ELABORAÇÃO DE UM PROCEDIMENTO PARA CONTROLE DE QUALIDADE EM SISTEMAS DE RADIODIAGNÓSTICO ODONTOLÓGICO
}

\author{
Paula Serra Sasaki Andrade
}

Dissertação apresentada como parte dos requisitos para obtenção do Grau de Mestre em Ciências na Área de Tecnologia Nuclear Aplicações.

Orientadora:

Dra. Maria da Penha Albuquerque

Potiens

São Paulo 


\section{Dedicatória}

Ao Marcos,

Aos meus pais,

e a Deus 


\section{Agradecimentos}

Agradeço a minha orientadora Dra. Maria da Penha Albuquerque Potiens pela amizade, por sua dedicação na orientação deste trabalho, pela paciência e pelos conhecimentos adquiridos para minha formação científica.

Dra. Linda V. E. Caldas pela oportunidade de ingressar nesta nova área.

Dr. Vitor Vivolo pelas contribuições para o desenvolvimento deste trabalho.

Dr. Reynaldo Pugliesi por disponibilizar o laboratório do seu grupo de pesquisa.

Ao IPEN pela oportunidade para o desenvolvimento deste trabalho.

Aos colegas do LCI que sempre me receberam com carinho.

A minha mãe e meu pai pelo incentivo e apoio durante mais esta etapa da minha vida.

Especialmente ao meu Marcos pelo apoio, incentivo, dedicação, compreensão e acima de tudo pelo seu amor durante todos esses anos.

A todos que, de algum modo, tenham participado direta ou indiretamente na realização deste trabalho.

E acima de tudo e todos a Deus, por mais esta etapa vencida.

Paula Sasaki 


\title{
ELABORAÇÃO DE UM PROCEDIMENTO PARA CONTROLE DE QUALIDADE EM SISTEMAS DE RADIODIAGNÓSTICO ODONTOLÓGICO
}

\author{
Paula Serra Sasaki Andrade
}

\section{RESUMO}

O trabalho apresenta uma metodologia para aplicação de procedimentos de referência, seguindo as recomendações da Portaria Federal n 453 do Ministério da Saúde (PF 453), para controle de qualidade em sistemas de radiodiagnóstico odontológico, que possa ser aplicada em consultórios odontológicos, visando uma melhoria na qualidade da imagem radiológica e a diminuição da dose no paciente. Foram realizados testes em um equipamento de raios $X$ intrabucal, seguindo uma metodologia desenvolvida neste trabalho e os requisitos da PF 453. Foi desenvolvido neste trabalho um objeto teste (objeto simulador) para a verificação da melhor qualidade de imagem em relação ao menor tempo de exposição. A utilização deste objeto permitiu a redução do tempo de exposição de $0,5 \mathrm{~s}$, maior valor da região linear da curva característica, para $0,2 \mathrm{~s}$. O sistema de raios $X$ testado atendeu de maneira satisfatória à norma, destacando que a dose de entrada na pele diminuiu com o uso de posicionadores, mas o tamanho do campo aumentou e ultrapassou o valor máximo de $6 \mathrm{~cm}$ recomendado nesta portaria. A importância do controle de qualidade em sistemas de radiodiagnóstico odontológico é evidenciada pelo uso rotineiro da radiação $X$ nos consultórios odontológicos. A PF 453 recomenda a realização dos testes de constância com freqüência mínima de 2 anos, porém sugere-se que o próprio profissional, cirurgião-dentista, implemente seu controle interno da qualidade das radiografias obtidas em seu aparelho. Isto poderá ser executado por meio de exposições mensais do objeto teste (objeto simulador) desenvolvido neste trabalho. 


\title{
QUALITY CONTROL PROCEDURES OF DENTAL DIAGNOSTIC RADIOLOGY SYSTEMS
}

\author{
Paula Serra Sasaki Andrade
}

\begin{abstract}
This work presents quality control reference procedures for dental diagnostic radiology systems, following the recommendations of the Publication 453 of the Brazilian Health Ministry (PF 453), to be applied in dental clinics, in order to achieve an improvement in the radiological image qualities and the patient dose reduction. All tests were applied in an intraoral $X$ rays system, following the methodology developed and the requirements of the PF 453. In order to verify the best quality of the image in relation to the smaller exposition time an object test was also developed in this work. The use of this object allowed the reduction of the exposition time of 0.5 seconds, the maximum value of the linear region of the characteristic curve, for 0.2 seconds. The tested $X$ rays system showed a very good agreement with the applied procedures, detaching the reduction of the skin entrance dose using the film-holding devices. However, the size of the field increased and exceeded the maximum value of $6 \mathrm{~cm}$ recommended in the standard. The importance of the quality control in dental diagnostic radiology systems is essential due to the constant use of $X$ radiation in dental clinics. The PF453 recommends the frequency of at least two years for the constancy tests. However, it is suggested that the professional, surgeon-dentist, should be responsible for the internal control of the image quality obtained from the $X$ rays device. This can be done through monthly exposures of the object test developed in this work.
\end{abstract}




\section{SUMÁRIO}

1. INTRODUÇÃO

1.1 Histórico sobre a utilização dos raios X em odontologia............................. 4

1.2 Responsabilidades dos profissionais na área odontológica.......................... 7

2. FUNDAMENTOS

2.1 Raios X

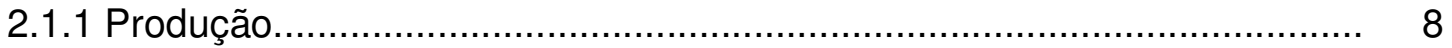

2.1.2 Aparelhos de raios X odontológicos................................................. 9

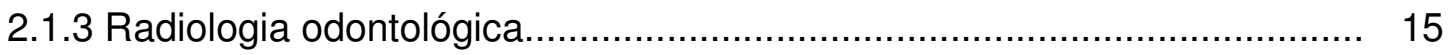

2.2 Grandezas e unidades em dosimetria e radioproteção.............................. 16

2.2.1 Exposição................................................................................ 16

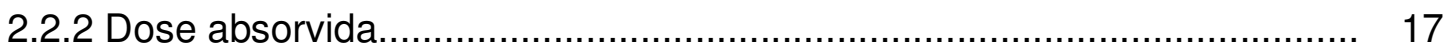

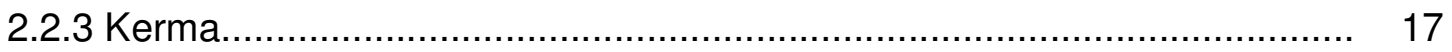

2.2.4 Dose de entrada na pele (DEP) ..................................................... 18

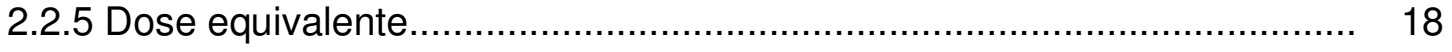

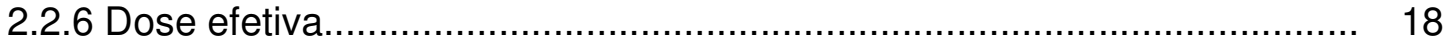

2.3 Efeitos biológicos da radiação.............................................................. 18

2.4 Controle de qualidade em radiodiagnóstico.............................................. 20

2.4.1 Formação da imagem radiográfica.................................................... 21

2.4.2 Fatores de exposição da imagem...................................................... 22

2.4.3 Critérios de qualidade para imagens radiográficas................................... 23

2.4.4 Métodos para redução da dose no paciente............................................. 24

2.5 Normas e recomendações................................................................ 25

2.5.1 Portaria Federal n 453 do Ministério da Saúde, Secretaria de Vigilância Sanitária.

2.5.2 National Council on Radiation Protection and Measurements, report 145: Radiation Protection in Dentistry .................................... 27

2.5.3 European guidelines on radiation protection in dental radiology - The

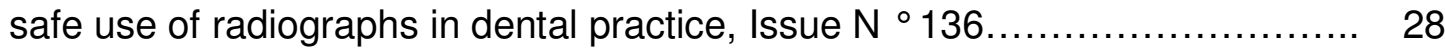

2.5.4 Protocolo Español de Control de Calidad en Radiodiagnóstico............. 28 


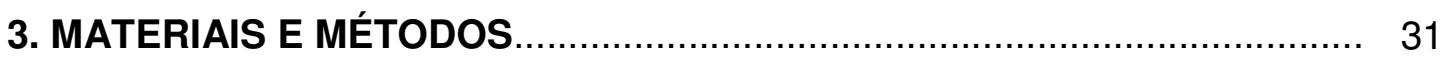

3.1 Sistema de radiação - X.................................................................. 31

3.2 Instrumentos de medida................................................................... 31

3.2.1 Tempo de exposição..................................................................... 31

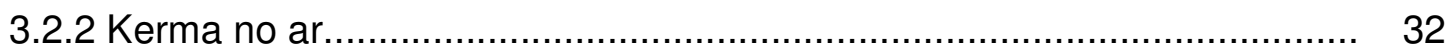

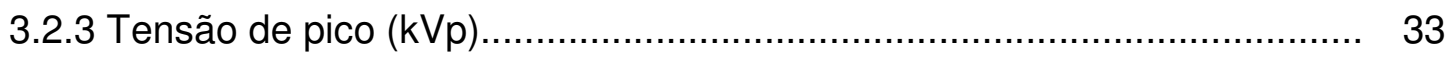

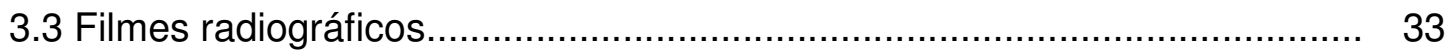

3.4 Absorvedores de alumínio................................................................ 34

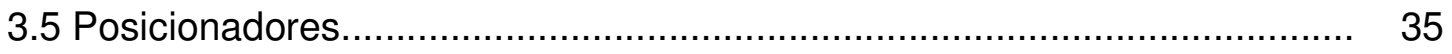

3.6 Materiais para objeto teste............................................................... 35

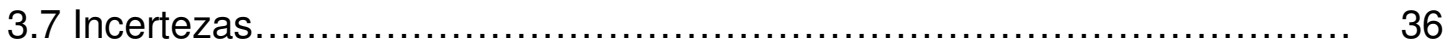

4. RESULTADOS E DISCUSSÕES …….............................................. 37

4.1 Determinação da camada semi-redutora (CSR) ...................................... 37

4.1.1 Primeiro arranjo experimental.......................................................... 37

4.1.2 Segundo arranjo experimental....................................................... 41

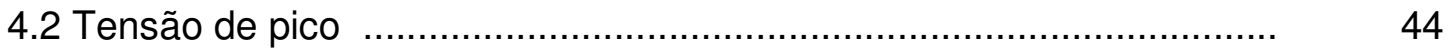

4.3 Tamanho de campo ......................................................................... 45

4.4 Reprodutibilidade do tempo de exposição e da taxa de kerma no ar........... 47

4.5 Linearidade da taxa de kerma no ar com o tempo de exposição.................. 50

4.6 Dose de entrada na pele (DEP)....................................................... 54

4.7 Padrão de imagem radiográfica: desenvolvimento de um objeto teste

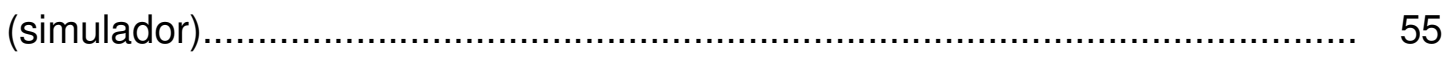

4.8 Integridade das vestimentas de proteção individual................................... 60

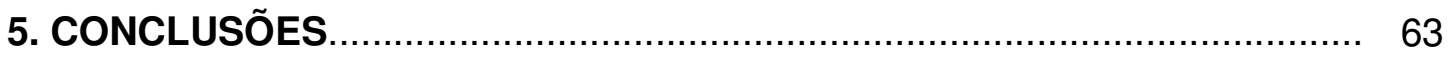

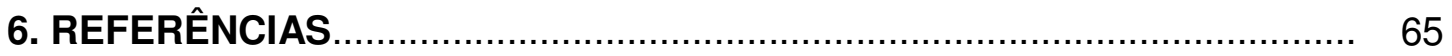




\section{LISTA DE FIGURAS}

FIGURA 1.1 - O físico alemão Wilhelm Conrad Roentgen e a radiografia da mão de sua esposa...........................................................................

FIGURA 1.2 - A primeira radiografia dentária obtida pelo Dr. Otto Walkhoff...... 5

FIGURA 2.1 - Esquema genérico de um aparelho de raios X.......................... 8

FIGURA 2.2 - Exemplo qualitativo de espectros de raios $X$ emitidos para

várias tensões de aceleração entre anodo e catodo.........................................

FIGURA 2.3 - a) Esquema genérico de um tubo de raios $X$ odontológico; b)

Esquema genérico de uma ampola de raios $X$ odontológico; $c$ ) Tubo de raios

$X$ utilizado no trabalho; d) Ampola tipicamente utilizada em aparelhos

odontológicos.

FIGURA 2.4 - Filtro de alumínio utilizado em aparelhos de raios $X$

odontológicos

FIGURA 2.5 - Colimador de chumbo utilizado em aparelhos de raios $X$

odontológicos.

FIGURA 2.6 - Cilindro localizador utilizado em aparelhos de raios $X$ de $70 \mathrm{kV}$

FIGURA 2.7 - Controle do tempo de exposição e cabo de conexão com o aparelho

FIGURA 2.8 - Suportes disponíveis para aparelhos odontológicos.

FIGURA 2.9 - Geometria ideal para a realização de radiografias utilizando a técnica do paralelismo

FIGURA 2.10 - Geometria ideal para a realização de radiografias utilizando a técnica da bissetriz.

FIGURA 2.11 - Primeiros casos de câncer nas mãos de médicos, relatados em 1907

FIGURA 2.12 - Filme radiográfico utilizado no trabalho: a) Face exposta aos raios X e para abertura; b) Seqüência de acomodação interna; c) Capa protetora, película, lâmina de chumbo e papel.

FIGURA 2.13 - Câmara escura portátil utilizada para revelação de filmes intrabucais. 
FIGURA 3.1 - Aparelho de raios X Dabi Atlante, Spectro 70X, seletronic, com $70 \mathrm{kV}, 8 \mathrm{~mA}$ e filtração nominal total equivalente a 2,71 mm Al..

FIGURA 3.2 - Detector de tempo de exposição marca Fabinject calibrado pelo IEE/USP

FIGURA 3.3 - Câmara de ionização marca Gammex, modelo RMI 242, e calibrada em termos de kerma no ar (IPEN/CNEN-SP).

FIGURA 3.4 - Medidor de quilovoltagem (kVp), marca Unfors, e calibrado conforme certificado do IEE/USP.

FIGURA 3.5 - Filmes radiográficos para a determinação do tamanho de campo (feixe útil) de aparelhos de raios $\mathrm{X}$.

FIGURA 3.6 - Placas de alumínio, com $1 \mathrm{~mm}$ de espessura cada, posicionadas para a determinação da camada semi-redutora (CSR) do feixe de raios $X$

FIGURA 3.7 - Posicionador utilizado frequentemente na prática odontológica, utilizado para fixar filmes radiográficos e alinhá-los com o localizador dos aparelhos de raios $X$

FIGURA 4.1 - Arranjo experimental utilizado para a medição da camada semi-redutora: a) sem absorvedor de alumínio; b) com absorvedor de alumínio.

FIGURA 4.2 - Resultados obtidos de kerma no ar em função da espessura de alumínio, na série 1, para a determinação da CSR (média $=2,37 \pm 0,11 \mathrm{~mm}$ Al), por meio da função exponencial ajustada aos pontos experimentais. FIGURA 4.3 - Resultados obtidos de kerma no ar em função da espessura de alumínio, na série 2, para a determinação da CSR (média = 2,410 00,019 $\mathrm{mm} \mathrm{Al}$ ), por meio da função exponencial ajustada aos pontos experimentais... 
FIGURA 4.4 - Resultados obtidos de kerma no ar em função da espessura de alumínio, na série 3, para a determinação da CSR (média =2,26 $\pm 0,06 \mathrm{~mm}$ $\mathrm{Al})$, por meio da função exponencial ajustada aos pontos experimentais. FIGURA 4.5 - Arranjo experimental utilizado para a medição da camada semi-redutora, segundo a RE $n^{\circ} 64$.

FIGURA 4.6 - Resultados obtidos de kerma no ar em função da espessura de alumínio obtido para a determinação da CSR (média = 2,21 $\pm 0,05 \mathrm{~mm} \mathrm{Al}$ ), por meio da função exponencial ajustada aos pontos experimentais

FIGURA 4.7 - Arranjo experimental utilizado para a medida de kVp: a) sem posicionador DFF = $20 \mathrm{~cm}$; b) com posicionador DFF $=27,5 \mathrm{~cm}$

FIGURA 4.8 - Arranjo experimental utilizado para a determinação do tamanho de campo: a) DFF $=20 \mathrm{~cm}$ com localizador; b) $\mathrm{DFF}=27,5 \mathrm{~cm}$ com localizador.

FIGURA 4.9 - Arranjo experimental utilizado para a medição da reprodutibilidade do tempo de exposição sem posicionador $(D F F=20 \mathrm{~cm}) \ldots \ldots$ FIGURA 4.10 - Arranjo experimental utilizado para a medição do kerma no ar para $\mathrm{DFF}=20 \mathrm{~cm}$ e $27,5 \mathrm{~cm}$.

FIGURA 4.11 - Teste de linearidade do sistema de raios $X$, kerma no ar em função do tempo de exposição nominal, com DFF $=20 \mathrm{~cm}$ (série 1)

FIGURA 4.12 - Teste de linearidade do sistema de raios $X$, kerma no ar em função do tempo de exposição nominal, com DFF = 27,5 cm (série 1).

FIGURA 4.13 - Teste de linearidade do sistema de raios $X$, kerma no ar em função do tempo de exposição nominal, com DFF $=20 \mathrm{~cm}$ (série 2)

FIGURA 4.14 - Teste de linearidade do sistema de raios X, kerma no ar em função do tempo de exposição nominal, com DFF = 27,5 cm (série 2)..............

FIGURA 4.15 - Teste de linearidade do sistema de raios $X$, kerma no ar em função do tempo de exposição nominal, com DFF = $20 \mathrm{~cm}$ (série 3).................

FIGURA 4.16 - Teste de linearidade do sistema de raios $X$, kerma no ar em função do tempo de exposição nominal, com DFF = 27,5 cm (série 3).

FIGURA 4.17 - Gráfico utilizado para a determinação do fator de retroespalhamento, para DFF $=20 \mathrm{~cm}$ e $27,5 \mathrm{~cm}$, para uma CSR de 2,21 cm 
FIGURA 4.18 - Placa de acrílico, placas de alumínio perfuradas, que foram sobrepostas para confecção do objeto teste, e a base de alumínio..

FIGURA 4.19 - Objeto teste desenvolvido para avaliar a qualidade da imagem radiográfica, composta de uma placa de alumínio perfurada, com diâmetros e profundidades diferentes recoberta por acrílico.

FIGURA 4.20 - Curva de tempo de exposição característica do filme

ektaspeed, Kodak

FIGURA 4.21 - Imagens do objeto teste irradiado em intervalos de tempo de

0,1 a 0,5 segundos.

FIGURA 4.22 - Aventais de proteção individual testados: (a) avental de borracha plumbífera e (b) avental de chumbo.

FIGURA 4.23 - Arranjo utilizado para detecção de trincas em vestimentas plumbífera.

FIGURA 4.24 - Imagem da uma trinca detectada na inspeção da vestimenta. 


\section{LISTA DE TABELAS}

TABELA 4.1 - Resultados obtidos da CSR em alumínio utilizando as duas

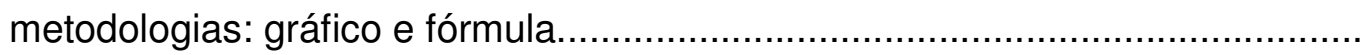

TABELA 4.2 - Resultados obtidos da CSR utilizando as duas metodologias:

gráfico e fórmula, seguindo a RE $n^{\circ} 64$

TABELA 4.3 - Valores obtidos para a tensão de pico para $20 \mathrm{~cm}$ e $27,5 \mathrm{~cm}$.

Tensão nominal.

TABELA 4.4 - Valores de tamanho de campo obtidos utilizando quatro arranjos diferentes

TABELA 4.5 - Valores obtidos de tempo de exposição (DFF $=20 \mathrm{~cm}$ ) do sistema de raios $X$ Dabi Atlante de $70 \mathrm{kV} / 8 \mathrm{~mA}$, utilizando-se detector

Fabinject.

TABELA 4.6 - Valores obtidos de kerma no ar (K) e respectivos tempos de exposição $(\Delta \mathrm{t})$ para DFF $=20 \mathrm{~cm}$ sistema de raios $\mathrm{X}$ Dabi Atlante de $70 \mathrm{kV} / 8$ $\mathrm{mA}$, com a câmara de ionização do medidor Gammex

TABELA 4.7 - Valores obtidos de kerma no ar (K) e respectivos tempos de exposição $(\Delta \mathrm{t})$ para DFF $=27,5 \mathrm{~cm}$ sistema de raios $X$ Dabi Atlante de $70 \mathrm{kV} / 8$ $\mathrm{mA}$, com a câmara de ionização com o medidor Gammex.

TABELA 4.8 - Valores de dose de entrada na pele (DEP) a partir dos resultados obtidos de kerma no ar, para DFF $=20 \mathrm{~cm}$

TABELA 4.9 - Valores de dose de entrada na pele (DEP) a partir dos resultados obtidos de kerma no ar, para DFF $=27,5 \mathrm{~cm}$. 


\section{INTRODUÇÃO}

As principais fontes de dose de radiação para a população são oriundas das radiações naturais e das artificiais utilizadas na área de saúde ${ }^{1}$. No mundo são realizadas em torno de 2 milhões e 500 mil exposições para diagnósticos por ano, dentre os quais $78 \%$ são provenientes de raios $X$ médicos, $21 \%$ de odontológicos e $1 \%$ de exames na área de medicina nuclear ${ }^{2,3}$. As doses absorvidas devido a exames radiológicos podem ser consideradas pequenas em relação a outros procedimentos, como por exemplo, à radioterapia, e normalmente não oferecem riscos para a indução de efeitos determinísticos. No entanto, em alguns tipos de exames radiológicos estas doses podem ser significativas, mesmo quando executados por profissionais treinados e aparelhos modernos. Este fato indica a necessidade de aplicação de testes de controle de qualidade adequados ${ }^{4}$.

Nas últimas décadas houve um aumento significativo na preocupação mundial com as doses de radiação provenientes dos exames radiológicos em geral, incluindo os odontológicos. Isto pode ser observado em publicações da Agência Internacional de Energia Atômica (IAEA), como a TEC-DOC 796 "Radiation doses in diagnostic radiology and methods for doses reduction", publicada em abril de $1995^{5}$. No ano seguinte foi publicado o Protocolo Espanhol de Controle de Qualidade em Radiodiagnóstico. Na sua $2^{\text {a }}$ revisão, em 2002, este documento estabeleceu critérios para controle de qualidade em equipamentos de radiodiagnóstico, inclusive odontológico, que contribuam para o uso eficiente das radiações ionizantes, permitindo a obtenção de imagens de alta qualidade diagnóstica com menor risco aos pacientes e aos profissionais da área ${ }^{6}$.

Com o mesmo objetivo foi publicado pela Comunidade Européia em 2004 o "European guidelines on radiation protection in dental radiology :The safe use of radiographs in dental practice", $N^{0} 136^{7}$. Este documento fornece um guia prático de proteção radiológica para profissionais dentistas, assistentes e membros do público, baseado em duas diretrizes da União Européia. A primeira é a "Directive 96/29/Euratom", de 13.05.1996, sobre a proteção da saúde dos profissionais e públicos em geral aos danos causados pela radiação ionizante. A 
segunda, "Directive 97/43/Euratom" de 30.06.1997, sobre a proteção individual aos danos causados pela radiação ionizante em relação às exposições médicas. Todas as medidas adotadas neste documento visam não somente evitar exposições desnecessárias e excessivas, mas também fornecer qualidade e eficácia no uso da radiação na medicina ${ }^{7}$.

O National Council on Radiation Protection (NCRP) na sua publicação 145 de 2003, Radiation Protection in Dentistry ${ }^{8}$, faz 109 recomendações relacionadas à minimização dos riscos da radiação nos procedimentos radiográficos dentais. O principal objetivo é a redução da exposição aos pacientes, trabalhadores e indivíduos do público utilizando o princípio "ALARA" (as low as reasonably achievable), tão baixo quanto razoavelmente exeqüível, que a publicação interpreta como sendo uma redução adicional às doses que já estão abaixo dos limites estabelecidos. A intenção é eliminar toda exposição à radiação que pode ser evitada 9 .

Na odontologia verifica-se, nos últimos anos, um aumento na utilização da radiologia devido ao desenvolvimento tecnológico dos instrumentos e a necessidade de se obter diagnósticos cada vez mais precisos. Além disso, no Brasil, este aumento também leva em consideração que a condição sócioeconômica impede o acesso de parte da população a tratamentos odontológicos particulares e especializados. Portanto, ao longo dos últimos anos surgiram muitos convênios odontológicos, que oferecem tratamentos por um custo mensal relativamente baixo. Isto gerou um aumento significativo de pacientes em muitos consultórios, cujos profissionais aceitam as condições impostas pelas empresas que administram estes convênios considerando que o número de profissionais na área odontológica vem crescendo a cada ano, diminuindo a oferta de vagas no mercado de trabalho, devido ao grande número de faculdades de odontologia no país. Para controlar o grande número de conveniados e verificar a realização dos tratamentos, conforme condições pré-estabelecidas em contrato, a empresa administradora exige que o profissional em odontologia faça uso de radiografias intrabucais antes e após cada tratamento, apenas para comprovar a necessidade e a conclusão do mesmo, acarretando um aumento significativo do número de radiografias intrabucais realizadas no Brasil $^{9}$.

Em 1998 o Ministério da Saúde publicou a Portaria Federal $453^{10}$ (PF 453) aprovando o Regulamento Técnico que estabelece as diretrizes básicas de 
proteção radiológica em radiodiagnóstico médico e odontológico e dispõe sobre o uso dos raios $\mathrm{X}$ diagnósticos em todo o território nacional. Esta portaria estabelece que os serviços de saúde devem implantar o Programa de Garantia da Qualidade que compreendam a execução do controle de qualidade dos equipamentos e do controle de procedimentos, estabelecendo as freqüências com que devem ser realizados. Além disso, esta portaria estabelece que os instrumentos para medição de níveis de radiação devem ser calibrados a cada dois anos em laboratórios credenciados, rastreados à rede nacional ou internacional de metrologia das radiações ionizantes, nas qualidades de feixes de raios $\mathrm{X}$ diagnósticos.

Para isso, o Laboratório de Calibração de Instrumentos (LCI) do IPEN possui um sistema de referência composto por duas câmaras de ionização, uma para medidas do feixe direto e outra para medidas de feixe espalhado, um eletrômetro para a conexão das câmaras, e um sistema de radiação- $X$, da marca Pantak/Seifert, onde foi possível estabelecer campos padrões de radiação ${ }^{11}$ segundo a norma IEC $61267^{12}$, para a calibração dos instrumentos de medida utilizados em radiodiagnóstico.

A crescente utilização da radiologia diagnóstica em odontologia tem feito com que vários estudos sejam realizados com relação às doses e ao controle da utilização destes instrumentos ${ }^{13-16}$. No Brasil alguns estudos vêm sendo realizados, principalmente com relação à proteção radiológica em sistemas de radiologia odontológica ${ }^{17,18}$. Entretanto, ainda não existe um programa de controle de qualidade efetivo na área odontológica que siga todos os parâmetros definidos na Portaria Federal $453^{10}$, que contribua para a qualidade da imagem radiológica e diminuição da dose. Na área médica foi publicado, em 2003, um guia de procedimentos para segurança e qualidade de imagem em radiodiagnóstico, que estabelece procedimentos específicos para equipamentos de raios $X$ convencionais, mamógrafos, com fluoroscopia e tomógrafos computadorizados ${ }^{19}$. A Agência Internacional de Energia Atômica (IAEA) está finalizando um código de prática onde, além da recomendação do uso da norma IEC 61267 para os laboratórios, estabelecerá procedimentos específicos para aplicação em cada área do radiodiagnóstico, incluindo o odontológico ${ }^{20}$.

O objetivo deste trabalho é a elaboração de um procedimento de referência, seguindo as recomendações da $\mathrm{PF} 453^{10}$, para controle de qualidade 
em sistemas de radiodiagnóstico odontológico, que possa ser aplicado nas clínicas de odontologia, visando uma melhoria na qualidade da imagem radiológica e a diminuição da dose no paciente. É importante destacar que estes procedimentos também poderão auxiliar a análise dos laudos técnicos emitidos por especialistas em física de radiodiagnóstico, bem como a fiscalização, por técnicos da Agência Nacional da Vigilância Sanitária (ANVISA).

\subsection{Histórico sobre a utilização dos raios $\mathrm{X}$ em odontologia}

Em 8 de novembro de 1895 o físico alemão Wilhelm Conrad Roentgen (1845-1923) se ocupava com a observação da condução de eletricidade através de um tubo de Crookes no seu laboratório, na Universidade de Wurzburg, na Alemanha. Nas proximidades do tubo de vácuo havia uma tela coberta com platinocianeto de bário, sobre a qual se projetava uma inesperada luminosidade, resultante da fluorescência do material. Foi então que resolveu colocar sua mão na frente do tubo, vendo seus ossos projetados na tela. Roentgen observava, pela primeira vez, aquilo que passou a ser denominado raios $X^{21}$. Em seguida Roentgen radiografou a mão de sua esposa, conforme FIG. 1.1. Esta descoberta trouxe benefícios tanto para a medicina quanto para a odontologia, pois a radiografia tornou-se um exame complementar de extrema importância para diagnósticos, tratamentos e prognósticos de qualidade. 

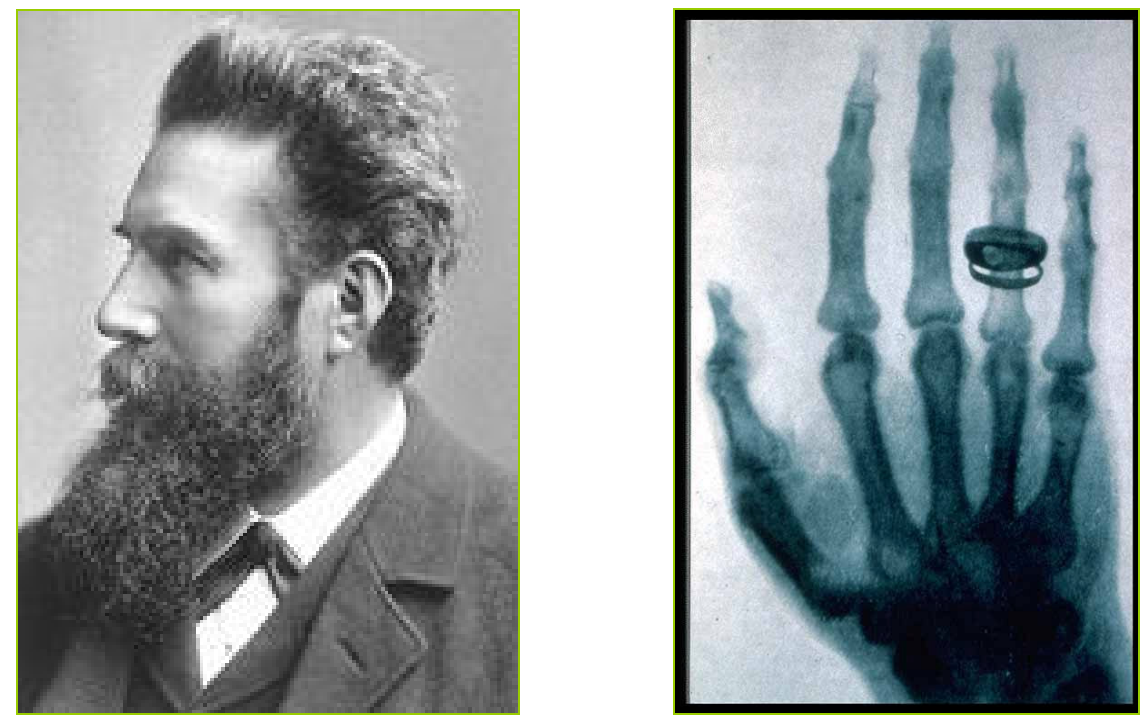

FIGURA 1.1 - O físico alemão Wilhelm Conrad Roentgen e a radiografia da mão de sua esposa ${ }^{21}$.

Vinte dias após a descoberta dos raios X por Wilhelm Conrad Roentgen, o Dr. Otto Walkhoff realizou a primeira radiografia dentária, expondo sua própria boca durante 25 minutos $^{22,23}$, mostrada na FIG. 1.2.

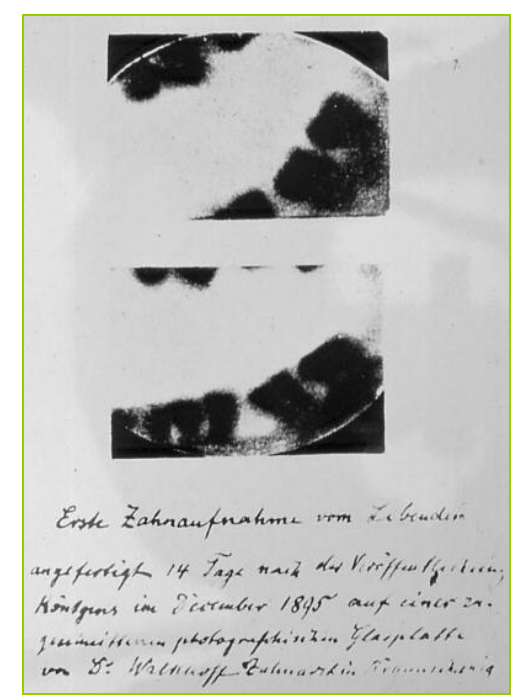

FIGURA 1.2 - A primeira radiografia dentária obtida pelo Dr. Otto Walkhoff22. 
No ano seguinte, com as pesquisas realizadas pelo Dr. Edmund Kells os raios $\mathrm{X}$ tornaram-se indispensáveis ao diagnóstico odontológico ${ }^{23,24}$.

Com a finalidade de realizar estudos e publicar recomendações sobre grandezas e unidades de radiação para aplicação em radiologia clínica e radiobiologia, foi criado em 1925, no Primeiro Congresso Internacional de Radiologia em Londres, a International Commission on Radiological Units and Measurements (ICRU). E em seguida, no Segundo Congresso Internacional de Radiologia foi criada a International Commission on Radiological Protection (ICRP), que recomenda limites de doses relativos à exposição à radiação ionizante para trabalhadores e públicos em geral ${ }^{15}$.

Em 1898 o Dr. José Carlos F. Pires foi o primeiro brasileiro a adquirir um aparelho de raios X odontológico, e em 1913 o Dr. Antonio Lima Netto, juntamente com o Dr. Carlos Newlands iniciaram o uso dos raios $X$ na prática odontológica. O ensino da radiologia odontológica teve como pioneiros os professores Cyro de Andrade e Carlos Newlands em 1932, e este último publicou o primeiro livro de radiologia dentária em 1937, segundo Freitas e outros ${ }^{22}$.

A baixa qualidade das radiografias pode originar falsos diagnósticos, sendo estas responsáveis pelo alto índice de repetições, ou seja, pelo aumento da dose nos pacientes. A obtenção de radiografias de qualidade, que possibilitam um bom diagnóstico, e conseqüentemente baixas doses, requer a execução de procedimentos para controle de qualidade ${ }^{25,26}$. Desde 1980 a Organização Panamericana de Saúde sugere um protocolo para a implantação de programas de garantia de qualidade, segundo Arguirópulo ${ }^{27}$.

No Brasil, diversos estudos vêm demonstrando o desempenho inadequado de aparelhos de raios $\mathrm{X}$ odontológicos e médicos, e apesar dos aparelhos de raios $X$ odontológicos serem utilizados desde 1913, somente no final de 1994 foi publicada uma resolução no Estado de São Paulo, que exigiu dos serviços odontológicos um programa de garantia de controle desses aparelhos ${ }^{28}$. Após quase quatro anos, em 01.06.1998, foi publicada a Portaria Federal $453^{10}$ do Ministério da Saúde que estabeleceu as diretrizes básicas de proteção radiológica em radiodiagnóstico médico e odontológico, e dispõe sobre o uso dos raios $X$ diagnósticos em todo o território nacional e dá outras providências. 


\subsection{Responsabilidades dos profissionais na área odontológica}

O profissional, cirurgião-dentista, além de obedecer aos requisitos legais de licenciamento e funcionamento do estabelecimento ${ }^{10}$, deve seguir os princípios básicos de radioproteção: justificação da prática e das exposições individuais; otimização da proteção radiológica; limitação de doses individuais.

O exame radiográfico deve ser indicado e justificado, produzindo assim um benefício real para o paciente, em comparação com o detrimento que possa ser causado pela radiação utilizada para a realização do exame ${ }^{8}$.

A otimização da proteção radiológica estabelece o princípio ALARA (as low as reasonably achievable), que tem como objetivo manter as doses de radiação tão baixas quanto razoavelmente exeqüíveis, levando em consideração fatores sócio-econômicos, além das restrições de doses aplicadas. Este princípio exige dos profissionais dentistas a otimização de diversas práticas, como exposições adequadas, seleção de equipamentos, técnicas e interpretação das radiografias dentárias, garantindo uma alta qualidade das imagens radiográficas.

A limitação de doses individuais corresponde a valores de dose efetiva (ou equivalente) estabelecidos para exposição ocupacional, ou do público, decorrentes dessas práticas, que não devem ser excedidas ${ }^{29}$.

Portanto, o dentista deve conduzir suas práticas radiológicas de acordo com os requisitos da PF $453^{10}$ e sugestões do NCRP $145^{8}$ com o objetivo de obter o máximo de benefício no tratamento com um mínimo de exposição ao paciente, assistente e público em geral. Podemos destacar fatores técnicos como blindagens, equipamentos adequados, técnicas radiológicas, câmaras escuras, receptores de imagem e um programa de garantia de qualidade. Além disso, o julgamento do dentista em prescrever exames radiológicos e a interpretação de resultados é considerado um dos fatores mais importantes nas práticas realizadas. 


\section{FUNDAMENTOS}

\subsection{Raios X}

\subsubsection{Produção}

Raios $\mathrm{X}$ podem ser produzidos num tubo de raios catódicos, aplicandose uma alta voltagem (dezenas de quilovolts, $\mathrm{kV}$ ) entre o anodo e o catodo, conforme FIG. 2.1.

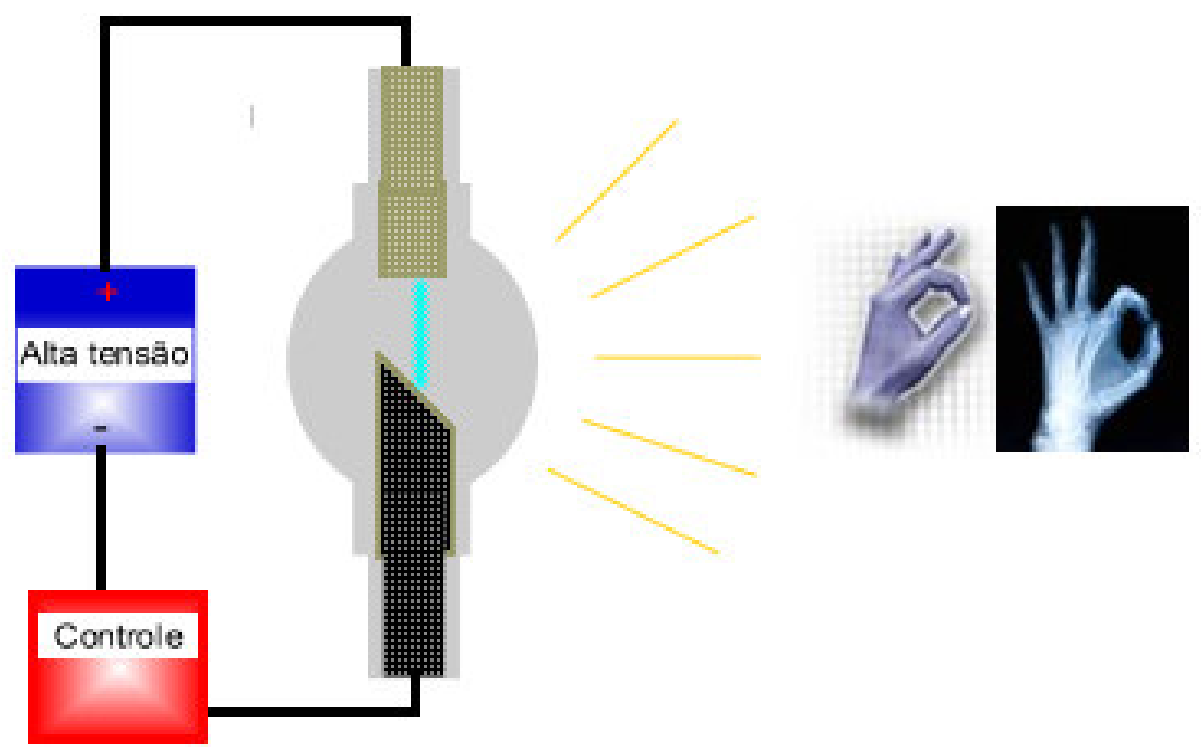

FIGURA 2.1 - Esquema genérico de um aparelho de raios $X^{21}$.

Os raios $\mathrm{X}$ são produzidos por conversão de energia quando um feixe de elétrons acelerados perde sua energia cinética de modo gradual em inúmeras colisões com o material alvo, gerando também calor. Este processo acontece dentro de uma ampola de vidro com vácuo, que possui um filamento de tungstênio, responsável pela produção dos elétrons, e um anodo que corresponde à área do alvo. A maior parte da energia é convertida em calor e apenas $1 \% \mathrm{em}$ raios $X$. Este processo é conhecido como radiação de freamento ou bremsstrahlung ${ }^{30}$. 
O choque do feixe de elétrons com o anodo (alvo) produz dois tipos de raios $\mathrm{X}$. Um deles constitui o espectro contínuo, e resulta da desaceleração do elétron durante a penetração no anodo, conforme descrito acima. O outro tipo é característico do material do anodo. Assim, cada espectro de raios $X$ é a superposição de um espectro contínuo e de uma série de linhas espectrais características do anodo. Na FIG. 2.2 podemos observar alguns espectros contínuos obtidos com um anodo de tungstênio e os respectivos potenciais usados para acelerar os elétrons. O espectro contínuo é simplesmente uma curva de contagens (número de fótons) por segundo, versus comprimento de onda do raio $X^{1,21,30,31,32}$.

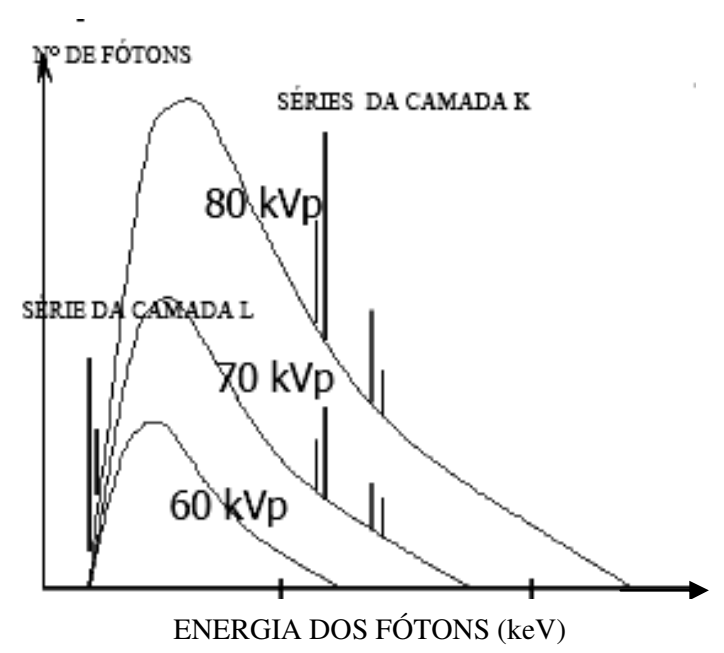

FIGURA 2.2 - Exemplo qualitativo de espectros de raios $X$ emitidos para várias tensões de aceleração entre anodo e catodo ${ }^{21}$.

\subsubsection{Aparelhos de raios $X$ odontológicos}

Os aparelhos de raios $X$ utilizados na odontologia são versões simplificadas dos empregados na área médica, onde somente o tempo de exposição pode ser variado e controlado pelo cirurgião dentista. Os principais componentes de um cabeçote são: ampola de raios $X$, filtro de alumínio, colimador e cilindro localizador. Além disso, há o suporte de cabeçote e o disparador para o controle do tempo de exposição.

A ampola de raios $X$ possui um anodo (positivo) e um catodo (negativo) no seu interior sob vácuo. No catodo há um filamento de tungstênio emissor de 
elétrons, que são acelerados por uma diferença de potencial (kV), entre o anodo e o catodo, em direção ao material alvo. Nesta interação há perda de energia cinética dos elétrons devido à interação com o forte campo coulombiano (repulsão entre elétrons) e a sua trajetória é alterada, conforme FIG. 2.3. Este fenômeno é conhecido como "Bremmstrahlung" ou "radiação de freamento".

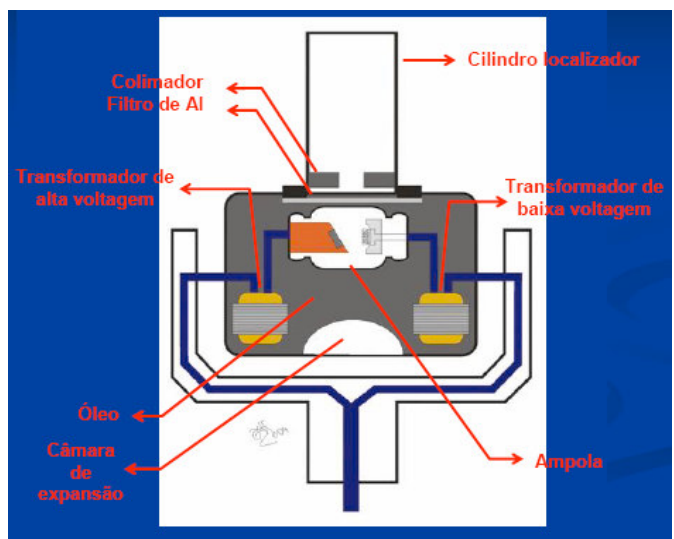

(a)

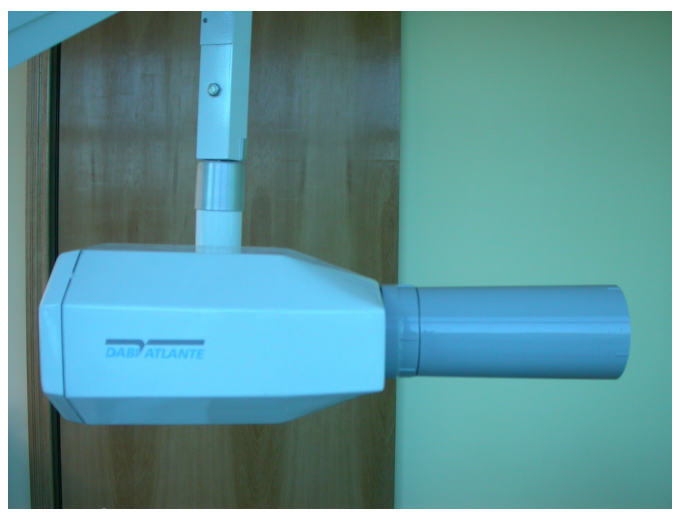

(c)

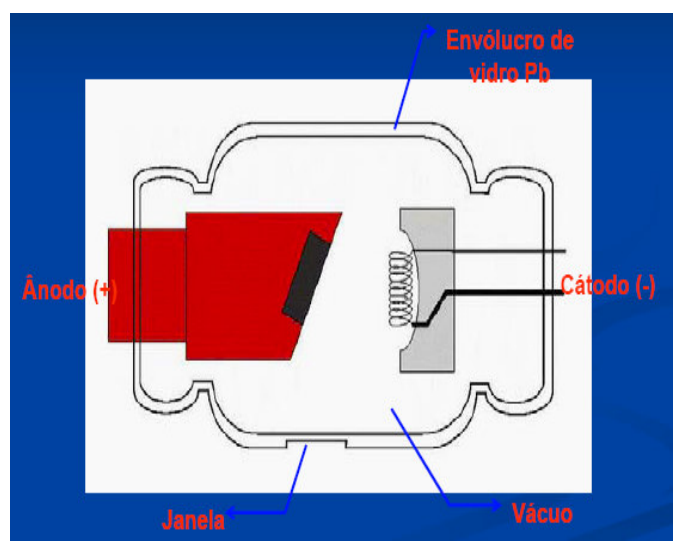

(b)

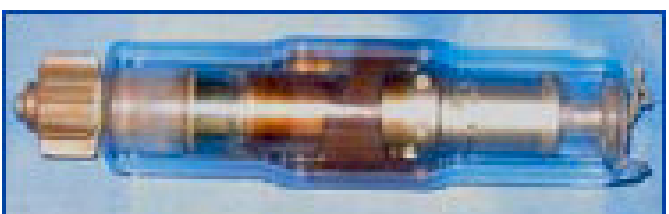

(d)

FIGURA 2.3 - a) Esquema genérico de um tubo de raios $X$ odontológico; b) Esquema genérico de uma ampola de raios $X$ odontológico; $c)$ Tubo de raios $X$ utilizado no trabalho; d) Ampola tipicamente utilizada em aparelhos odontológicos.

A energia cinética é convertida em calor (99\%) e raios $X(1 \%)$, por isso toda ampola de raios $X$ deve ser refrigerada a óleo ou água ${ }^{1,23,30}$. A qualidade dos raios $X$ gerados é proporcional à tensão de pico aplicada, e esta é fixa para 
aparelhos de raios $\mathrm{X}$ odontológicos. $\mathrm{O}$ valor mínimo recomendado por normas internacionais e nacionais é de $50 \mathrm{kV}$, pois abaixo deste valor os raios $\mathrm{X}$ não contribuem para a formação da imagem, mas somente para um aumento na dose no paciente ${ }^{6,7,10}$. A corrente elétrica do cabeçote está relacionada com o filamento de tungstênio no catodo, ou seja, a quantidade de raios $X$ gerados pela ampola. Para raios $X$ odontológicos este valor é fixo e não ultrapassa $10 \mathrm{~mA}$. $O$ cabeçote deve ficar na posição recomendada pelo fabricante quando não estiver sendo utilizado.

A filtração utilizada nestes aparelhos tem a finalidade principal de remover os fótons de raios $X$ de baixa energia do feixe, que não contribuem para a formação da imagem, mas aumentam a dose de radiação no paciente. $O$ material utilizado é o alumínio, possui formato circular com diâmetro aproximado de $2 \mathrm{~cm}$ por $1 \mathrm{~mm}$ de espessura, conforme FIG. 2.4.
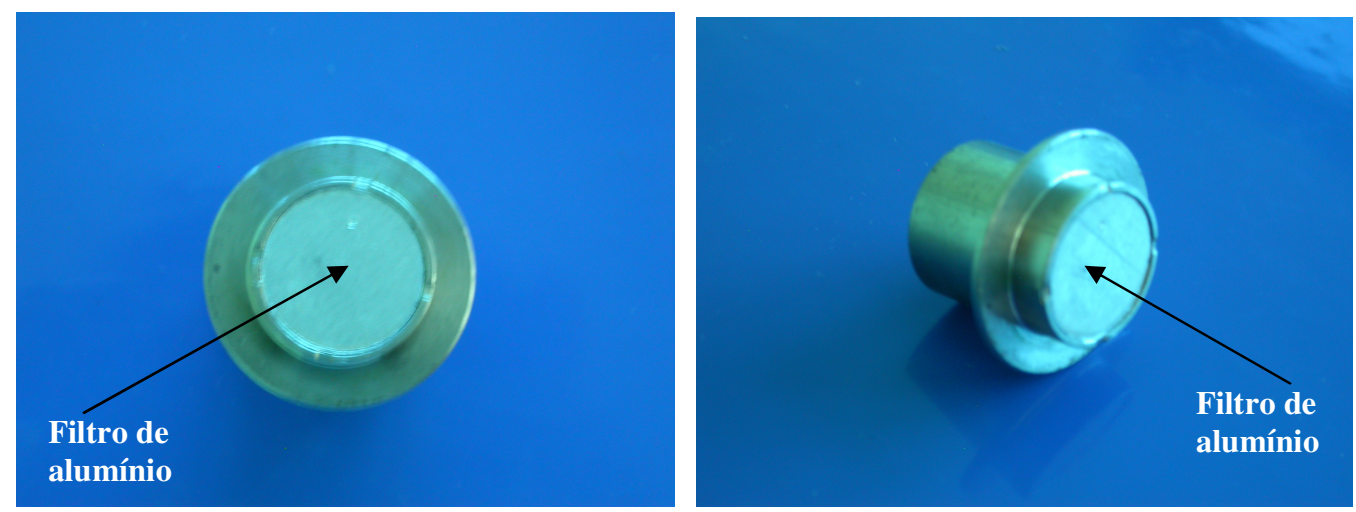

FIGURA 2.4 - Filtro de alumínio utilizado em aparelhos de raios X odontológicos.

É importante lembrar que existem outros materiais entre o ponto onde os raios X são gerados (foco) e a saída (colimador), tais como óleo e vidro, que devem ser levados em consideração para se estimar o valor equivalente em alumínio (filtração inerente). A espessura dos filtros deverá estar de acordo com normas vigentes ${ }^{1,7,10,23,30}$.

O colimador é uma peça utilizada para dar forma ao feixe e concentrar os fótons de raios $X$ gerados pela ampola em uma direção (feixe primário). É confeccionado de chumbo, possui formato circular e é fixado no cabeçote do 
aparelho, conforme FIG. 2.5. Sua largura é tal que o diâmetro do feixe formado, que incide na pele do paciente, não seja superior a $6 \mathrm{~cm}^{6,7,10}$.

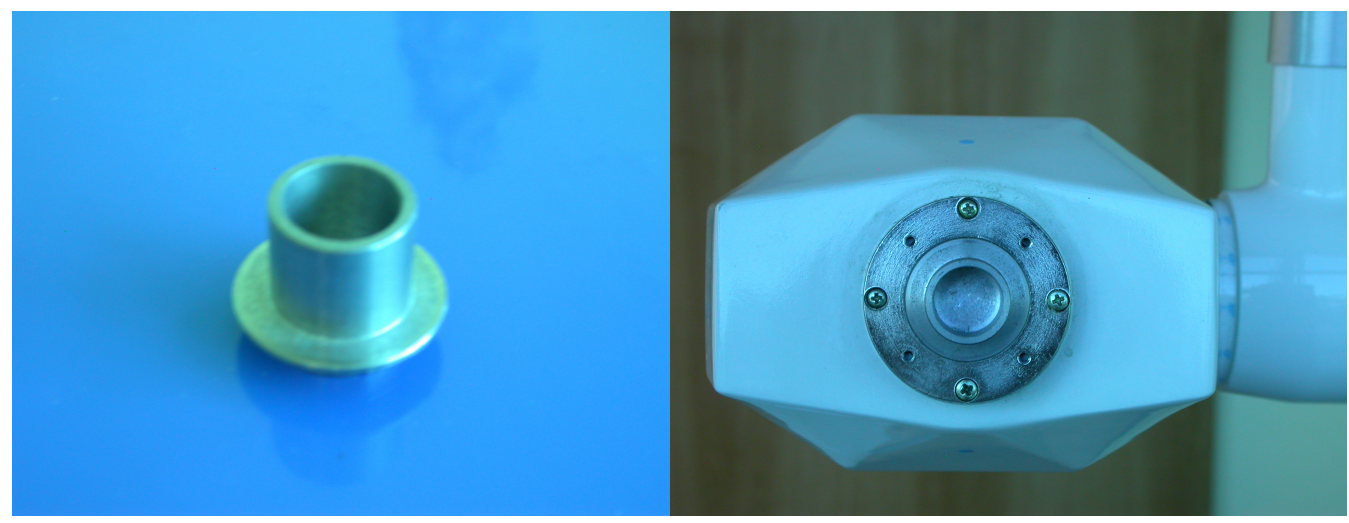

FIGURA 2.5 - Colimador de chumbo utilizado em aparelhos de raios X odontológicos.

Adicionalmente, o colimador tem a função de reduzir a dose no paciente, pois concentra o feixe na região de interesse a ser radiografada, evitando exposições desnecessárias, por exemplo, no cristalino e na tireóide. Embora as recomendações internacionais indiquem a utilização de colimadores retangulares, com dimensões de $4 \times 3 \mathrm{~cm}^{2}$, para a redução da dose entre 50 a $60 \%{ }^{7,8,23}$, no mercado nacional ainda não é possível se encontrar aparelhos com colimador retangular.

O cilindro localizador tem a função de orientar a área exata a ser radiografada, pois a sua extremidade deve ser colocada o mais próximo da face do paciente. O comprimento do localizador varia com a tensão de aceleração aplicada (kV) entre o anodo e catodo, e deve estar de acordo com normas vigentes de cada país ${ }^{6,7,10}$. No Brasil, aparelhos de raios $X$ entre 50 e $60 \mathrm{kV}$ devem possuir localizador de no mínimo $18 \mathrm{~cm}$, e os aparelhos de $70 \mathrm{kV}, 20 \mathrm{~cm}^{10}$, como mostrado na FIG. 2.6. O diâmetro do localizador deve coincidir com o do feixe de raios $X$ obtido pelo colimador, que, segundo a $P F 453^{10}$, não deve exceder $6 \mathrm{~cm}$, evitando a irradiação de áreas desnecessárias. 

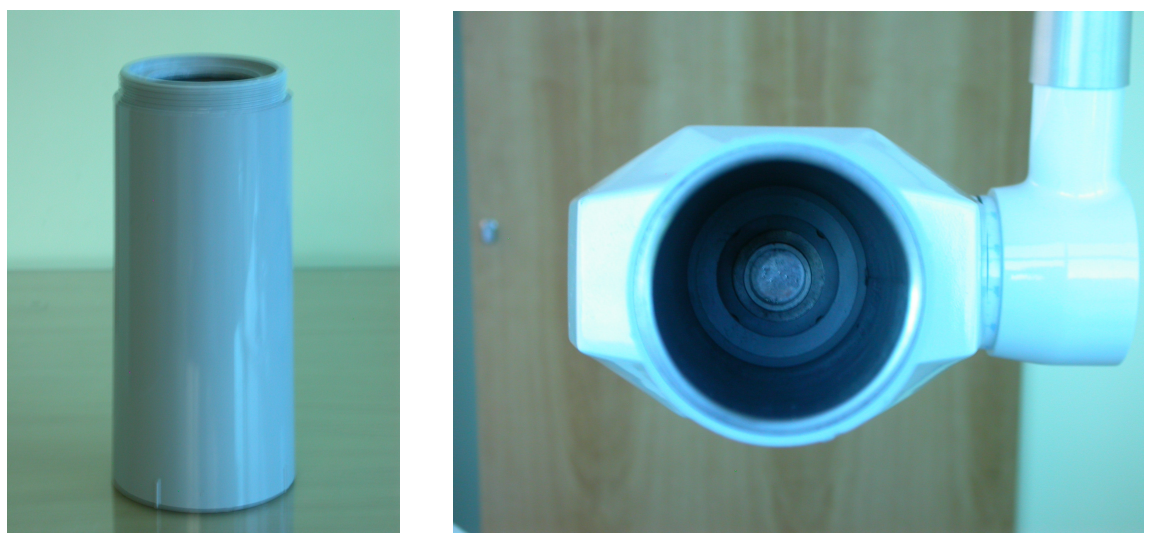

FIGURA 2.6 - Cilindro localizador utilizado em aparelhos de raios X de $70 \mathrm{kV}$.

O uso de cilindros localizadores curtos e fechados não é permitido ${ }^{6,7,10}$, pois ao atingir a ponta o feixe é espalhado irradiando regiões que extrapolam as de interesse, além de áreas vizinhas (radiação secundária). Outra informação importante é que esta radiação espalhada irá participar da formação da imagem, contribuindo assim para uma redução na sua qualidade, pois os fótons do feixe não estão paralelos.

O controle de tempo de exposição, chamado de disparador ou "timer", é o único parâmetro que o profissional pode controlar, de acordo com a região a ser radiografada e o tipo de paciente. Este controle deve ser eletrônico, e não mecânico, indicar o valor em segundos e não permitir exposições superiores a 5 segundos. $\mathrm{O}$ cabo do controle do disparador ligado ao aparelho de raios $\mathrm{X}$ deve ser de no mínimo 2 metros de comprimento, conforme FIG. 2.7, permitindo proteção adequada ao profissional e ainda manter o paciente no seu campo de visão, evitando possíveis movimentos dele. O uso de disparador automático, mais conhecido como retardo não é mais permitido ${ }^{7,10}$. Tal fato pode ser atribuído à falhas de sistema, além de possíveis movimentos do paciente, possibilitando ao profissional o maior controle da exposição da radiação. 

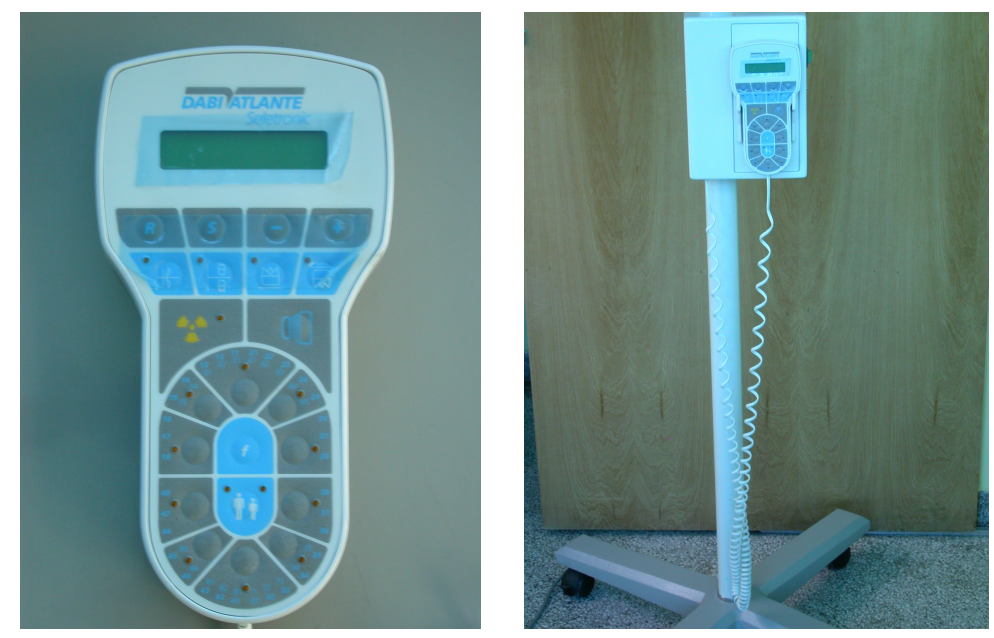

FIGURA 2.7 - Controle do tempo de exposição e cabo de conexão com o aparelho.

Os aparelhos de raios $X$ podem ser fixos ou móveis a critério do profissional e da disposição de seu consultório, conforme ilustrado na FIG. 2.8. Devem fornecer sustentação mantendo o cabeçote fixo e estável para a realização de radiografias, evitando pequenas distorções nas imagens radiográficas, devido a movimentação do cabeçote. É importante deixar o cabeçote na posição de repouso, recomendada pelo fabricante, quando não estiver em uso.

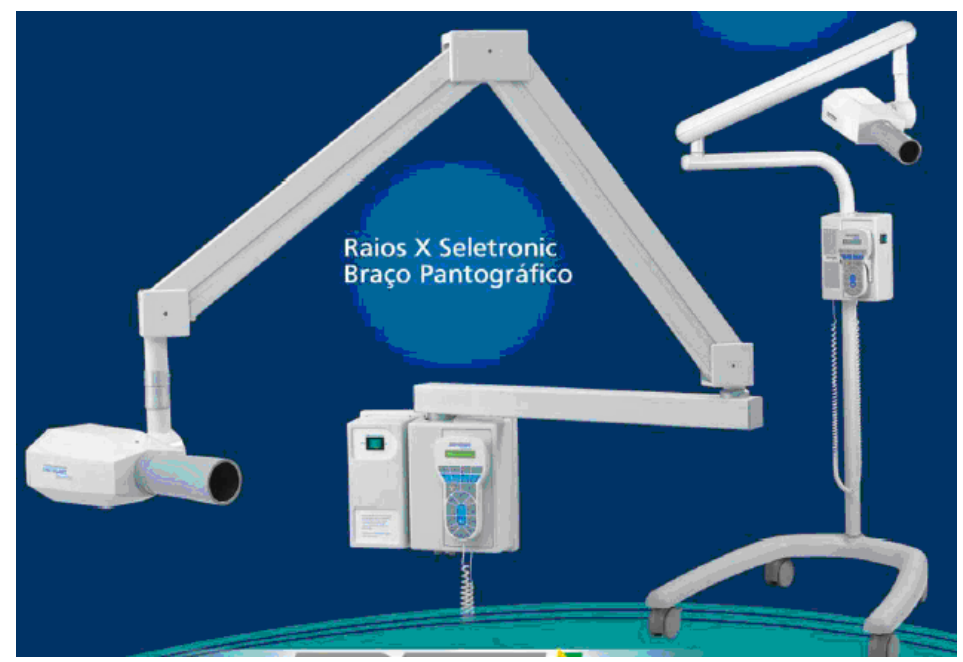

FIGURA 2.8 - Suportes disponíveis para aparelhos odontológicos ${ }^{33}$. 


\subsubsection{Radiologia odontológica}

É uma área da odontologia que estuda órgãos e estruturas internas da cavidade oral, através de imagens obtidas a partir da utilização dos raios $\mathrm{X}$, com fins diagnósticos e terapêuticos, envolvendo processos digitais, ou de revelação no caso de filmes convencionais.

Existem dois tipos de radiografias a intra e extrabucal, sendo a intrabucal a mais utilizada em consultórios odontológicos. A radiografia extrabucal é mais aplicada em clínicas especializadas em documentação odontológica, empregada em estudos de pacientes para tratamentos ortodônticos. Neste trabalho será abordado somente a do tipo intrabucal ${ }^{22}$.

A técnica radiográfica intrabucal mais realizada em consultórios é a periapical, mostrando dentes individualmente e tecidos ao redor do ápice, raiz do dente. O filme radiográfico usado nesta técnica, chamado de periapical, possui dimensões de $4 \mathrm{~cm} \times 3 \mathrm{~cm}$ e consegue visualizar de 2 a 3 dentes, fornecendo informações sobre o dente e dos tecidos alveolares e ossos.

Dentre as principais indicações para o uso de radiografias intrabucais podemos destacar: infecções e inflamações na raiz, após traumas, presença de dentes inclusos, antes de cirurgias, tratamentos endodônticos, evolução de implantes, entre outros.

$\mathrm{Na}$ radiografia periapical podemos realizar a técnica da bissetriz e do paralelismo. Nesta última o requisito fundamental é a posição do filme e do feixe de raios $\mathrm{X}$, devem ser paralelos aos dentes ${ }^{34}$, conforme FIG. 2.9.

Filme radiográfico em firme contato com o dente

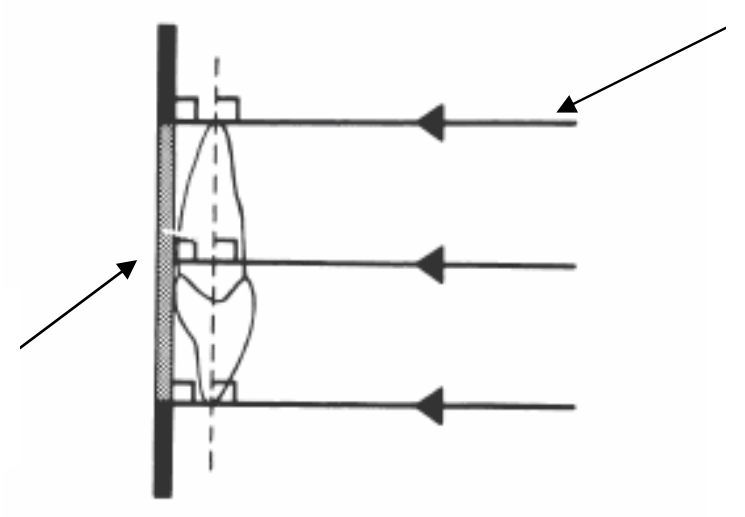

Feixe de raios $X$ paralelos

FIGURA 2.9 - Geometria ideal para a realização de radiografias utilizando a técnica do paralelismo ${ }^{34}$. 
Nesta etapa, o uso de posicionadores (item 3.5) é de fundamental importância para obtenção de radiografias de qualidade.

$\mathrm{Na}$ técnica da bissetriz a direção do feixe de raios $\mathrm{X}$ central deve ser perpendicular à bissetriz do ângulo diedro formado pelo longo eixo do dente e do filme, conforme mostra FIG. 2.10. A manutenção do filme na posição deve ser digital, com o próprio paciente realizando este procedimento.

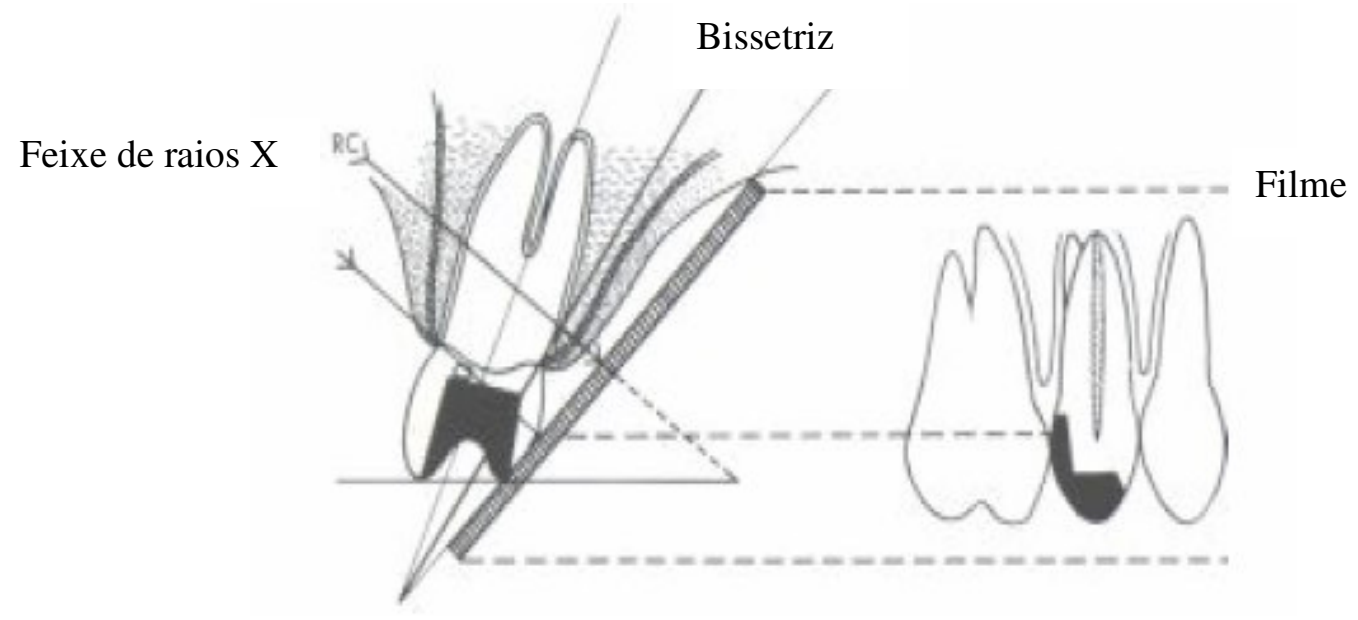

FIGURA 2.10 - Geometria ideal para a realização de radiografias utilizando técnica da bissetriz ${ }^{34}$.

Os principais erros mais comuns na realização de radiografias odontológicas são: erros de posicionamento do paciente, filme e aparelho de raios $\mathrm{X}$; imagens claras ou escuras, manchadas e com imperfeições. Estes problemas poderão ser evitados mediante um programa de controle de qualidade efetivo, que é um dos principais objetivos da Portaria Federal $453^{10}$, envolvendo testes de qualidade em aparelhos de raios $\mathrm{X}$ e processamentos adequados dos filmes radiográficos ${ }^{35}$.

\subsection{Grandezas e unidades em dosimetria e radioproteção}

\subsubsection{Exposição $(X)$}

É uma grandeza física que permite avaliar a radiação emitida por uma fonte específica a partir de sua capacidade de ionizar uma quantidade de matéria. 
É definida para raios $\mathrm{X}$ e gama tendo $\mathrm{o}$ ar como meio de interação e determinada pelo quociente de $d Q$ por dm (Equação 1), onde $d Q$ é o valor absoluto total dos íons de mesmo sinal produzidos no ar quando todos os elétrons e pósitrons liberados ou criados por fótons na massa de ar dm são completamente freados no ar:

$$
X=\frac{d Q}{d m}
$$

A unidade do Sistema Internacional (SI) é $\mathrm{C} / \mathrm{kg}$ e a especial é o roentgen $(R)$, onde $1 \mathrm{R}=2,58 \times 10^{-4} \mathrm{C} / \mathrm{kg}^{36}$.

\subsubsection{Dose absorvida (D)}

A grandeza dose absorvida é definida como o quociente $\mathrm{dE}$ por $\mathrm{dm}$, onde dE é a energia média cedida em um volume de massa dm (Equação 2):

$$
D=\frac{d E}{d m}
$$

A unidade no SI de dose absorvida é o joule por quilograma $(\mathrm{J} / \mathrm{kg})$ e a especial é denominada gray (Gy) ${ }^{36}$.

\subsubsection{Kerma (K)}

É a grandeza definida como o quociente de $\mathrm{dE}_{\mathrm{tr}}$ por $\mathrm{dm}$, onde $\mathrm{dE}_{\mathrm{tr}}$ é a energia cinética inicial de todas partículas carregadas liberadas por partículas não carregadas em um material de massa dm (Equação 3):

$$
K=\frac{d E_{t r}}{d m}
$$

A unidade no SI é o joule por quilograma $(\mathrm{J} / \mathrm{kg})$, e a especial denominada gray $(G y)^{36}$. 


\subsubsection{Dose de entrada na pele (DEP)}

É a dose absorvida no centro do feixe incidente na superfície do paciente submetido a um procedimento radiológico, incluindo 0 retroespalhamento ${ }^{10}$.

\subsubsection{Dose equivalente $\left(\mathrm{H}_{\mathrm{T}}\right)$}

É a grandeza expressa por

$$
H_{T}=D_{T} \cdot W_{R}
$$

onde $\mathrm{D}_{\mathrm{T}}$ é dose absorvida média no órgão ou tecido e $\mathrm{w}_{\mathrm{R}}$ é o fator de ponderação da radiação. A unidade no sistema internacional é o joule por quilograma $(\mathrm{J} / \mathrm{kg})$, e a especial denominada sievert $(\mathrm{Sv})^{29}$.

\subsubsection{Dose efetiva (E)}

É a soma das doses equivalentes ponderadas nos diversos órgãos e tecidos,

$$
E=\Sigma w_{T} \cdot H_{T}
$$

onde $H_{T}$ é a dose equivalente no tecido ou órgão e $w_{T}$ é o fator de ponderação de órgão ou tecido. A unidade no sistema internacional é o joule por quilograma $(\mathrm{J} / \mathrm{kg})$, e a especial denominada sievert $(\mathrm{Sv})^{29}$.

\subsection{Efeitos biológicos da radiação}

Em 1896, logo após a descoberta dos raios X, o médico J.Daniels notificou o primeiro efeito biológico da radiação, a queda de cabelo de um de seus colegas, cuja radiografia de crânio havia sido realizada. $O$ uso de raios $X$ na terapia produziu resultados desagradáveis como eritema de pele e em seguida ulcerações nas mãos de médicos, além de câncer nos ossos, resultante das exposições durante os tratamentos dos pacientes ${ }^{30}$. Em 1907 foram relatados os primeiros casos de câncer em profissionais, inclusive fatais, conforme apresentado na FIG. 2.11. Em 1908 apareceram os primeiros sinais de esterilidade em dentistas ${ }^{21}$. 

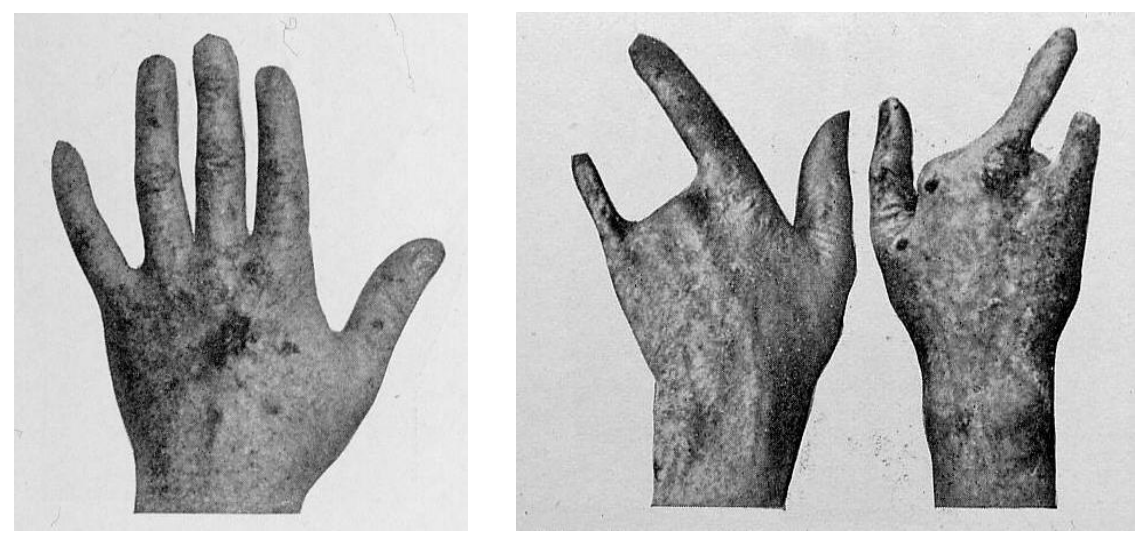

FIGURA 2.11 - Primeiros casos de câncer nas mãos de médicos, relatados em $1907^{21}$.

O Dr. Edmund Kells, considerado mártir da radiologia odontológica, foi vítima dos efeitos biológicos dos raios $X$, sofrendo inúmeras queimaduras $\mathrm{e}$ amputações de falanges, dedos e mãos, levando-o ao suicídio. Outra provável vítima dos efeitos biológicos foi o próprio Roentgen, que faleceu devido a um câncer no duodeno ${ }^{23}$.

A passagem da radiação e a liberação de sua energia em volumes muito pequenos, como em células, podem produzir ionização e excitação dos átomos, quebra de moléculas e como conseqüência a formação de radicais livres altamente reativos. Estes podem atacar, modificar e até matar moléculas de DNA, causando efeitos biológicos a longo prazo, como os tumores ${ }^{7,30}$.

Os efeitos biológicos são divididos em estocásticos e determinísticos. Os efeitos determinísticos são observados em horas, dias ou semanas após a exposição de um indivíduo a radiação, e geralmente são associados a altas doses de radiação, acima de 1 Sv, recebidas em grande área do corpo, e num curto período de tempo. Os efeitos estocásticos ou tardios podem surgir em dois casos, pessoas que receberam altas doses de radiação, não letais, em curto espaço de tempo ou pequenas doses num longo intervalo de tempo, que são os casos de profissionais da área médica e odontológica, por exemplo. Os efeitos tardios são divididos em genéticos e somáticos. Os genéticos ocorrem quando a radiação atinge as células reprodutoras que afetam gerações futuras. Os somáticos são 
aqueles que afetam diretamente o individuo exposto à radiação e não são transmitidos a gerações futuras. Estes efeitos dependem do tipo de radiação, profundidade atingida no tecido, volume do corpo exposto, dose total recebida e tempo de irradiação. Entre os efeitos no homem está o aumento na incidência de câncer, anormalidade no desenvolvimento do embrião, indução de catarata, e redução da vida média ${ }^{30}$.

Nos últimos anos as radiações ionizantes e seus efeitos biológicos têm sido intensamente investigados nas áreas biomédicas. Os efeitos de altas doses de radiação são bem conhecidos e há diversos trabalhos publicados. No caso da radiologia odontológica as doses e os riscos são pequenos, mas existem inúmeros estudos epidemiológicos que indicam um aumento nos riscos de câncer em cérebro, glândulas salivares e tireóide, decorrentes de radiografias obtidas em raios $\mathrm{X}$ odontológicos ${ }^{7}$. Recentemente foi publicado um estudo sobre danos a células da mucosa, de pacientes expostos à radiação odontológica extraoral gerando efeitos citogenéticos por indução de apoptose ${ }^{37}$. É importante destacar que a dose efetiva de um paciente submetido a um exame intrabucal de toda a boca realizado corretamente, é aproximadamente 15 vezes maior do que um exame panorâmico e $50 \%$ maior que um exame de tórax ${ }^{23}$.

Portanto, exames incorretos, repetições desnecessárias e erros de diagnósticos por radiografias de má qualidade podem acarretar um aumento significativo nas doses nos pacientes.

\subsection{Controle de qualidade em radiodiagnóstico}

O objetivo comum entre os programas de controle de qualidade em radiodiagnóstico é estabelecer critérios mínimos para um correto funcionamento dos aparelhos geradores de raios $\mathrm{X}$ odontológicos, onde seja possível obter a melhor radiografia possível, em termos de qualidade de diagnóstico, em uma única exposição, reduzindo ao máximo a dose no paciente ${ }^{1}$. Dentre os principais aspectos de um programa de controle de qualidade podemos citar a qualidade da imagem - a qual está relacionada com a tensão de aceleração (kV) e a filtração inerente e adicional - a dose no paciente, a otimização de técnicas e custos, bem como aspectos profissionais e legais ${ }^{27}$. 


\subsubsection{Formação da imagem radiográfica}

Os filmes radiográficos consistem principalmente de uma emulsão, que é uma gelatina composta de cristais ou grãos de halogeneto de prata (brometo e iodeto de prata), a qual é depositada em um ou em ambos os lados de uma base plástica transparente e flexível, de acetato de celulose e poliéster.

Todos os filmes odontológicos utilizados na técnica intrabucal são de exposição direta, sem a utilização de telas intensificadoras, e apresentam um envoltório preto, que evita a sensibilização pela luz; lâmina de chumbo, que é colocada na face posterior do filme, reduz a dose de radiação no paciente, evita a contribuição da radiação secundária na imagem e também dá sustentação ao filme; e um envelope branco, que impermeabiliza o filme, como pode ser observado na FIG. 2.12.

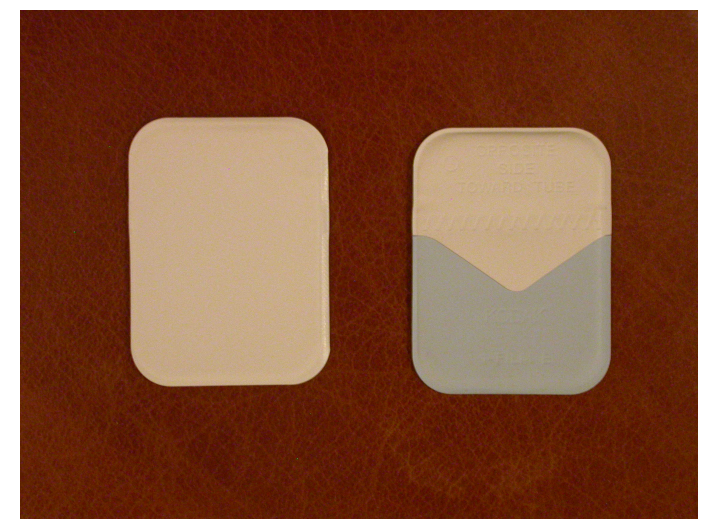

(a)

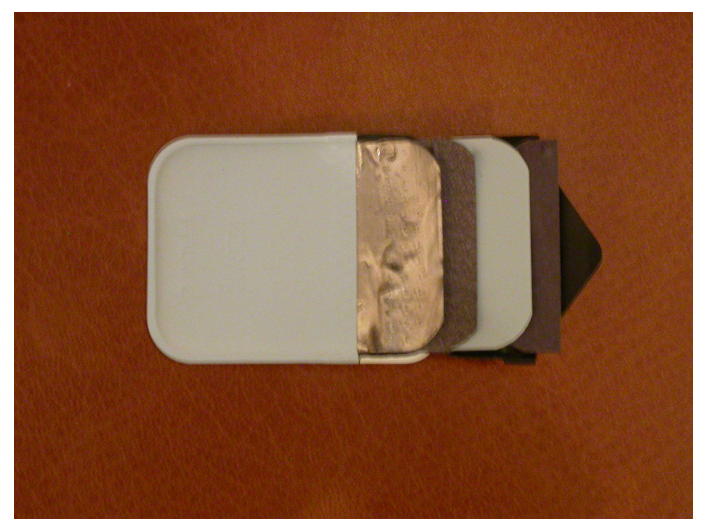

(b)

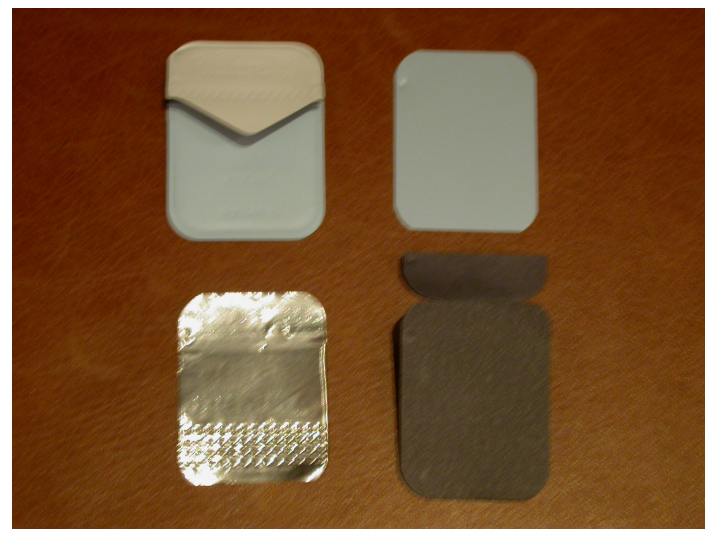

(c)

FIGURA 2.12 - Filme radiográfico utilizado no trabalho: a) Face exposta aos raios X e para abertura; b) Seqüência de acomodação interna; c) Capa protetora, película, lâmina de chumbo e papel. 
Após a exposição do filme aos raios $\mathrm{X}$ será formada a imagem latente, interações dos raios $X$ com os cristais de brometo e iodeto de prata, e somente será visível após o processamento do filme.

A maioria dos profissionais da odontologia utiliza uma câmara escura portátil para o processamento dos filmes, totalmente opaca à luz, contendo em seu interior três recipientes com soluções recomendadas pelo fabricante, FIG. 2.13.

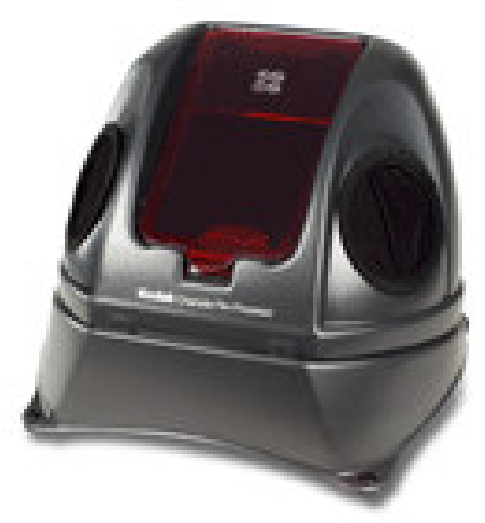

FIGURA 2.13 - Câmara escura portátil utilizada para revelação de filmes intrabucais.

Após um ataque químico adequado, ou revelação, surgirão pontos enegrecidos (cristais atingidos pela radiação ionizante) e pontos transparentes (não atingidos), os quais formarão uma imagem visível e bidimensional.

\subsubsection{Fatores de exposição da imagem}

Existem dois fatores que afetam a exposição de uma imagem radiográfica, a tensão e a corrente aplicada no tubo.

A tensão aplicada ao tubo, quantificada em quilovolts (kV), está relacionada com a qualidade do feixe gerado, ou seja, com o poder de penetração deste na matéria, como por exemplo, o tecido, e também ao contraste.

A corrente de um aparelho está diretamente ligada à quantidade de elétrons do filamento, ou seja, à quantidade de fótons emitidos pelo aparelho.

$\mathrm{Na}$ odontologia existem diversos modelos de aparelhos, onde a tensão e corrente são fixos, mas podem ser encontrados modelos com tensões de 50, 60 ou $70 \mathrm{kV}$ e correntes de 7 ou $10 \mathrm{~mA}$. Neste caso o único parâmetro que o 
profissional pode alterar é o tempo de exposição, que será utilizado para aumentar ou diminuir a densidade óptica na imagem radiográfica.

\subsubsection{Critérios de qualidade para imagens radiográficas}

Dentre os critérios para se avaliar a qualidade de uma radiografia podemos destacar: densidade e contraste radiográfico, resolução espacial e distorção.

A densidade radiográfica, ou densidade ótica, fornece o grau de enegrecimento dos filmes, e seu comportamento é obtido pela curva característica, que descreve o comportamento da densidade ótica, $D_{o p}$, (grau de enegrecimento do filme) em função do tempo de exposição, $t$, ao feixe de raios $X$ do equipamento, onde:

$$
D_{\mathrm{op}}=\log \left(\mathrm{I}_{\mathrm{o}} / \mathrm{I}\right)
$$

sendo "Io" e "I" as intensidades de luz incidente e transmitida pelo filme.

Basicamente este comportamento é regido pelas dimensões dos grãos do filme e do tipo da radiação ionizante. Por meio desta curva (Equação 6) determina-se o intervalo de exposição ótimo para a obtenção de uma radiografia, ou seja, para o qual tempo de exposição (t) o contraste óptico "G" na imagem, definido pela equação 7 , é máximo :

$$
G=\frac{\Delta D_{o P}}{\Delta(\log t)}
$$

O contraste radiográfico é a diferença entre as densidades de diferentes regiões de uma radiografia, e depende principalmente da tensão aplicada, velocidade do filme, objeto e seu processamento. Pode-se dizer que quanto maior o contraste mais detalhes anatômicos de uma radiografia podem ser vistos. Em radiologia odontológica o ideal é um contraste médio, obtido entre 60 e $70 \mathrm{kV}$. Em geral, uma radiografia que apresenta áreas muito claras e escuras é chamada de alto contraste. 
A resolução espacial obtida na imagem, ou definição, é a menor distância distinguível entre dois pontos, demonstrada pela clareza de linhas estruturais finas e pelos limites de tecidos visíveis na imagem radiográfica. A insuficiência de detalhes na imagem radiográfica é chamada de "borramento", que ocorre principalmente devido ao movimento dos pacientes, cabeçote e filmes.

As distorções em imagens radiográficas mostram tamanhos e formas de objetos que não representam a realidade, e são devidos principalmente a distância foco-filme, alinhamento do objeto com o feixe de raios $X . N a$ odontologia, de maneira geral, deve-se: a) colocar o filme o mais próximo possível do dente a ser radiografado para a imagem não ser ampliada; b) a região de interesse estar paralela ao filme; c) ter o feixe principal perpendicular ao dente e ao filme evitando imagens "alongadas ou encurtadas"; d) utilizar maior distância foco-filme, propiciando a utilização dos feixes centrais, menos divergentes, minimizando a penumbra na imagem ${ }^{38}$.

\subsubsection{Métodos para redução da dose no paciente}

A redução de dose nos pacientes deve seguir o princípio ALARA, pois os exames realizados em radiologia odontológica fornecem uma contribuição significativa para a dose coletiva da população. Dentre os principais métodos para a redução pode-se destacar: velocidade do filme (média ou alta), processamento do filme de acordo com o fabricante, seguindo tabelas de tempo por temperatura e o uso de colimador adequado para reduzir o campo irradiado $0^{6,8}$.

Deve-se ainda considerar a filtração adicional, que reduz a dose no paciente e remove os fótons de baixa energia, que não contribuem para a formação da imagem radiográfica; a correta tensão no tubo do aparelho e o tempo de exposição adequado e determinado pela curva característica, na região de maior contraste.

É importante lembrar que se o aparelho de raios $\mathrm{X}$ estiver funcionando de acordo com um programa de controle de qualidade adequado serão evitadas falhas nas radiografias, tais como: densidade radiográfica excessiva ou insuficiente, contraste insuficiente. Outros detalhes a serem considerados são: a perfeita vedação da câmara escura, evitando o velamento de filmes e a utilização de soluções novas com tabelas "tempo $x$ temperatura" fornecidas pelo fabricante dos filmes, que evitam o excesso ou a falta de revelação ${ }^{10}$. 


\subsection{Normas e recomendações}

\subsubsection{Portaria Federal nº 453 do Ministério da Saúde, Secretaria de Vigilância Sanitária}

No Brasil somente em $1^{\circ}$ de junho de 1998 foi aprovada a Portaria Federal $453^{10}$ do Ministério da Saúde que estabeleceu o Regulamento Técnico e as diretrizes básicas de proteção radiológica em radiodiagnóstico médico e odontológico, que dispõe sobre o uso dos raios $\mathrm{X}$ diagnósticos em todo território nacional.

Esta norma tem o objetivo de garantir a qualidade dos serviços de radiodiagnóstico prestados à população, assim como de assegurar os requisitos mínimos de proteção radiológica aos pacientes, aos profissionais e ao público em geral. Para isto padronizou, a nível nacional, os requisitos de proteção radiológica para o funcionamento dos estabelecimentos que operam com raios $X$ diagnósticos e a necessidade de detalhar os requisitos de proteção em radiologia diagnóstica e intervencionista estabelecidos na Resolução no 6, de 21 de dezembro de 1988, do Conselho Nacional de Saúde.

A Portaria $453^{10}$ do Ministério da Saúde segue as recentes Diretrizes Básicas de Proteção Radiológica estabelecidas em conjunto pela Organização Mundial da Saúde, Organização Panamericana da Saúde, Organização Internacional do Trabalho, Organização de Alimento e Agricultura, Agência de Energia Nuclear e Agência Internacional de Energia Atômica, e também as recomendações do Instituto de Radioproteção e Dosimetria da Comissão Nacional de Energia Nuclear, órgão de referência nacional em proteção radiológica e metrologia das radiações ionizantes.

\section{Parâmetros recomendados para controle de qualidade em raios $X$ odontológicos}

De acordo com a Portaria Federal $453^{10}$, a execução do controle de qualidade em radiologia odontológica consiste basicamente no estudo dos seguintes parâmetros:

a) Camada semi-redutora (CSR): espessura de material que atenua em $50 \%$ um feixe de raios $\mathrm{X}$, e está diretamente ligada a qualidade do feixe ${ }^{39}$. 
Considera-se excluída a contribuição de qualquer radiação espalhada que não estava presente inicialmente no feixe considerado $^{10}$. A CSR é usada como medida de penetrabilidade da radiação ${ }^{30}$.

b) Tensão (kV): é a diferença de potencial elétrico entre o catodo e o anodo e determina a distribuição de energia do feixe de radiação. No entanto, a tensão de pico $(k V p)$ é a máxima voltagem aplicada através de um tubo de raios $X$, e como conseqüência indica a energia máxima dos fótons produzidos. É também um dos parâmetros mais importantes que determinam o contraste e a densidade óptica de uma imagem radiográfica, além de contribuir para a dose nos pacientes ${ }^{1,19,32,40}$. No caso de aparelhos odontológicos a tensão de pico é fixa, e os mais comuns existentes nos consultórios possuem 50,60 ou $70 \mathrm{kVp}$.

c) Tamanho de campo: definido como sendo o diâmetro do feixe útil de radiação, e representa a área e o volume de tecido exposto ao feixe primário de raios $X^{27,41,42}$.

d) Reprodutibilidade do tempo de exposição: tem a finalidade de avaliar a precisão do temporizador de um aparelho de raios $\mathrm{X}$ odontológico, pois mede o tempo total, em segundos, de emissão dos fótons de raios $X$ produzidos no tubo.

e) Kerma no ar: definido no item 2.2.3.

f) Linearidade da taxa de kerma no ar com o tempo de exposição: avalia a variação da intensidade de um feixe de raios $X$, em termos de kerma no ar, em função do tempo de exposição, medido em segundos.

g) Dose absorvida: conforme definição apresentada no item 2.2.2.

h) Dose de entrada na pele (DEP) : definido no item 2.2.4.

i) Integridade das vestimentas de proteção individual: todo consultório odontológico é obrigado a possuir e utilizar proteção individual, ou seja, aventais e protetores de tiróide ${ }^{10}$. Neste caso, é necessária uma inspeção para verificação do tamanho e da integridade destes objetos utilizados para proteção de pacientes, de acompanhantes autorizados ou de profissionais durante as exposições ${ }^{27,43}$.

j) Padrão de imagem radiográfica: avalia a qualidade da imagem radiográfica, que pode ser feita por meio de um simulador padrão, em termos de contraste, nitidez e sensibilidade ${ }^{44,45,46}$. 


\subsubsection{National Council on Radiation Protection, report 145: Radiation Protection in Dentistry}

O National Council on Radiation Protection and Measurements, NCRP, publicou em 2003 o report $N^{\circ} 145^{8}$ "Radiation Protection in Dentistry", em substituição ao NCRP № 35 de 1970. O objetivo deste documento é fornecer métodos e procedimentos para proteção radiológica em consultórios e clínicas odontológicas, como por exemplo, a eliminação de exposições desnecessárias aos pacientes, manter as exposições dos profissionais e públicos em geral abaixo dos limites recomendados, aplicação do princípio ALARA, além de fazer inúmeras outras recomendações aos profissionais.

Os procedimentos apresentados estão relacionados ao uso dos aparelhos de raios $X$ em radiodiagnósticos odontológicos, seu desempenho, otimização do uso, recomendações de segurança radiológica e monitoração dos profissionais envolvidos.

Nas suas seções estão incluídas orientações específicas em proteção radiológica (limites de doses, ALARA, efeitos biológicos, etc.) aos dentistas e demais profissionais envolvidos, incluindo especialistas qualificados em proteção radiológica, além de procedimentos de calibração de instrumentos, evolução do desempenho dos equipamentos e determinação do layout e blindagens necessárias para os consultórios.

No capítulo 3, item 3.1.3, são apresentados os parâmetros utilizados nos aparelhos de raios $X$ intrabucais. As recomendações estão descritas a seguir:

- Tensão de aceleração (kV): não deve ser menor que 50 kVp;

- Distância foco-pele (DFF) mínima: não deve ser menor que $20 \mathrm{~cm}$;

- Tamanho do campo na extremidade do localizador: $3 \times 4 \mathrm{~cm}^{2}$ (colimador retangular)

- Movimentação do cabeçote: menor que $0,5 \mathrm{~cm}$;

Além disso, traz outras recomendações sobre a velocidade do filme (recomendação: $E$ ), vedação da câmara escura, revelação dos filmes de acordo com o fabricante (seguindo tabelas tempo-temperatura), e utilização de aventais e protetores de tireóide de chumbo para proteção do paciente. 


\subsubsection{European guidelines on radiation protection in dental radiology - The safe use of radiographs in dental practice, Issue $N{ }^{\circ} 136$}

O European Comission publicou em 2004 o documento $N^{\circ}$ 136, European guidelines on radiation protection in dental radiology: The safe use of radiographs in dental practice ${ }^{7}$, desenvolvido para fornecer um guia prático de radioproteção para orientar os dentistas e seus assistentes nas decisões quanto ao uso da radiação ionizante, fornecendo orientações para o uso seguro das radiografias na odontologia, uma vez que a exposição aos raios $X$ não pode ser considerada livre de risco. Essas recomendações podem ser variáveis de acordo com a avaliação clínica do paciente.

As principais recomendações são: uso de equipamento de raios $X$ entre 65 a 70 kV, com filtração de alumínio; uso de colimador retangular, juntamente com o posicionador de filme para técnica do paralelismo; uso de localizador com pelo menos $20 \mathrm{~cm}$. Recomenda-se ainda que os filmes radiográficos intrabucais sejam os mais rápidos disponíveis, como por exemplo, os filmes do grupo E. Este documento limita a dose em 4 mGy no ar, medida na extremidade do localizador.

O uso de avental plumbífero é opcional na prática rotineira, porém os protetores de tireóide devem ser usados nos casos em que a glândula tireóide está muito perto ou na direção do feixe primário.

Todo equipamento de raios $X$ odontológico deve submeter-se a testes iniciais e periódicos de controle de qualidade para assegurar a proteção radiológica.

Finalmente, este documento destaca ainda: toda radiografia odontológica deve ser justificada e fornecer benefícios ao paciente, compensando o potencial de detrimento; nenhuma radiografia deve ser realizada antes do exame clínico e histórico odontológico e deve-se procurar a utilização de métodos alternativos à radiação ionizante para diagnóstico da lesão-cárie.

\subsubsection{Protocolo Español de Control de Calidad en Radiodiagnóstico}

O protocolo Espanhol de Controle de Qualidade publicado inicialmente em 1996, sendo revisado em 2002, é um documento que tem como objetivo principal fornecer orientação no caso de detecção de anomalias nas doses dos 
pacientes e na qualidade de imagem, que possam estar relacionadas aos parâmetros do equipamento ${ }^{6}$.

A implantação deste Programa de Garantia de Qualidade em um serviço de radiodiagnóstico deve contemplar a utilização do Protocolo de forma global, sendo que as suas recomendações devem ser adaptadas a cada centro de diagnóstico, tipo de equipamento e pessoal envolvido.

O Protocolo é um documento técnico que fornece um conjunto de recomendações para os serviços de radiodiagnóstico se adaptarem, sendo exigido alguns instrumentos e pessoas necessárias para realizar as medidas requeridas.

O documento também tem a finalidade de esclarecer a diferença entre os critérios de aceitação deste protocolo e os critérios de aceitabilidade do equipamento radiológico, principalmente no que se refere aos níveis de intervenção que ao serem atingidos obrigam a realização de ações corretoras. Se mesmo após o conserto o equipamento não atingir os níveis exigidos, ele deverá ser colocado fora de uso (artigo 14, parágrafo 5 do Decreto Real de 1976/1999).

O capítulo 4 deste protocolo refere-se exclusivamente aos equipamentos odontológicos, intra e extrabucais, e as recomendações estão descritas abaixo:

- Distância foco-pele (DFF) mínima: $20 \mathrm{~cm}$ para equipamentos com tensão de pico superiores a $60 \mathrm{kV}$ e $10 \mathrm{~cm}$ para equipamentos com tensão de pico igual ou inferiores a $60 \mathrm{kV}$;

- Tamanho do campo na extremidade do cilindro localizador: $\leq 6 \mathrm{~cm}$;

- Exatidão e reprodutibilidade da tensão (kV): exatidão $\leq \pm 10 \%$, reprodutibilidade $\leq 10 \%$ e a tensão mínima deve ser de $50 \mathrm{kV}$;

- Filtração (Camada semi-redutora): $\geq 1,5 \mathrm{~mm}$ alumínio para equipamentos com tensão de pico nominal $\leq 70 \mathrm{kV}$ e $\geq 2,5 \mathrm{~mm}$ de alumínio para equipamentos com tensão de pico nominal > $70 \mathrm{kV}$;

- Visualização da forma de onda: Segundo especificações do fabricante;

- Exatidão e reprodutibilidade do tempo de exposição: exatidão $\leq \pm 20 \%$ e reprodutibilidade $\leq 10 \%$;

- Reprodutibilidade do rendimento: < 10\%; 
- Valor do rendimento: de modo orientativo entre 30 e $80 \mu \mathrm{Gy} / \mathrm{mAs}$ a $1 \mathrm{~m}$ do foco para equipamentos com tensão de pico compreendidas entre 50 e $70 \mathrm{kV}$;

- Variação do rendimento com o tempo de exposição: Coeficiente de linearidade $<0,1$. 


\section{MATERIAIS E MÉTODOS}

\subsection{Sistema de radiação - $X$}

Todos os procedimentos foram aplicados a um aparelho de raios $X$ odontológico da marca Dabi Atlante, modelo Spectro 70X Seletronic, de um consultório particular em São Paulo/SP, apresentado na FIG. 3.1, com as seguintes características nominais: $70 \mathrm{kV}$ de voltagem aplicada ao tubo, $8 \mathrm{~mA}$ de corrente, $0,51 \mathrm{~mm}$ de Al de filtração inerente, tubo emissor de $0,8 \mathrm{~mm}$ de Al, 1,4 $\mathrm{mm}$ de Al de filtração adicional e $20 \mathrm{~cm}$ de distância foco-filme.

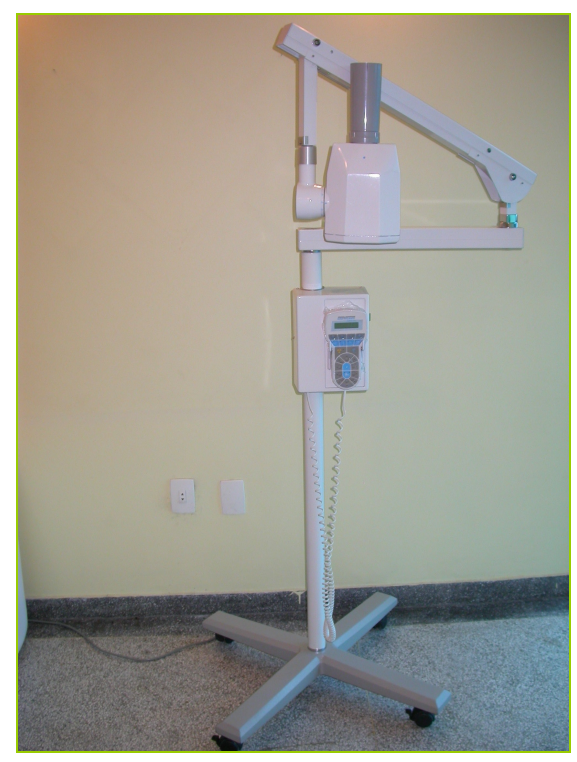

FIGURA 3.1 - Aparelho de raios X Dabi Atlante, Spectro 70X, seletronic, com $70 \mathrm{kV}, 8 \mathrm{~mA}$ e filtração nominal total equivalente a 2,71 mmAl.

\subsection{Instrumentos de medida}

\subsubsection{Tempo de exposição}

O detector de radiação para medida de tempo de exposição utilizado foi o da marca Fabinject, modelo Dual meter, de fabricação nacional, (FIG. 3.2), calibrado em termos de tempo de exposição (de 0,1 a 1,9 segundos), conforme certificado emitido pelo Instituto de Eletrotécnica e Energia da Universidade de São Paulo (IEE/USP)*. 


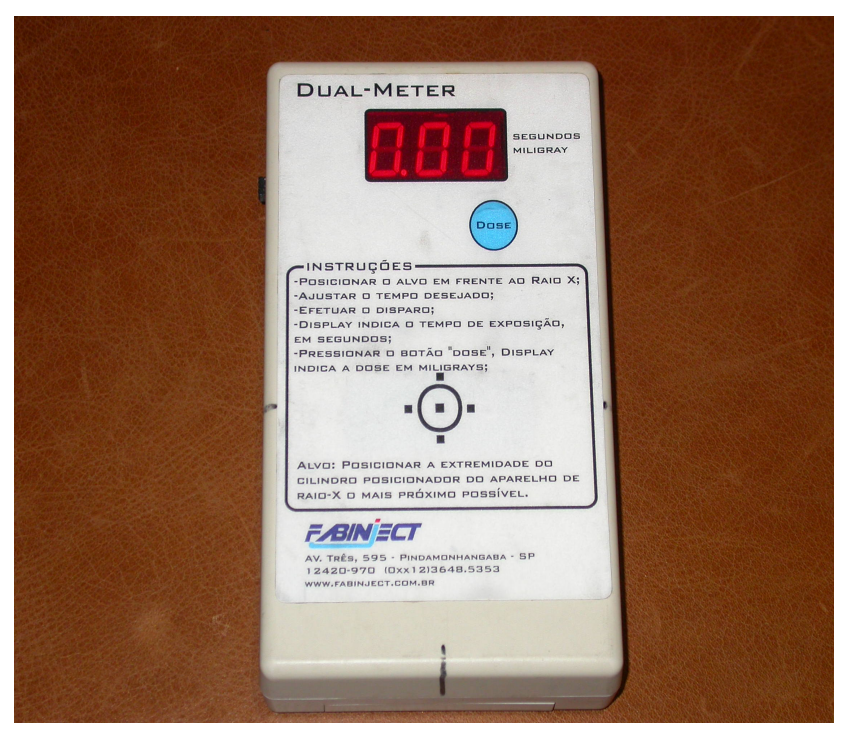

FIGURA 3.2 - Detector de tempo de exposição marca Fabinject calibrado pelo IEE/USP.

\subsubsection{Kerma no ar}

Para a determinação do kerma no ar foi utilizada a câmara de ionização de placas paralelas, marca Gammex, modelo RMI 242, com volume de $51 \mathrm{~cm}^{3}$, (FIG. 3.3), calibrada em termos de kerma no ar (mGy), conforme certificado emitido pelo Laboratório de Calibração de Instrumentos do IPEN/CNEN-SP*.

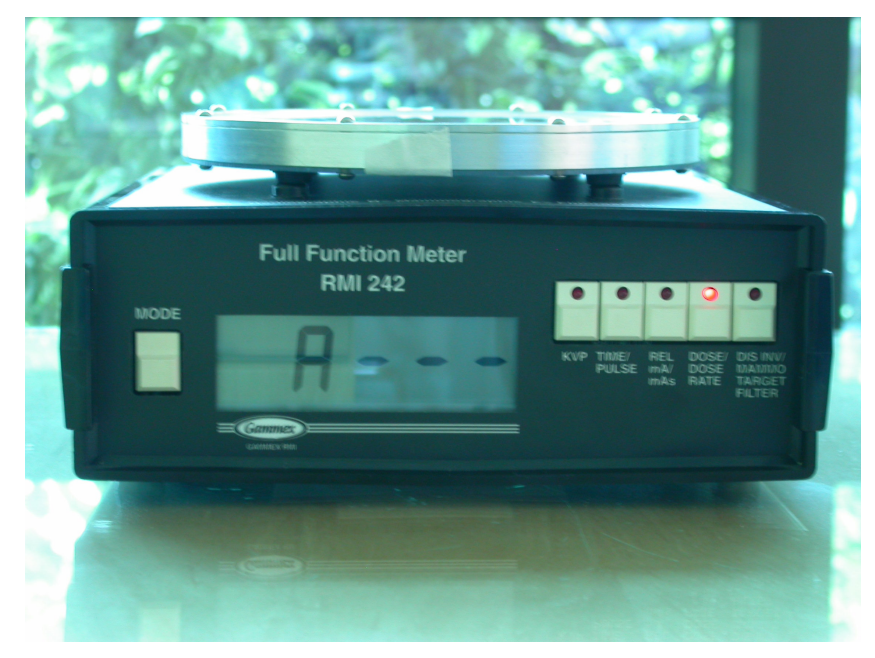

FIGURA 3.3 - Câmara de ionização marca Gammex, modelo RMI 242, e calibrada em termos de kerma no ar (IPEN/CNEN-SP). 


\subsubsection{Tensão de pico}

Foi utilizado o medidor de tensão de pico $(\mathrm{kVp})$ da marca Unfors, modelo DENT, para utilização no intervalo de 50 a $100 \mathrm{kVp}$ (FIG. 3.4), calibrado pelo IEE/USP*.

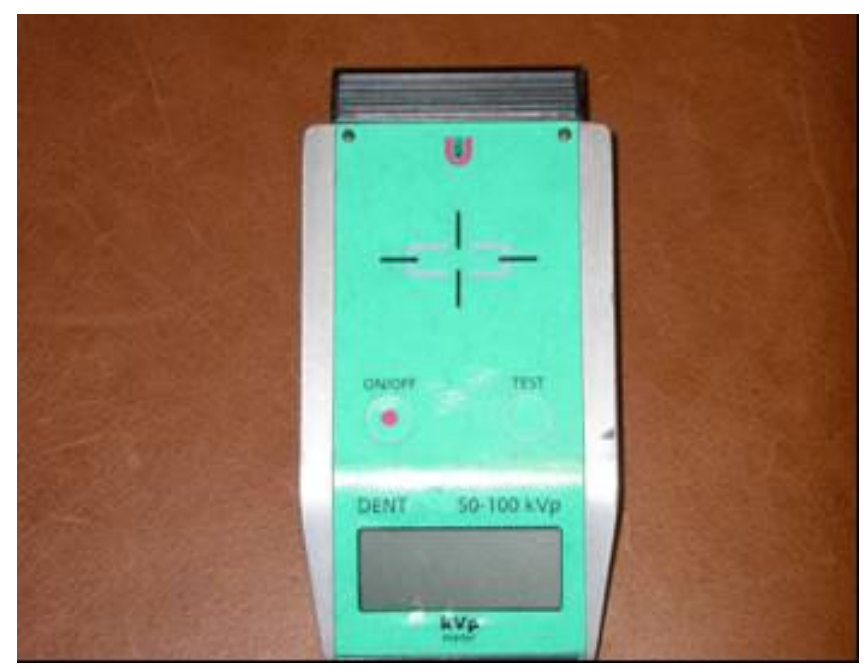

FIGURA 3.4 - Medidor de quilovoltagem (kVp), marca Unfors, e calibrado conforme certificado do IEE/USP.

\subsection{Filmes radiográficos}

Para a determinação do tamanho de campo e padrão de imagem radiográfica do sistema de raios $X$ foram utilizados filmes radiográficos intrabucais da marca Kodak, com velocidade $\mathrm{E}$ (ektaspeed) de tamanho $3 \times 5 \mathrm{~cm}^{2}$, lote 3103576, com data de fabricação 02.2005, conforme FIG. 3.5. 


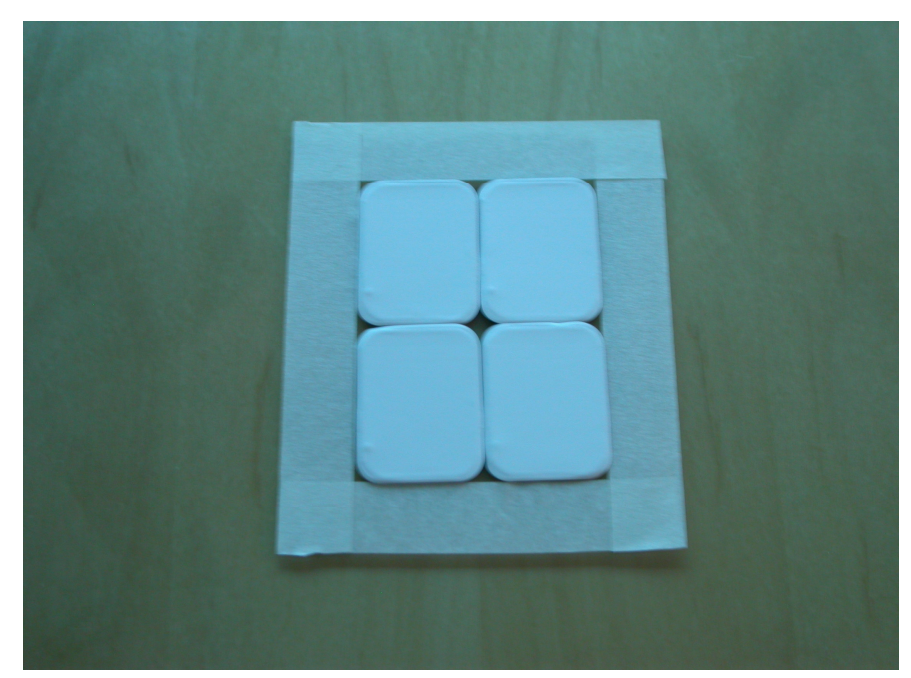

FIGURA 3.5 - Filmes radiográficos para a determinação do tamanho de campo (feixe útil) de aparelhos de raios $\mathrm{X}$.

\subsection{Absorvedores de alumínio}

Para a determinação da camada semi-redutora (CSR) do feixe de raios $X$ foram utilizadas 4 placas de alumínio de alta pureza $(>99,9 \%)$ com espessuras variando de $1 \mathrm{~mm}$ a $4 \mathrm{~mm}$ com dimensões de $10 \times 10 \mathrm{~cm}^{2}$ (FIG. 3.6)

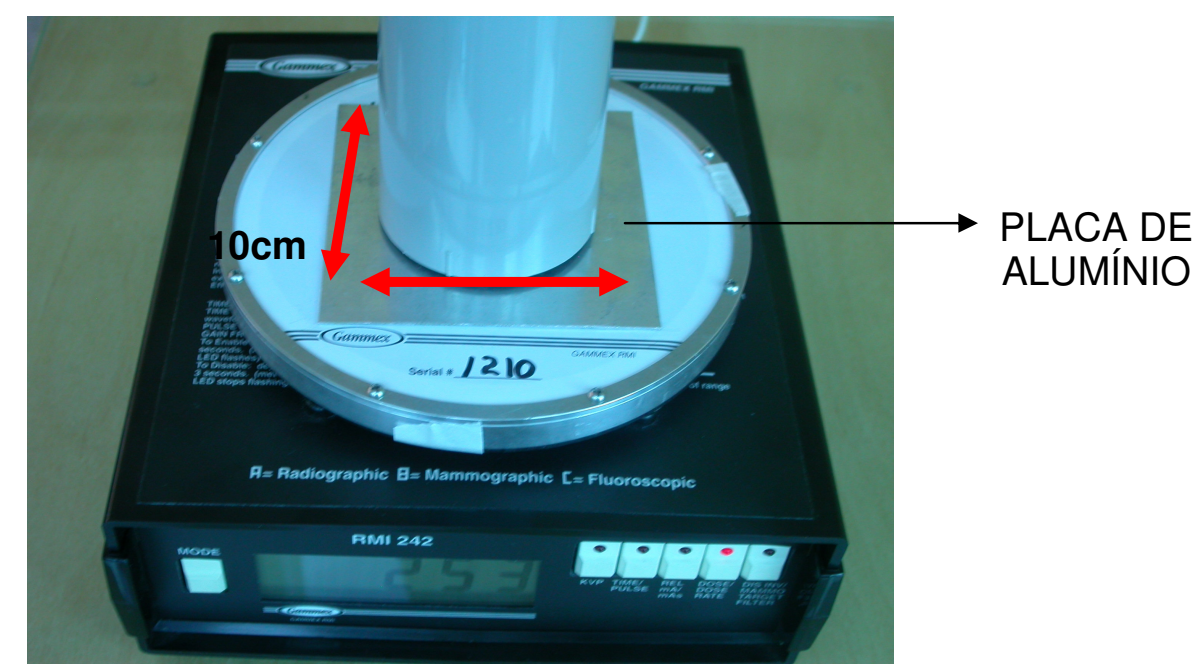

FIGURA 3.6 - Placas de alumínio, com $1 \mathrm{~mm}$ de espessura cada, posicionadas para a determinação da camada semi-redutora (CSR) do feixe de raios $\mathrm{X}$. 


\subsection{Posicionadores}

Os posicionadores são instrumentos utilizados na odontologia, e recomendados pela Portaria Federal $453^{10}$, para fixar os filmes radiográficos na boca dos pacientes, deixando-os paralelos aos dentes, e facilitando o alinhamento do feixe de raios $X$ (FIG. 3.7). Este sistema reduz significativamente a perda de radiografias, pois não ocorre movimentação do filme, distorções por dobra e erros por posicionamento da cabeça do paciente ${ }^{35}$.

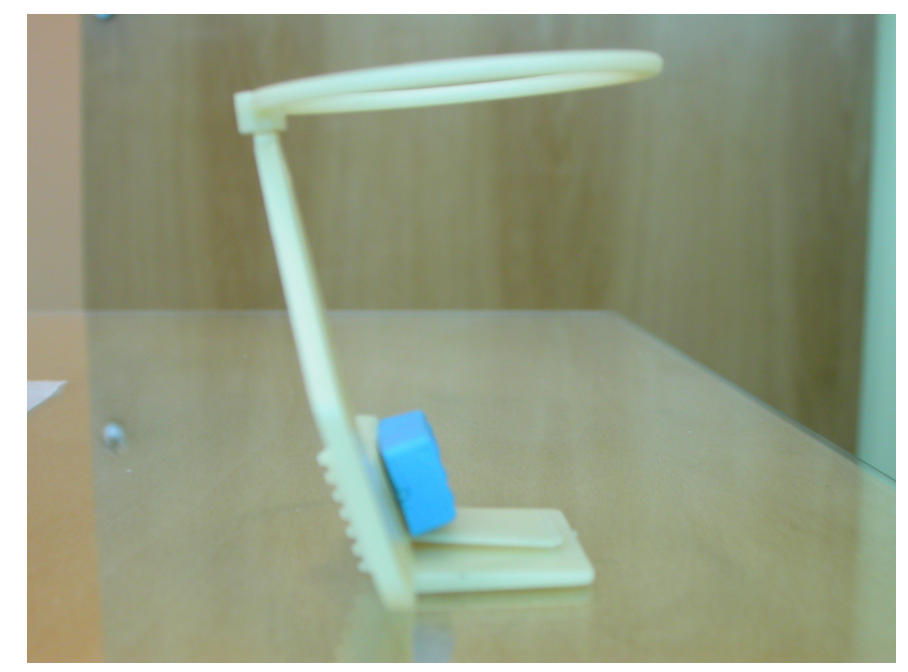

FIGURA 3.7 - Posicionador utilizado frequentemente na prática odontológica, utilizado para fixar filmes radiográficos e alinhá-los com o localizador dos aparelhos de raios $\mathrm{X}$.

\subsection{Material para o objeto teste}

Para o desenvolvimento de um objeto teste que corresponda a um dente médio ${ }^{47}$, foram utilizadas placas de alumínio de alta pureza (> 99,9\%) com espessura variando de $0,05 \mathrm{~mm}$ a $1 \mathrm{~mm}$. As placas foram sobrepostas e perfuradas utilizando-se um motor odontológico de alta rotação com brocas diamantadas, gerando orifícios com profundidades variando entre $0,05 \mathrm{~mm}$ e $0,7 \mathrm{~mm}$. Estas placas foram recobertas por uma placa de acrílico com 1,5 mm de espessura. $O$ objeto teste possui dimensões de $3 \times 4 \mathrm{~cm}^{2}$. 


\subsection{Incertezas}

As incertezas apresentadas representam a incerteza expandida para um nível de confiança de $95,4 \%(\mathrm{k}=2)^{48}$. A incerteza combinada foi encontrada pela soma quadrática das incertezas do tipo A e do tipo B. Neste caso foi considerada incerteza do tipo A, o desvio padrão da média das medidas e do tipo B, apenas a incerteza obtida na calibração do instrumento de medida de radiação utilizado, considerando-se que em medidas de campo não é possível se estimar a incerteza em todos os parâmetros utilizados, como em um laboratório de metrologia. 


\section{RESULTADOS E DISCUSSÕES}

Neste capítulo serão descritos em detalhes os procedimentos de controle de qualidade aplicados ao sistema de raios $\mathrm{X}$ odontológico descrito no capítulo anterior, seguindo as recomendações da PF $453^{10}$.

\subsection{Determinação da camada semi-redutora (CSR)}

Para a determinação da camada semi-redutora, inicialmente foi selecionado no temporizador do aparelho de raios $X$ o tempo de 0,5 segundos, que é o valor indicado pelo fabricante dos filmes radiográficos (Kodak) para exposições utilizando o tipo ektaspeed, largamente empregado pelos cirurgiõesdentistas $^{49}$. Foram realizadas medidas utilizando dois arranjos experimentais.

\subsubsection{Primeiro arranjo experimental}

Neste caso foi realizada uma exposição com o localizador do aparelho encostado perpendicularmente ao detector ${ }^{27}$, a uma distância foco-filme (DFF) de $20 \mathrm{~cm}$, conforme FIG. 4.1a. Em seguida foram feitas novas exposições, acrescentando placas de alumínio. A cada exposição realizada foi acrescida $1 \mathrm{~mm}$ de espessura de absorvedor, registrando o valor de kerma no ar correspondente, até o valor total de $5 \mathrm{~mm}$, conforme FIG. 4.1b. Estes procedimentos foram realizados em três séries de cinco repetições. 


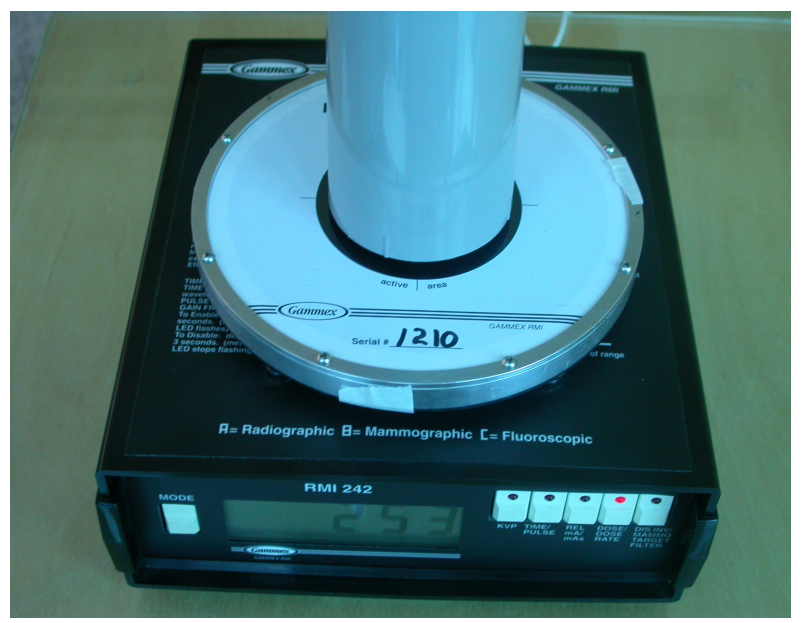

(a)

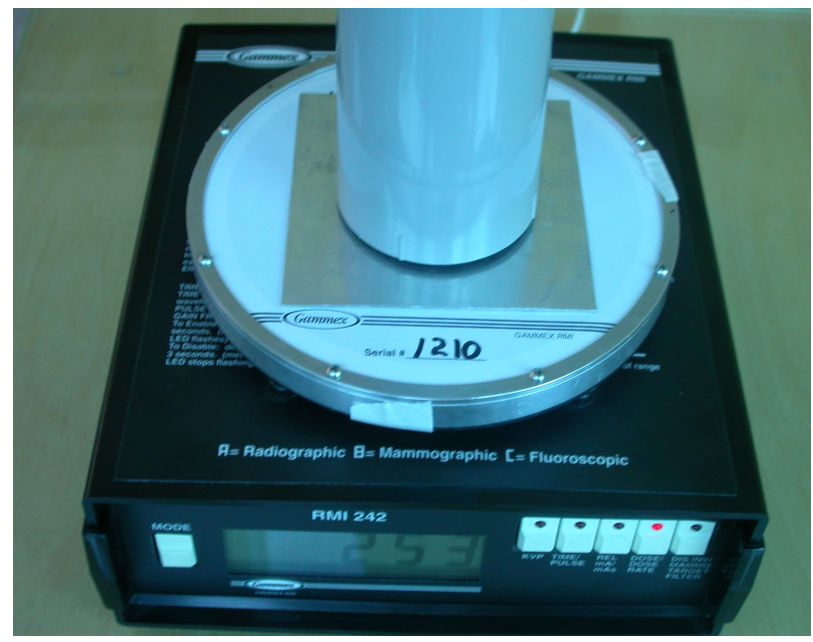

(b)

FIGURA 4.1 - Arranjo experimental utilizado para a medição da camada semiredutora: a) sem absorvedor de alumínio; b) com absorvedor de alumínio.

Neste arranjo, a CSR foi determinada por dois métodos diferentes. 0 primeiro utiliza um gráfico dos valores de kerma no ar em função da espessura de absorvedores. Neste caso, foi feito um ajuste exponencial aos pontos experimentais e a CSR foi determinada inserindo-se a metade do valor inicial de kerma no ar, quando não há absorvedor de alumínio, na função ajustada. Os gráficos obtidos, bem como as respectivas funções ajustadas aos pontos experimentais, apresentaram um comportamento similar. Os resultados obtidos na série 1, 2 e 3 estão apresentados nas FIG. 4.2, 4.3 e 4.4, respectivamente. 


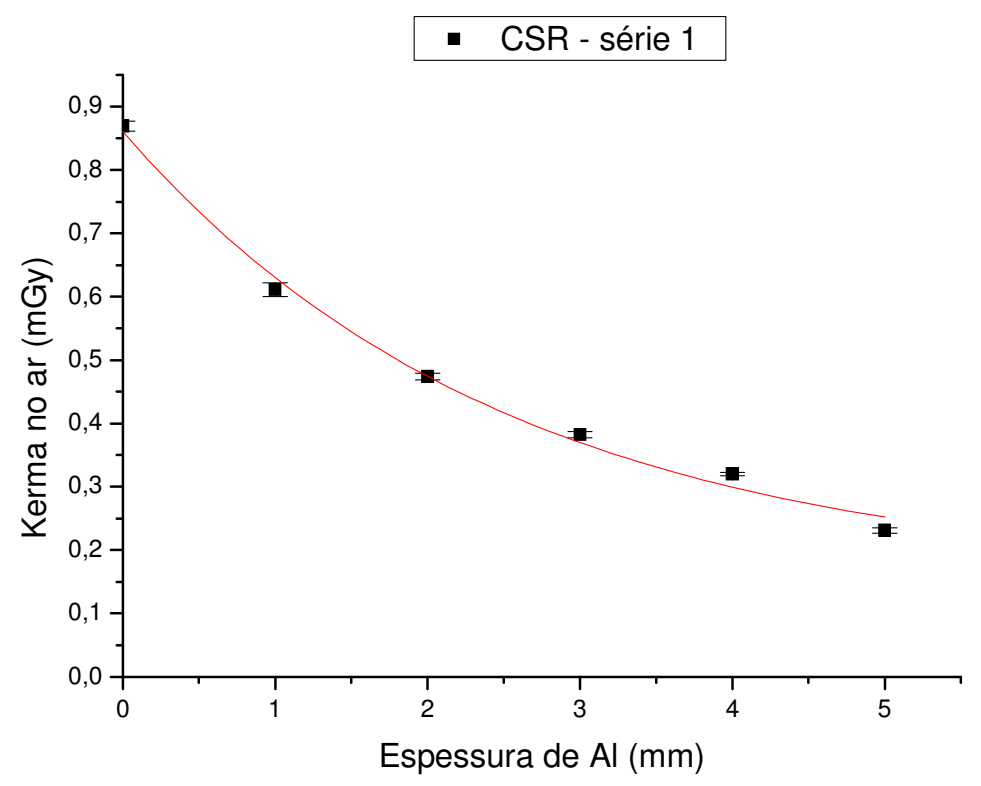

FIGURA 4.2 - Resultados obtidos de kerma no ar em função da espessura de alumínio, na série 1, para a determinação da CSR (média $=2,37 \pm 0,11 \mathrm{~mm} \mathrm{Al}$ ), por meio da função exponencial ajustada aos pontos experimentais.

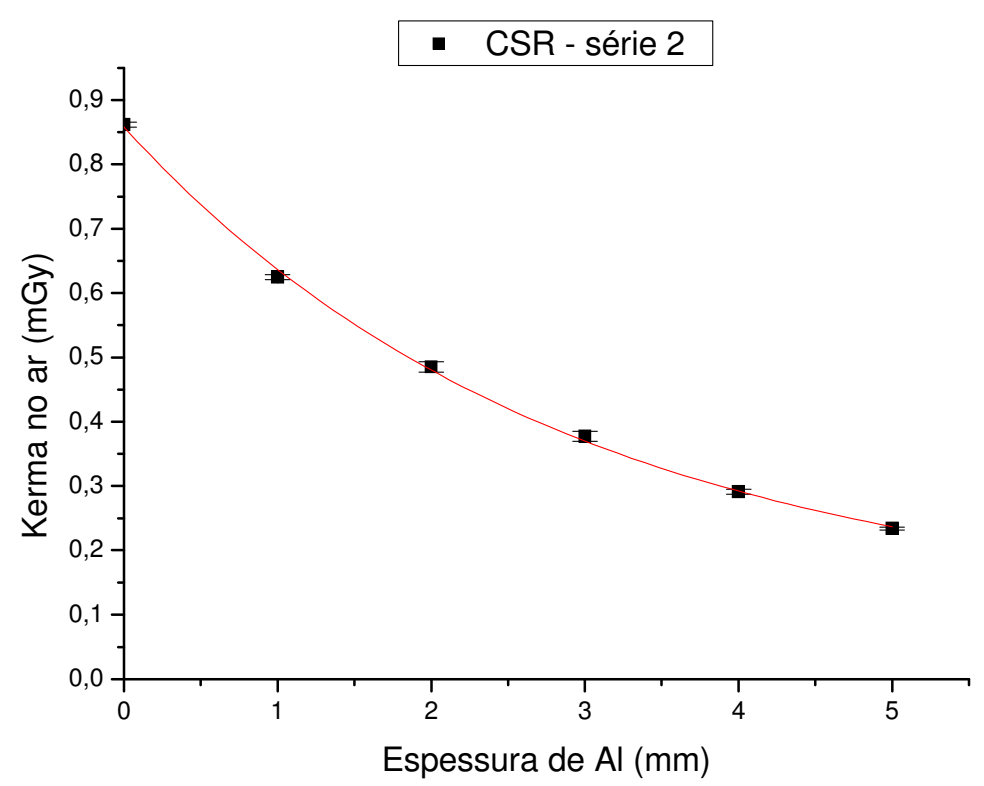

FIGURA 4.3 - Resultados obtidos de kerma no ar em função da espessura de alumínio, na série 2, para a determinação da CSR (média $=2,410 \pm 0,019 \mathrm{~mm} \mathrm{Al}$ ), por meio da função exponencial ajustada aos pontos experimentais. 


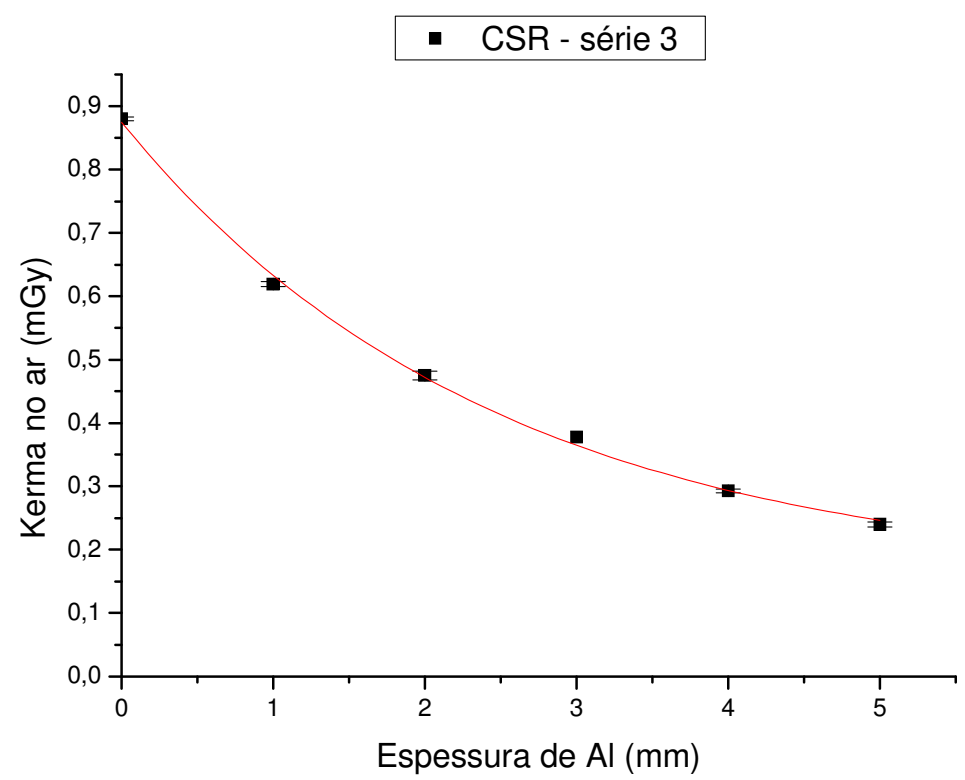

FIGURA 4.4 - Resultados obtidos de kerma no ar em função da espessura de alumínio, na série 3, para a determinação da CSR (média $=2,26 \pm 0,06 \mathrm{~mm} \mathrm{Al}$ ), por meio da função exponencial ajustada aos pontos experimentais.

O segundo método utiliza a seguinte expressão, representada na equação 8 , recomendada pela Resolução RE $n^{\circ} 64^{19,50}$ para diagnóstico médico convencional:

$$
\mathrm{CSR}=\left[\mathrm{Xb}^{*} \mathrm{Ln}\left(2^{*} \mathrm{La} / \mathrm{L}_{0}\right)-\mathrm{Xa}{ }^{*}\left(2^{*} \mathrm{Lb} / \mathrm{L}_{0}\right)\right] / \mathrm{Ln}(\mathrm{La} / \mathrm{Lb}),
$$

Onde:

$\mathrm{L}_{0}=$ leitura de kerma no ar sem absorvedor de alumínio

$\mathrm{La}=$ leitura imediatamente superior a $\mathrm{L}_{0} / 2$

$\mathrm{Lb}=$ leitura imediatamente inferior $\mathrm{a} \mathrm{L}_{0} / 2$

$\mathrm{Xa}=$ espessura de absorvedor de alumínio correspondente a $\mathrm{La}$

$\mathrm{Xb}=$ espessura de absorvedor de alumínio correspondente $\mathrm{a} L b$

As médias dos resultados obtidos para a camada semi-redutora (CSR), nas três séries, utilizando a primeira metodologia (gráfico) e a segunda metodologia, que utiliza a equação 8, estão apresentadas na TAB. 4.1. 
TABELA 4.1 - Resultados obtidos da CSR em alumínio utilizando as duas metodologias: gráfico e fórmula.

\begin{tabular}{cccc}
\hline \multirow{2}{*}{ Metodologia } & \multicolumn{3}{c}{ CSR $(\mathrm{mm} \mathrm{Al})$} \\
\cline { 2 - 4 } & Série 1 & Série 2 & Série 3 \\
\hline \hline Gráfico & $2,37 \pm 0,11$ & $2,410 \pm 0,019$ & $2,26 \pm 0,06$ \\
\hline Equação 8 & $2,40 \pm 0,09$ & $2,470 \pm 0,025$ & $2,32 \pm 0,07$ \\
\hline
\end{tabular}

Com base nestes resultados verifica-se que ambas as metodologias apresentam valores similares, com uma diferença de apenas 2,1\%. $\mathrm{Na}$ metodologia que emprega o gráfico, o resultado médio foi 2,35 $\pm 0,03 \mathrm{mmAl}$, e na

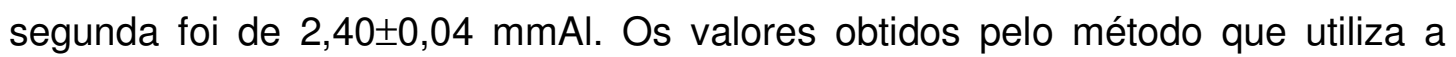
equação 8 estão, em todos os casos, acima dos obtidos graficamente. Ressaltase que um equipamento odontológico não permite a aplicação da RE $n^{\circ} 64$ na sua totalidade, pois não é possível variar o $\mathrm{mAs}$, por exemplo. No entanto, é importante destacar que estes resultados estão de acordo com os requisitos mínimos exigidos pela Portaria Federal $453^{10}$, item $5.15 \mathrm{~b}$, que exige uma CSR não inferior ao equivalente a $1,5 \mathrm{~mm}$ de alumínio para $70 \mathrm{kVp}$.

\subsubsection{Segundo arranjo experimental}

Seguindo a orientação da $R E n^{\circ} 64^{19,50}$, e em complemento aos valores obtidos no item anterior, foram realizadas exposições sem o localizador do aparelho, com DFF=20 cm, e com os absorvedores de alumínio colocados à meia distância, ou seja, a $10 \mathrm{~cm}$ acima do detector, conforme FIG. 4.5. A cada exposição realizada foi acrescida $1 \mathrm{~mm}$ de espessura de absorvedor, registrando 0 valor de kerma no ar correspondente, até o valor total de $5 \mathrm{~mm}$. Neste caso foi realizada uma série de cinco repetições. 


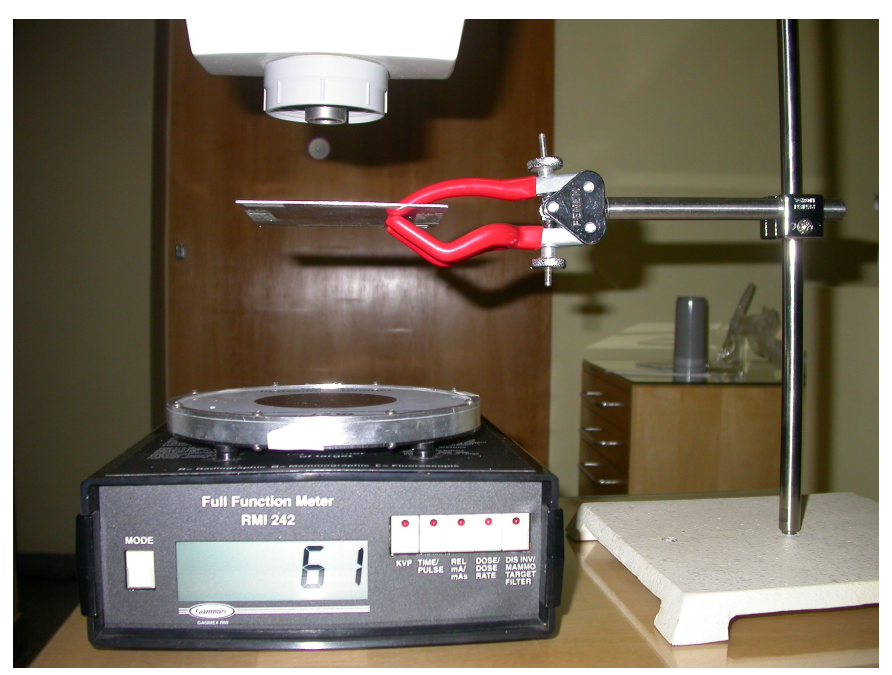

FIGURA 4.5 - Arranjo experimental utilizado para a medição da camada semiredutora, segundo a $R E n^{\circ} 64$.

A CSR foi determinada utilizando os mesmos métodos do item anterior, o primeiro via gráfico, relacionando os valores de kerma no ar em função da espessura de absorvedores. E o segundo método, que utiliza a expressão sugerida pela Resolução RE $n^{\circ} 64^{19,50}$.

Os gráficos obtidos a partir dos procedimentos realizados utilizando a primeira metodologia, bem como as respectivas funções ajustadas aos pontos experimentais, apresentaram um comportamento semelhante às do item anterior. Os resultados obtidos estão apresentados na FIG. 4.6. 


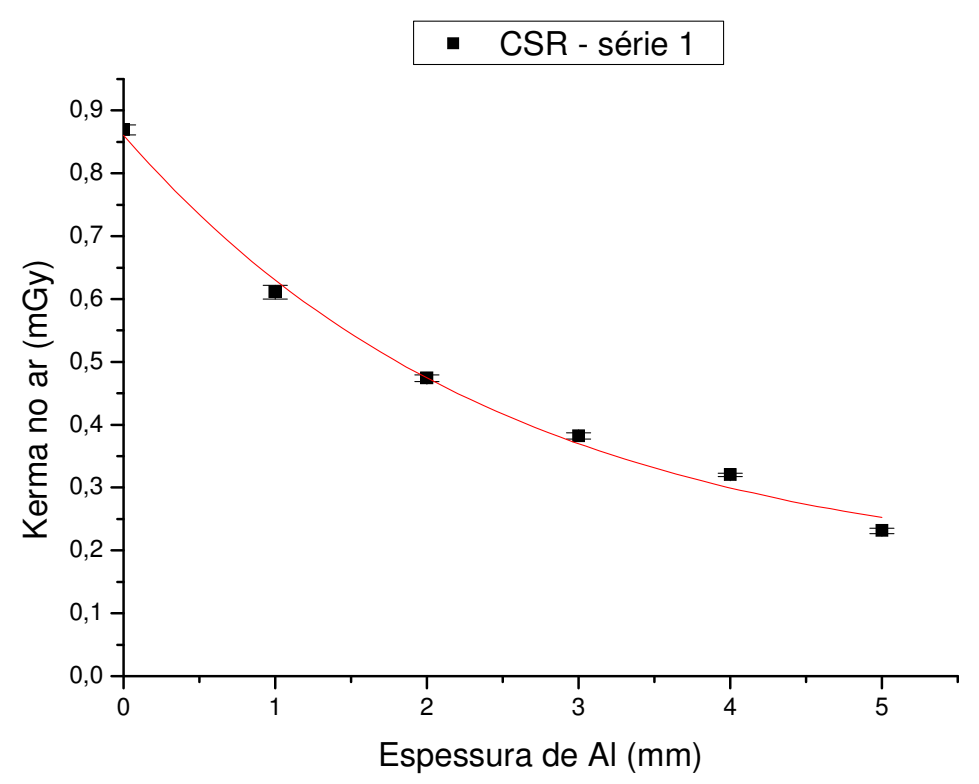

FIGURA 4.6 - Resultados obtidos de kerma no ar em função da espessura de alumínio obtido para a determinação da CSR (média $=2,21 \pm 0,05 \mathrm{~mm} \mathrm{Al}$ ), por meio da função exponencial ajustada aos pontos experimentais.

Os resultados obtidos para a camada semi-redutora (CSR), nesta série, utilizando a primeira metodologia (gráfico) e a segunda metodologia, que utiliza a equação 8, estão apresentados na TAB. 4.2.

TABELA 4.2 - Resultados obtidos da CSR utilizando as duas metodologias: gráfico e fórmula, seguindo a RE $n^{\circ} 64$.

\begin{tabular}{cc}
\hline Metodologia & CSR $(\mathrm{mm} \mathrm{Al})$ \\
\hline \hline Gráfico & $2,21 \pm 0,05$ \\
\hline Equação 8 & $2,27 \pm 0,05$ \\
\hline
\end{tabular}

Com base nestes resultados, verifica-se que ambas as metodologias, como no arranjo anterior, apresentaram valores semelhantes, com uma diferença menor que 3\%, conforme TAB. 4.2. Estes resultados também estão de acordo 
com os requisitos mínimos exigidos pela Portaria Federal $453^{10}$, itens $5.15 \mathrm{~b}$, que exige uma CSR não inferior ao equivalente a 1,5 mm de alumínio para $70 \mathrm{kVp}$.

No entanto, verifica-se que há uma pequena diferença, em torno de $6 \%$, entre os valores de CSR obtidos a partir dos arranjos experimentais utilizados. Esta diferença é atribuída à detecção dos fótons espalhados pelos absorvedores de alumínio, que deveriam ser excluídos do feixe de raios $\mathrm{X}$, acarretando uma maior CSR em relação ao valor real ${ }^{31,38}$.

\section{2 Tensão de pico}

Para as medidas de tensão de pico $(\mathrm{kVp})$ foi utilizado o mesmo tempo selecionado para o teste anterior, ou seja, 0,5 segundos. Inicialmente foram realizadas três séries de cinco medidas com o localizador do aparelho posicionado perpendicularmente ao medidor de tensão de pico citado anteriormente, numa distância foco-filme (DFF) de $20 \mathrm{~cm}$, conforme FIG. 4.7a. Em seguida foram repetidas as mesmas medidas, utilizando um posicionador de $7,5 \mathrm{~cm}$ de comprimento, aumentando a DFF para $27,5 \mathrm{~cm}$, conforme FIG.4.7b.

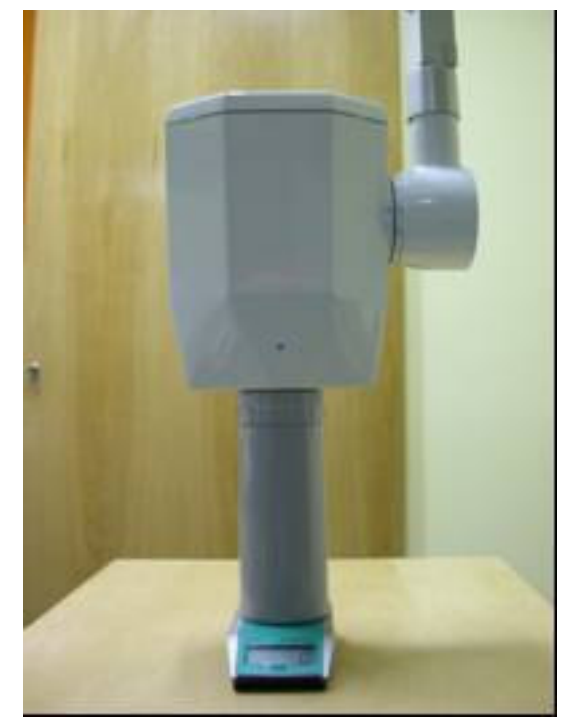

(a)

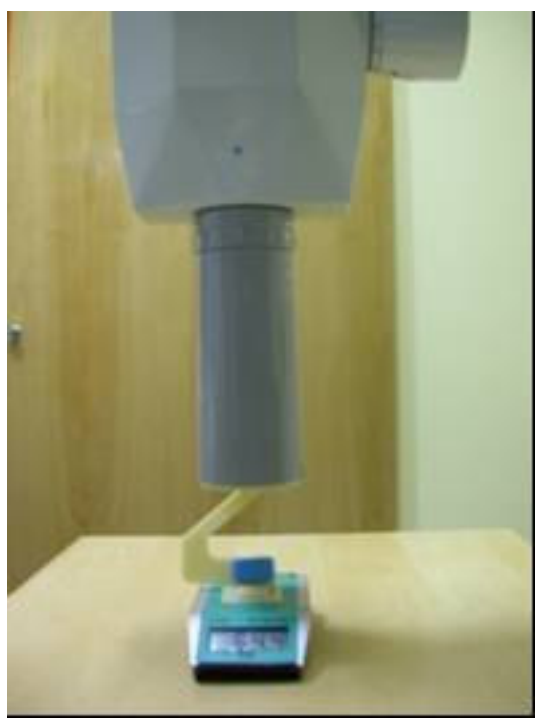

(b)

FIGURA 4.7 - Arranjo experimental utilizado para a medida de kVp: a) sem posicionador $\mathrm{DFF}=20 \mathrm{~cm}$; b) com posicionador $\mathrm{DFF}=27,5 \mathrm{~cm}$. 
Os resultados obtidos para a tensão de pico com distância foco-filme igual a $20,0 \mathrm{~cm}$ e $27,5 \mathrm{~cm}$ estão apresentados na TAB. 4.3.

TABELA 4.3 - Valores obtidos para a tensão de pico para $20 \mathrm{~cm}$ e $27,5 \mathrm{~cm}$. Tensão nominal.

\begin{tabular}{cccc}
\hline DFF & \multicolumn{3}{c}{ Tensão de pico $(\mathrm{kVp})$} \\
\cline { 2 - 4 }$(\mathrm{cm})$ & Série 1 & Série 2 & Série 3 \\
\hline 20,0 & $63,82 \pm 0,16$ & $63,68 \pm 0,10$ & $63,38 \pm 0,23$ \\
\hline 27,5 & $63,42 \pm 0,18$ & $63,66 \pm 0,19$ & $62,92 \pm 0,18$ \\
\hline
\end{tabular}

Embora este sistema de raios $\mathrm{X}$ possua uma tensão nominal de $70 \mathrm{kV}$, como citado no item 3.1, comprova-se que o valor da tensão de pico obtida não variou com o aumento da distância foco-filme, ou seja, quando se utiliza posicionador. A diferença na exatidão encontrada de aproximadamente $10 \%$ pode estar relacionada com a tensão da rede elétrica, que pode sofrer variação de local e horário ${ }^{51}$, lembrando que os sistemas de raios $X$ utilizados em consultórios normalmente estão sujeitos a estas variações, pois não são equipamentos controlados como os de laboratórios. De qualquer maneira, estes resultados estão de acordo com o padrão de desempenho descrito pela Portaria Federal $453^{10}$, item 5.15c, que exige uma tensão medida no tubo não inferior a $50 \mathrm{kVp}$, com uma tolerância de $-3 \mathrm{kVp}$.

\section{3 Tamanho de campo}

Para a determinação do tamanho do campo de radiação, ou feixe útil, foi selecionado o tempo de 0,5 segundos, e os filmes foram posicionados sobre uma superfície plana para serem expostos ao feixe de raios $X$. As exposições foram realizadas em quatro etapas, e em duas distâncias foco-filme (DFF): a) $D F F=20 \mathrm{~cm}$ com localizador; b) $D F F=27,5 \mathrm{~cm}$ com localizador; c) $D F F=20 \mathrm{~cm}$ sem localizador; d) $D F F=27,5 \mathrm{~cm}$ sem localizador. Os dois primeiros arranjos estão apresentados na FIG. 4.8. 

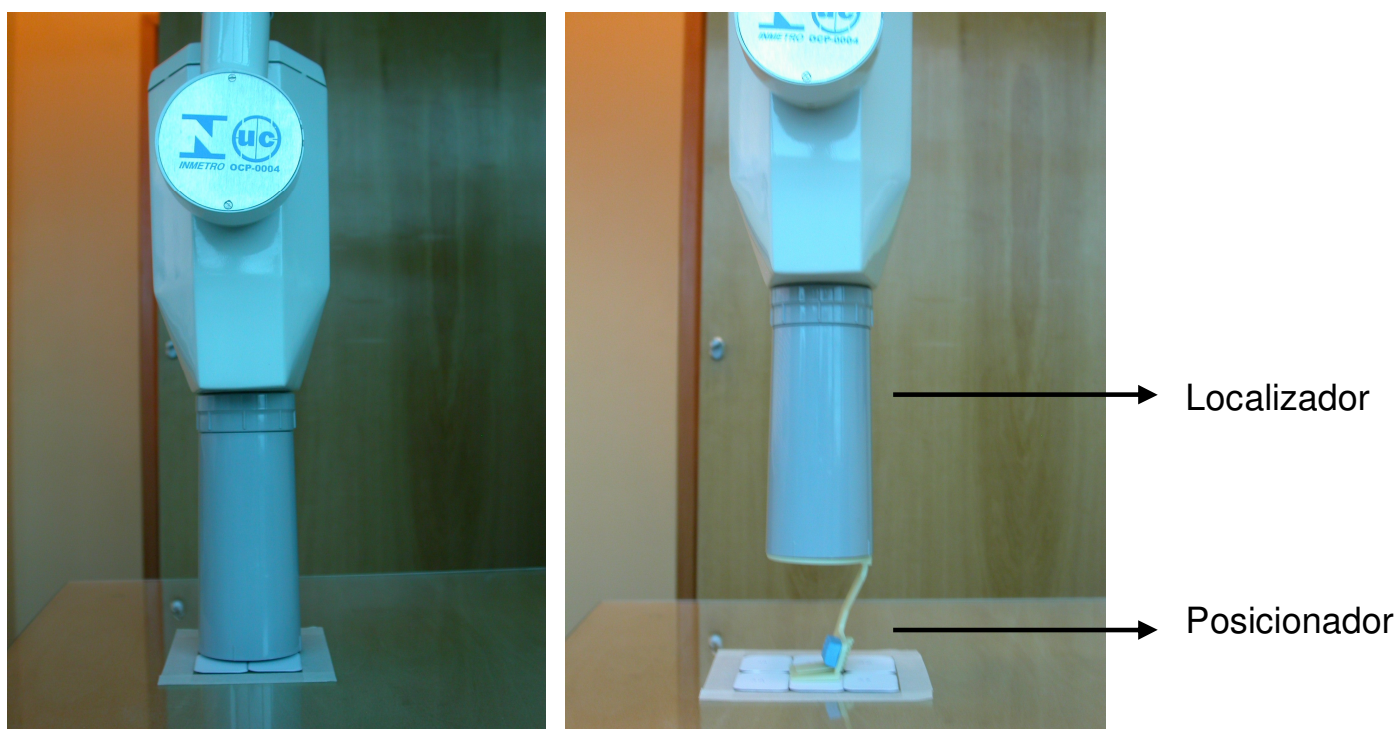

FIGURA 4.8: Arranjo experimental utilizado para a determinação do tamanho de campo: a) $D F F=20 \mathrm{~cm}$ com localizador; b) $D F F=27,5 \mathrm{~cm}$ com localizador.

Para cada arranjo o procedimento foi repetido cinco vezes, e a revelação dos filmes irradiados seguiu as recomendações do fabricante Kodak, levando em consideração a tabela tempo/temperatura ${ }^{49}$ fornecida. Os filmes revelados foram montados e analisados em um negatoscópio, medindo-se o diâmetro das imagens, em cinco posições diferentes. Os resultados obtidos para os arranjos estão apresentados na TAB. 4.4.

TABELA 4.4 - Valores de tamanho de campo obtidos utilizando quatro arranjos diferentes.

\begin{tabular}{ccc}
\hline \multirow{2}{*}{$(\mathrm{cm})$} & \multicolumn{2}{c}{ Tamanho de campo $(\mathrm{cm})$} \\
\cline { 2 - 3 } & Com localizador & Sem localizador \\
\hline 20,0 & $5,310 \pm 0,014$ & $5,50 \pm 0,008$ \\
\hline 27,5 (com posicionador) & $7,400 \pm 0,017$ & $7,620 \pm 0,019$ \\
\hline
\end{tabular}

Com base nos resultados obtidos pode-se concluir que o aparelho de raios $\mathrm{X}$ avaliado apresenta resultados satisfatórios quando é utilizada uma DFF de $20 \mathrm{~cm}$, pois em uma radiografia intrabucal o diâmetro do campo não deve ser 
superior a $6 \mathrm{~cm}$, valores entre 4 e $5 \mathrm{~cm}$ são permitidos apenas quando houver um sistema de alinhamento e posicionamento do filme, conforme descrito no item $5.7 d$ (ii). Mas, ao se utilizar o posicionador, a $27,5 \mathrm{~cm}$, que é o recomendado pela PF $453^{10}$, item $5.8 \mathrm{~d}$ (ii), o tamanho do campo ultrapassa o valor máximo de $6 \mathrm{~cm}$ exigido no mesmo documento. Este fato demonstra uma incoerência da norma, pois ao se aumentar a DFF o campo aumentará com certeza, dificultando o atendimento completo deste item.

\subsection{Reprodutibilidade do tempo de exposição e de kerma no ar}

Nesta etapa foram realizadas medidas para tempos de exposição selecionados no temporizador com o localizador do aparelho encostado perpendicularmente ao medidor do tempo de exposição Fabinject citado no item 3.2 (DFF=20 cm), conforme FIG. 4.9. O tempo de exposição foi variado de 0 a 1,5 s. Para cada tempo de exposição selecionado foram realizadas três séries de cinco medidas.

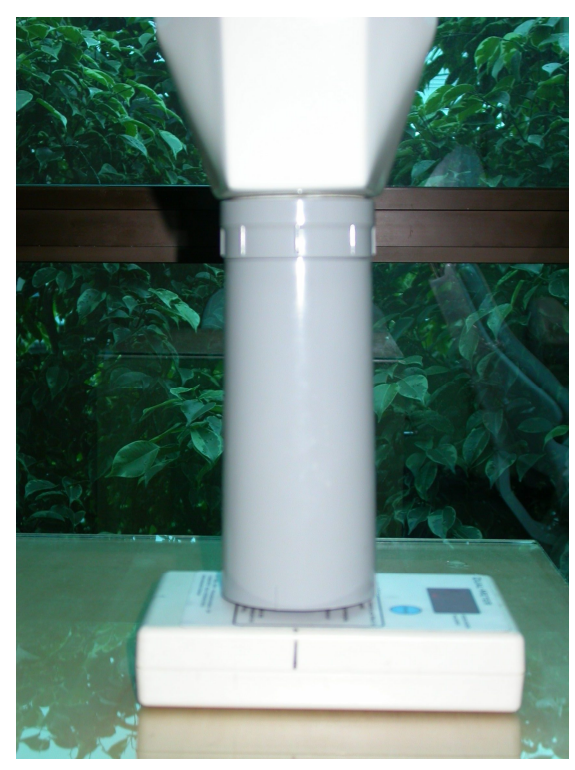

FIGURA 4.9 - Arranjo experimental utilizado para a medição da reprodutibilidade do tempo de exposição sem posicionador (DFF=20 cm).

Em seguida, para os mesmos tempos de exposição e mesma quantidade de repetições, foram determinados os respectivos valores de kerma 
no ar, para DFF=20 cm e $27,5 \mathrm{~cm}$, utilizando-se o instrumento multi-função da RMI, modelo Gammex, detalhado no item 3.2, conforme FIG. 4.10.
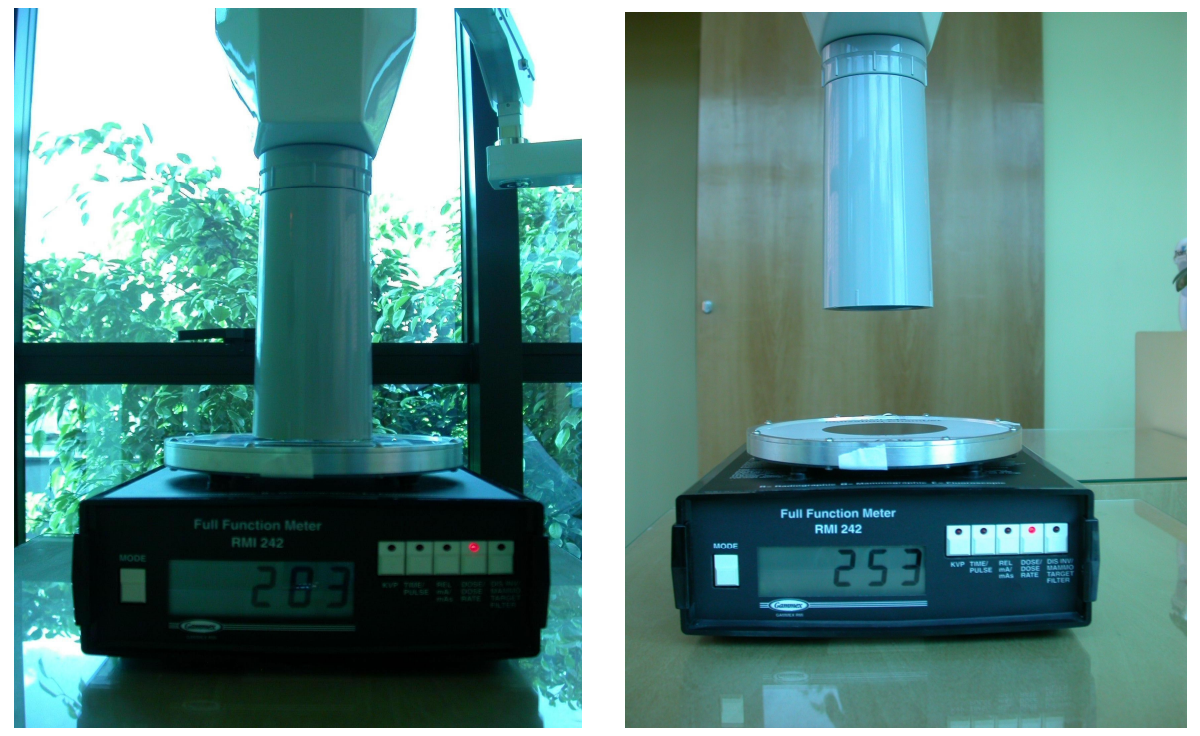

FIGURA 4.10 - Arranjo experimental utilizado para a medição do kerma no ar para $\mathrm{DFF}=20 \mathrm{~cm}$ e $27,5 \mathrm{~cm}$.

Os resultados obtidos para o tempo de exposição do sistema de raios $X$ avaliados e apresentados na TAB. 4.5, demonstraram que a variação entre o valor medido e o valor nominal esteve sempre abaixo de $10 \%$ que é o limite recomendado pelo item $5.15 d$ da PF $453^{10}$. Neste equipamento o valor nominal é substituído pela média dos valores de tempo medida pelo próprio sistema de raios $X$. 
TABELA 4.5 - Valores obtidos de tempo de exposição (DFF=20 cm) do sistema de raios $X$ Dabi Atlante de 70 kV/8 mA, utilizando-se o detector Fabinject.

\begin{tabular}{cccc}
\hline Tempo nominal & \multicolumn{3}{c}{ Tempo de exposição (s) } \\
\cline { 2 - 4 }$(\mathrm{s})$ & 0 & 2 $^{\text {a }}$ Série & 3 $^{\text {a }}$ Série \\
\hline 0 & $0,5480 \pm 0,0020$ & $0,524 \pm 0,009$ & $0,502 \pm 0,009$ \\
\hline 0,50 & $1,0340 \pm 0,0024$ & $0,992 \pm 0,009$ & $0,994 \pm 0,029$ \\
\hline 1,00 & $1,538 \pm 0,012$ & $1,478 \pm 0,010$ & $1,660 \pm 0,014$ \\
\hline 1,50 & & & 0 \\
\hline
\end{tabular}

Este modelo de equipamento de raios $X$ possui um temporizador que compensa possíveis variações na corrente elétrica, aumentando ou diminuindo os tempos de exposição selecionados. Sendo assim, quando se selecionou o tempo de $1,5 \mathrm{~s}$ na $3^{\mathrm{a}}$ série, o valor médio mostrado no controle foi de $1,646 \pm 0,016 \mathrm{~s}$. Portanto, a variação entre o tempo medido e o real foi bem inferior a 10\%, como recomenda a PF $453^{10}$.

Partiu-se então para a avaliação da reprodutibilidade dos valores de kerma no ar como já citado e cujo arranjo aparece na FIG. 4.10. Os resultados obtidos para a DFF=20 cm e de 27,5 cm estão apresentados nas TAB. 4.6 e 4.7, respectivamente.

TABELA 4.6 - Valores obtidos de kerma no ar $(\mathrm{K})$ e respectivos tempos de exposição $(\Delta \mathrm{t})$ para $\mathrm{DFF}=20 \mathrm{~cm}$ do sistema de raios $X$ Dabi Atlante de

70 kV/8 mA, com a câmara de ionização do medidor Gammex.

\begin{tabular}{ccccccc}
\hline $\begin{array}{c}\text { Tempo } \\
\text { nominal } \\
(\mathrm{s})\end{array}$ & $\mathbf{K}(\mathbf{m G y})$ & $\Delta \mathrm{t}(\mathbf{s})$ & $\mathbf{K}(\mathbf{m G y})$ & $\Delta \mathrm{t}(\mathbf{s})$ & $\mathbf{K}(\mathbf{m G y})$ & $\Delta t(\mathbf{s})$ \\
\cline { 2 - 7 } & 0 & 0 & 0 & 0 & 0 & 0 \\
\hline \hline 0 & & & & & & 3' Série \\
\hline 0,50 & $0,869 \pm 0,008$ & $0,534 \pm 0,004$ & $0,862 \pm 0,004$ & $0,546 \pm 0,011$ & $0,880 \pm 0,003$ & $0,530 \pm 0,000$ \\
\hline 1,00 & $1,769 \pm 0,006$ & $1,036 \pm 0,009$ & $1,721 \pm 0,006$ & $1,082 \pm 0,005$ & $1,8030 \pm 0,0023$ & $1,050 \pm 0,006$ \\
\hline 1,50 & $2,657 \pm 0,006$ & $1,632 \pm 0,008$ & $2,644 \pm 0,005$ & $1,624 \pm 0,010$ & $2,689 \pm 0,008$ & $1,572 \pm 0,018$ \\
\hline
\end{tabular}


TABELA 4.7: Valores obtidos de kerma no ar (K) e respectivos tempos de exposição $(\Delta \mathrm{t})$ para $\mathrm{DFF}=27,5 \mathrm{~cm}$ do sistema de raios $X$ Dabi Atlante de 70 kV/8 mA, com a câmara de ionização do medidor Gammex.

\begin{tabular}{ccccccc}
\hline $\begin{array}{c}\text { Tempos } \\
\text { nominais } \\
(\mathbf{s})\end{array}$ & $\mathbf{K}(\mathbf{m G y})$ & $\Delta \mathrm{t}(\mathbf{s})$ & $\mathbf{K}(\mathbf{m G y})$ & $\Delta \mathrm{t}(\mathbf{s})$ & $\mathbf{K}(\mathbf{m G y})$ & $\Delta \mathrm{t}(\mathbf{s})$ \\
\cline { 2 - 7 } & 0 & 0 & 0 & 0 & 0 & 0 \\
\hline \hline 0 & $0,758 \pm 0,004$ & $0,530 \pm 0,005$ & $0,738 \pm 0,006$ & $0,5440 \pm 0,0024$ & $0,766 \pm 0,008$ & $0,540 \pm 0,000$ \\
\hline 0,50 & $1,525 \pm 0,009$ & $1,054 \pm 0,004$ & $1,540 \pm 0,018$ & $1,038 \pm 0,052$ & $1,540 \pm 0,004$ & $1,102 \pm 0,005$ \\
\hline 1,00 & $2,348 \pm 0,015$ & $1,598 \pm 0,007$ & $2,374 \pm 0,011$ & $1,384 \pm 0,007$ & $2,395 \pm 0,035$ & $1,520 \pm 0,059$ \\
\hline 1,50 & & & & & & \\
\hline
\end{tabular}

Da mesma maneira que para o tempo de exposição, a variação máxima encontrada $(4,8 \%)$ entre os resultados médios de kerma no ar, para os três tempos de exposição e nas duas distâncias utilizadas esteve sempre abaixo do limite de $10 \%$ estabelecido pela PF $453^{10}$.

\subsection{Linearidade de kerma no ar com o tempo de exposição}

Para a verificação da linearidade dos valores de kerma no ar em relação ao tempo de exposição $(0,5,1,0$ e $1,5 \mathrm{~s})$ selecionado no temporizador do aparelho de raios $X$, foram utilizados os dados obtidos no item 4.4, TAB. 4.6 e 4.7. Com estas medidas foram confeccionados seis gráficos de valores de kerma no ar obtidos em função do tempo de exposição, três para a $\mathrm{DFF}=20 \mathrm{~cm}$ e três para a $D F F=27,5 \mathrm{~cm}$. Finalmente para cada conjunto de dados ajustou-se uma função linear. Os gráficos obtidos estão apresentados nas FIG. 4.11 a 4.16 . 


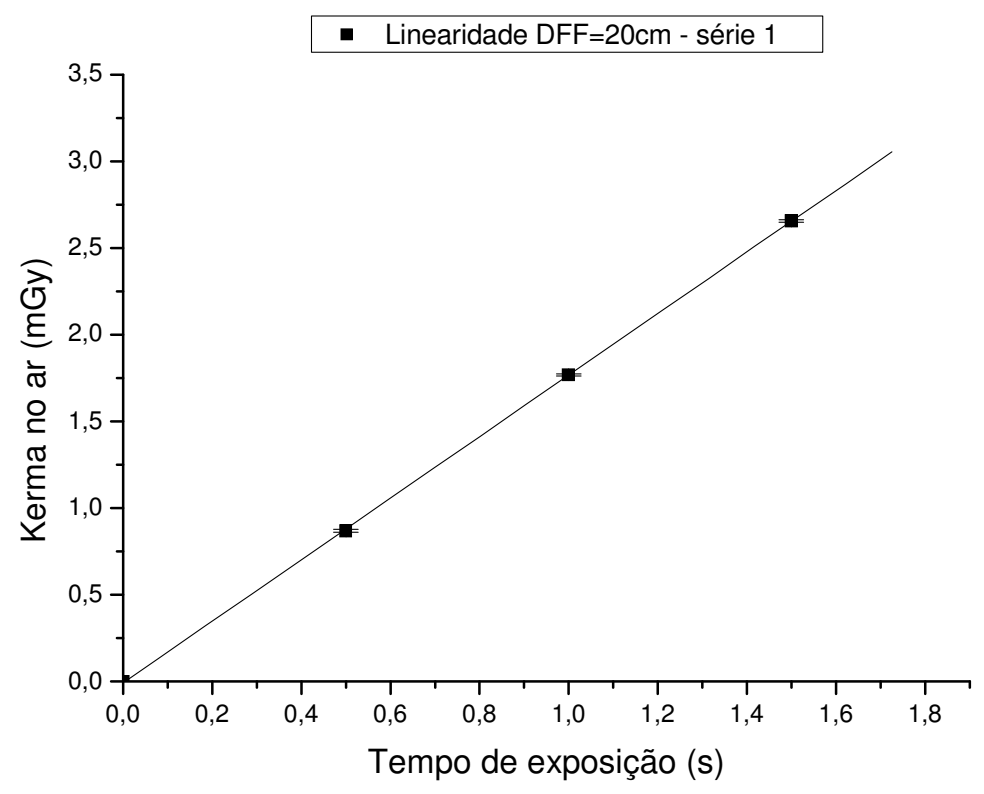

FIGURA 4.11 - Teste de linearidade do sistema de raios $\mathrm{X}$, kerma no ar em função do tempo de exposição nominal, com DFF=20 cm (série 1).

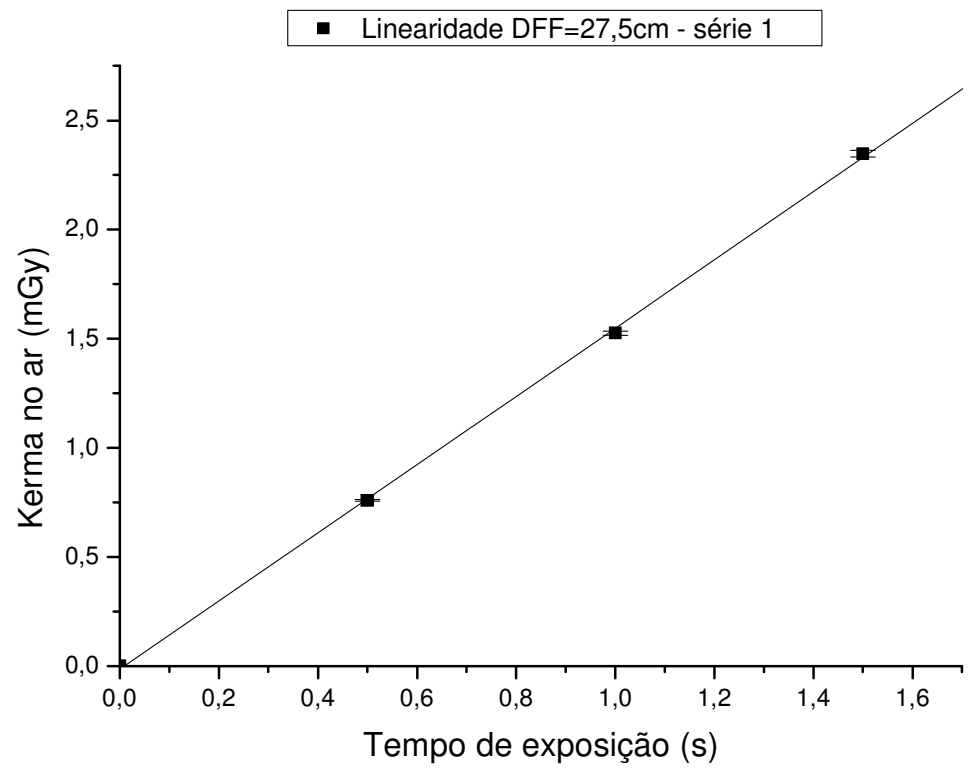

FIGURA 4.12 - Teste de linearidade do sistema de raios $X$, kerma no ar em função do tempo de exposição nominal, com DFF=27,5 cm (série 1). 


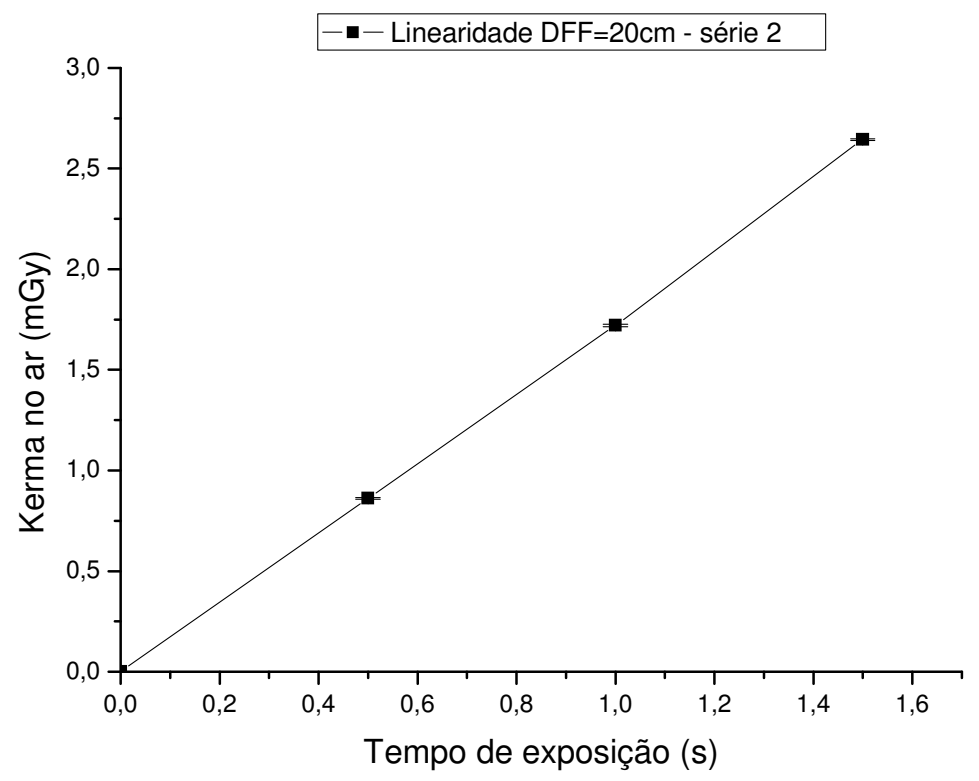

FIGURA 4.13 - Teste de linearidade do sistema de raios $X$, kerma no ar em função do tempo de exposição nominal, com DFF=20 cm (série 2).

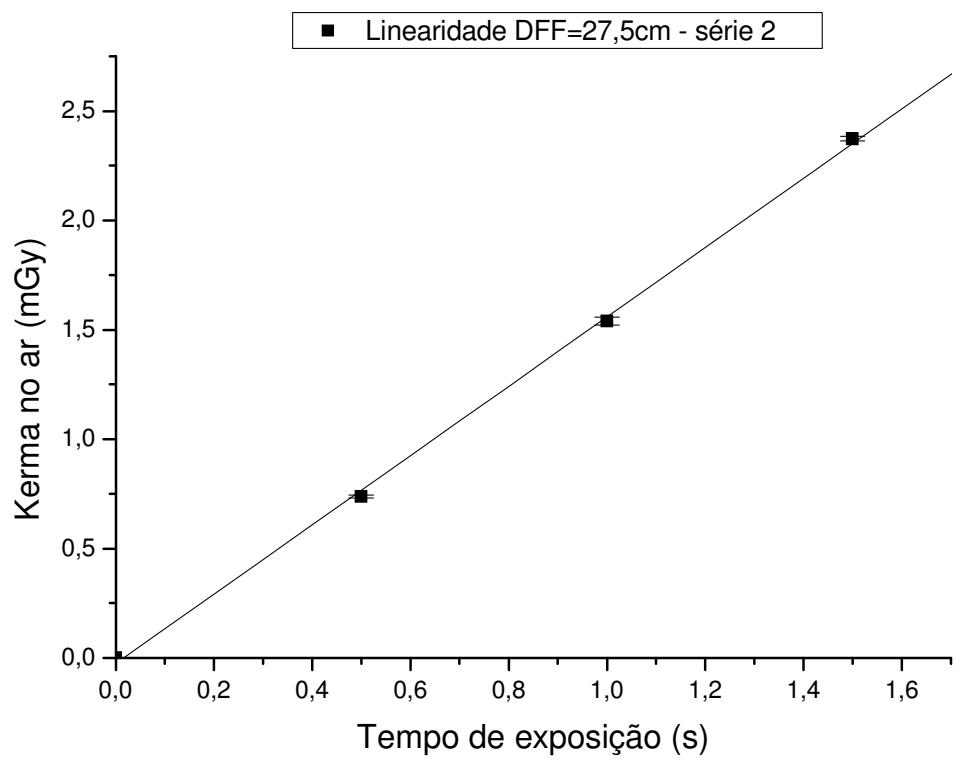

FIGURA 4.14 - Teste de linearidade do sistema de raios $X$, kerma no ar em função do tempo de exposição nominal, com DFF=27,5 cm (série 2). 


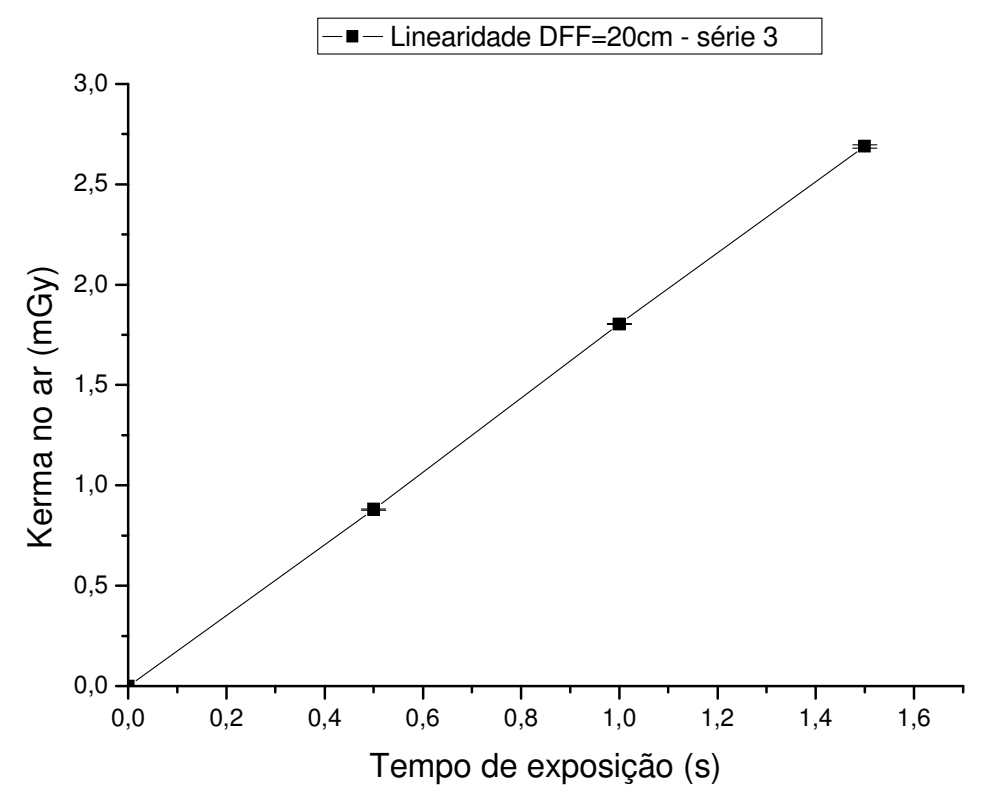

FIGURA 4.15 - Teste de linearidade do sistema de raios $\mathrm{X}$, kerma no ar em função do tempo de exposição nominal, com DFF=20 cm (série 3).

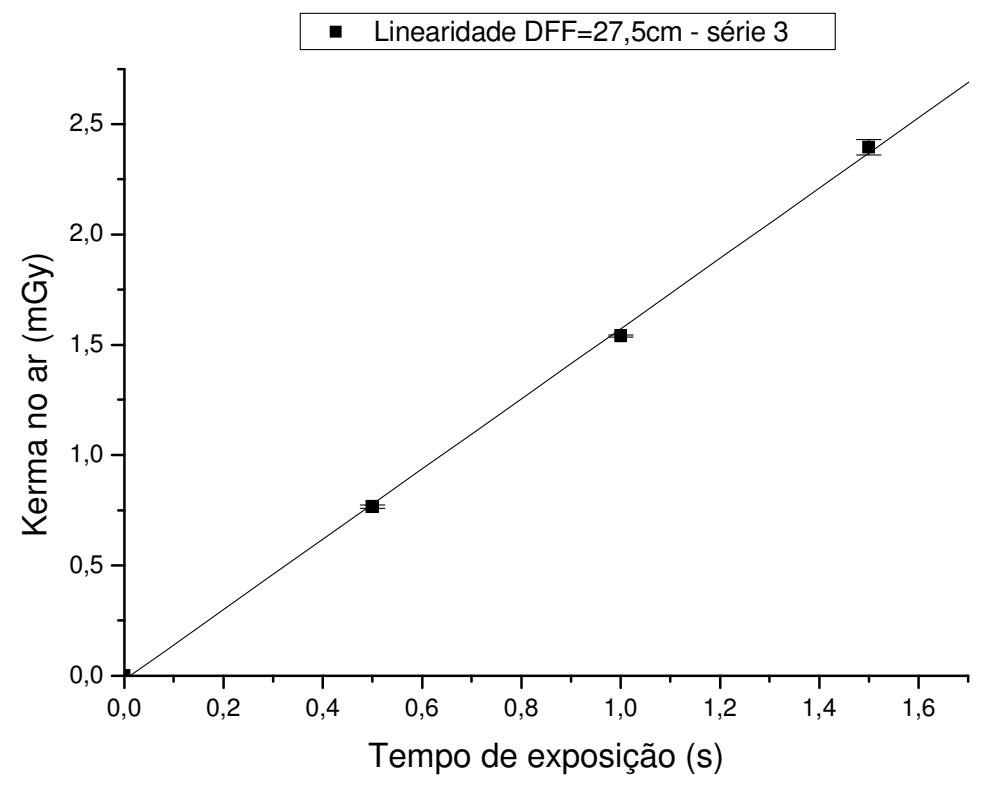

FIGURA 4.16 - Teste de linearidade do sistema de raios $\mathrm{X}$, kerma no ar em função do tempo de exposição nominal, com DFF=27,5 cm (série 3). 
Pelos ajustes lineares obtidos, verifica-se que o aparelho de raios $X$ avaliado, bem como a metodologia aplicada, apresentou uma linearidade satisfatória entre os tempos de exposição e os respectivos valores de kerma no ar, ficando bem abaixo da variação de $20 \%$ descrita na Portaria Federal $453^{10}$, item 5.15e (a taxa de kerma no ar deve ser linear com o tempo de exposição, o desvio - diferença entre duas medidas - máximo não deve ultrapassar $20 \%$ do valor médio, para os tempos comumente utilizados). A maior variação encontrada foi de aproximadamente $7 \%$ para a terceira série de medidas em $27,5 \mathrm{~cm}$ para 0 tempo de $1,5 \mathrm{~s}$.

\subsection{Dose de entrada na pele (DEP)}

Para a determinação da dose de entrada na pele (DEP) foram utilizadas as medidas de kerma no ar obtidas por meio do procedimento descrito no item 4.4, Tabelas 4.6 e 4.7. Cada valor obtido de kerma no ar foi multiplicado

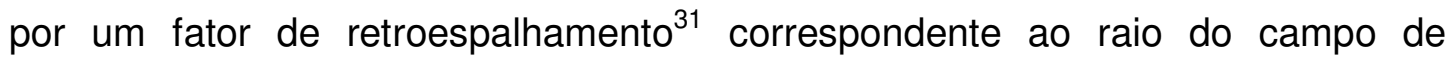
radiação utilizado em cada determinação, resultando na DEP já definida anteriormente. Valores de fatores de retroespalhamento para diferentes raios de campo de radiação foram publicados por Johns e Cunningham ${ }^{31}$. Para a determinação destes fatores para os raios de campos obtidos neste trabalho, foi confeccionado um gráfico utilizando-se os valores publicados, apresentado na FIG. 4.17, para a DFF de $20 \mathrm{~cm}$ (raio $=2,66 \mathrm{~cm}$ ) e para a DFF de $27,5 \mathrm{~cm}$ (raio=3,70 cm). Os fatores de retroespalhamento foram encontrados por um ajuste polinomial de terceira ordem, para uma CSR de 2,21 cm. Os valores de DEP obtidos estão apresentados nas TAB. 4.8 e 4.9.

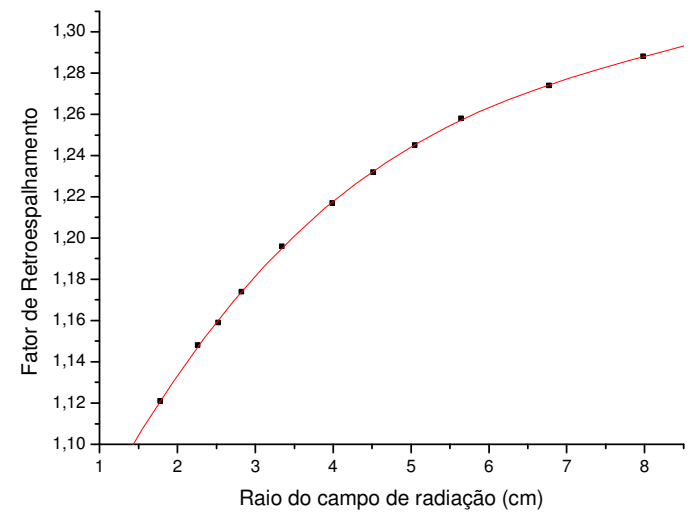

FIGURA 4.17 - Gráfico utilizado para a determinação do fator de retroespalhamento, para DFF $=20 \mathrm{~cm}$ e $27,5 \mathrm{~cm}$, para uma CSR de $2,21 \mathrm{~cm}$ 
TABELA 4.8 - Valores de dose de entrada na pele (DEP) a partir dos resultados obtidos de kerma no ar, para $D F F=20 \mathrm{~cm}$.

\begin{tabular}{cccc}
\hline $\begin{array}{c}\text { Tempo } \\
\text { nominal }(\mathrm{s})\end{array}$ & $\begin{array}{c}\text { Kerma no ar } \\
(\mathrm{mGy})\end{array}$ & $\begin{array}{c}\text { Fator de } \\
\text { Retroespalhamento }\end{array}$ & DEP (mGy) \\
\hline \hline 0 & 0 & 1,167 & 0 \\
\hline 0,50 & $0,869 \pm 0,008$ & 1,167 & $1,014 \pm 0,009$ \\
\hline 1,00 & $1,769 \pm 0,006$ & 1,167 & $2,064 \pm 0,007$ \\
\hline 1,50 & $2,657 \pm 0,006$ & 1,167 & $3,100 \pm 0,008$ \\
\hline
\end{tabular}

TABELA 4.9 - Valores de dose de entrada na pele (DEP) a partir dos resultados obtidos de kerma no ar, para DFF=27,5 cm.

\begin{tabular}{cccc}
\hline $\begin{array}{c}\text { Tempo } \\
\text { nominal }(\mathrm{s})\end{array}$ & $\begin{array}{c}\text { Kerma no ar } \\
(\mathrm{mGy})\end{array}$ & $\begin{array}{c}\text { Fator de } \\
\text { Retroespalhamento }\end{array}$ & $\begin{array}{c}\text { DEP } \\
(\mathrm{mGy})\end{array}$ \\
\hline \hline 0 & 0 & 1,208 & 0 \\
\hline 0,50 & $0,758 \pm 0,004$ & 1,208 & $0,916 \pm 0,005$ \\
\hline 1,00 & $1,525 \pm 0,009$ & 1,208 & $1,842 \pm 0,011$ \\
\hline 1,50 & $2,348 \pm 0,015$ & 1,208 & $2,837 \pm 0,018$
\end{tabular}

Verifica-se que mesmo considerando a dose devido à radiação retroespalhada nenhum valor de exposição ultrapassa o limite estabelecido na PF $453^{10}$, descrito no item $5.15 f$ (as doses na entrada na pele dos pacientes em radiografia intrabucal devem ser inferiores ao nível de referência de radiodiagnóstico, que é de 3,5 mGy, por radiografia para paciente adulto típico).

\subsection{Padrão de imagem radiográfica: desenvolvimento de um objeto teste (simulador)}

Para os profissionais da saúde, em especial na área odontológica, é de suma importância a qualidade de uma imagem radiográfica para um bom diagnóstico e conseqüente tratamento.

Neste trabalho foi construído um objeto teste correspondente a um dente médio para obtenção de imagens padrões com o objetivo de avaliar a 
qualidade de uma radiografia. O simulador consiste em uma base de alumínio recoberta por uma placa de acrílico, com dimensões de $4 \mathrm{~cm} \times 3 \mathrm{~cm}$ (mesmas do filme radiográfico), e espessura total de $3,0 \mathrm{~mm}$, conforme já descrito no item 3.6 e ilustrado na FIG. 4.18.

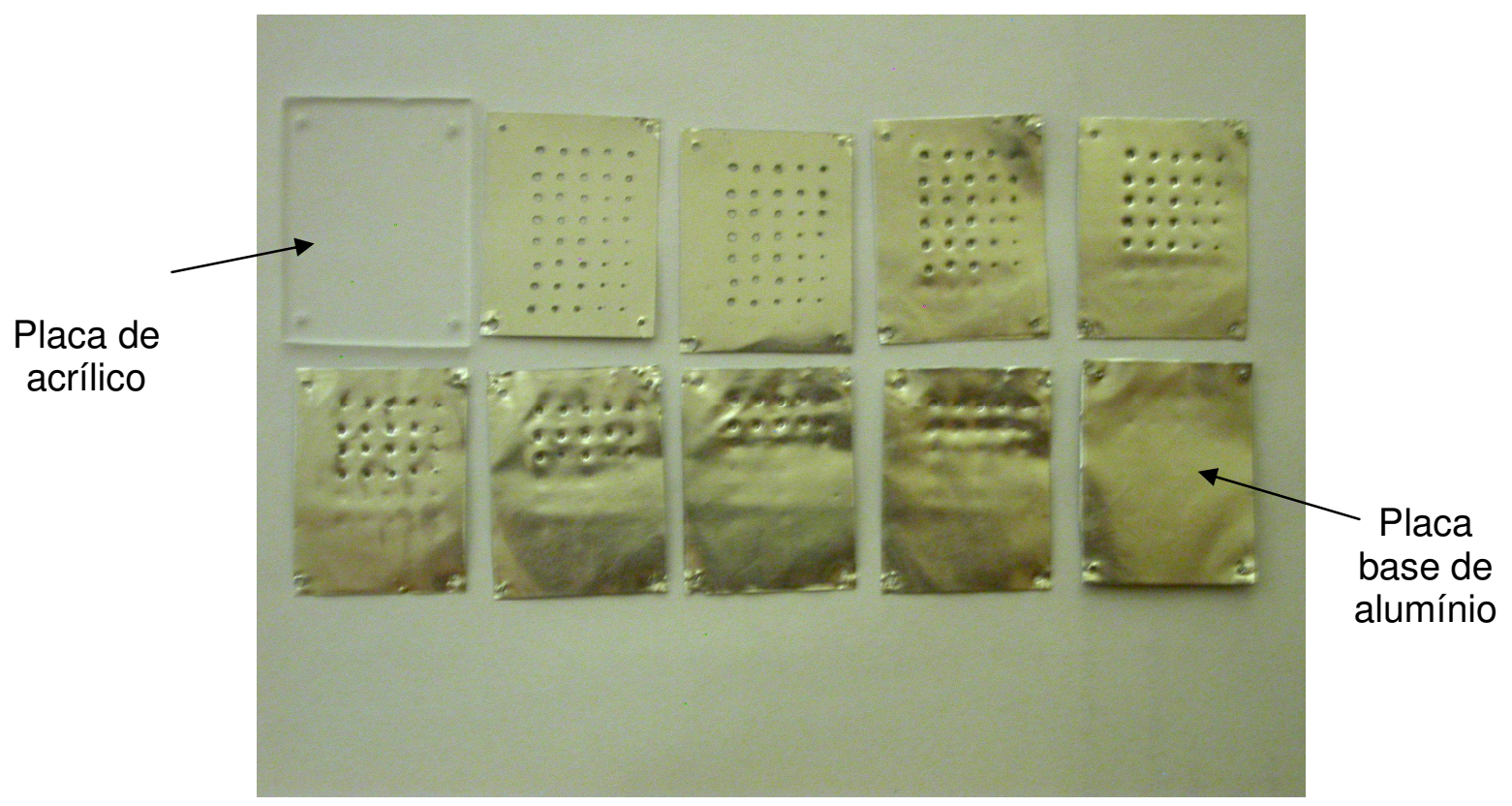

FIGURA 4.18 - Placa de acrílico, placas de alumínio perfuradas, que foram sobrepostas para confecção do objeto teste, e a base de alumínio.

O diâmetro dos orifícios foi variado de $0,25 \mathrm{~mm}$ a $1,0 \mathrm{~mm}$. O objeto teste possui uma espessura total de $1,5 \mathrm{~mm}$ de alumínio e é recoberto por uma placa de acrílico de 1,5 mm, conforme FIG. 4.19. 


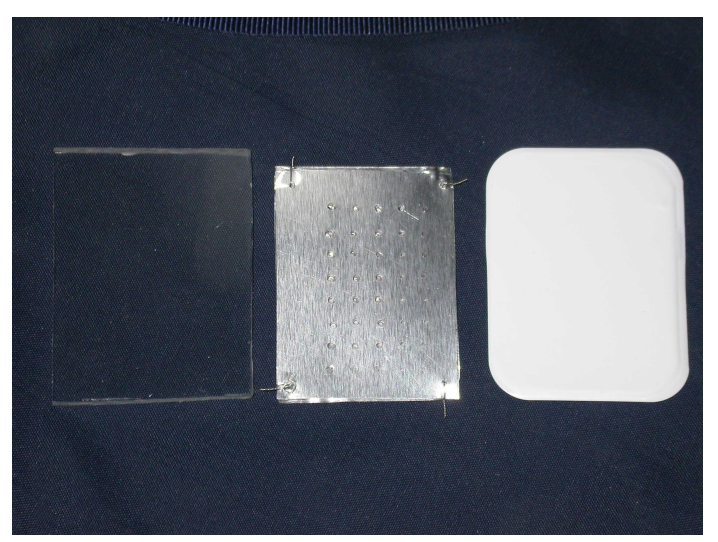

(a) Acrílico, alumínio e filme de raios $X$

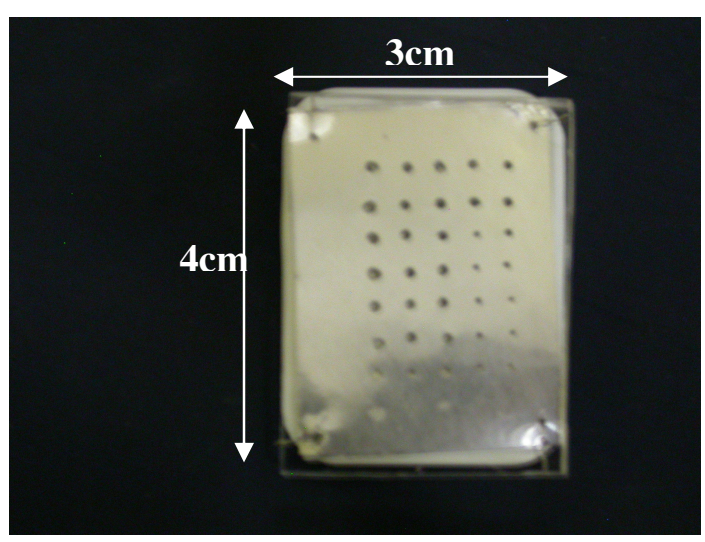

(b) Objeto teste montando

FIGURA 4.19 - Objeto teste desenvolvido para avaliar a qualidade da imagem radiográfica, composta de uma placa de alumínio perfurada, com diâmetros e profundidades diferentes recoberta por acrílico.

O objeto teste foi radiografado em um tempo de exposição tal que a densidade ótica na imagem esteja dentro da região de maior contraste do filme radiográfico utilizado, Kodak ektaspeed, obtida por meio da sua curva característica.

Conforme descrito no item 2.4, a curva característica descreve a variação da densidade ótica de um filme (grau de enegrecimento) em função da exposição, onde a região mais íngreme corresponde àquela de maior contraste. Para a obtenção desta curva, os filmes foram irradiados utilizando o aparelho de raios $X$ de $70 \mathrm{kVp}$ com tempos de exposição que variaram de 0,1 a 1,5 s, e revelados de acordo o fabricante. O resultado está apresentado na FIG. 4.20. 


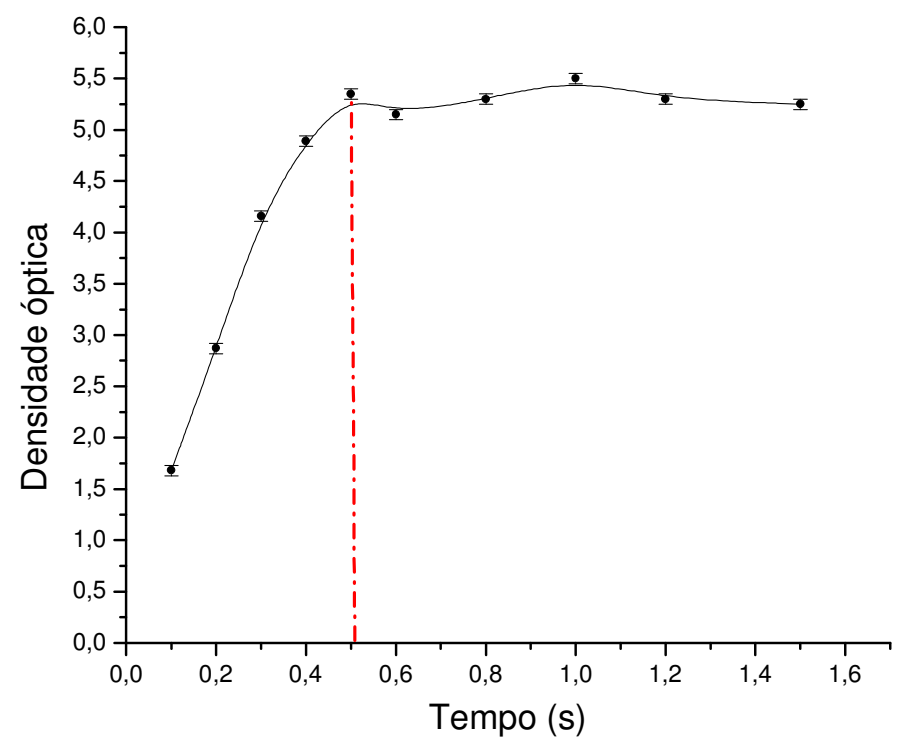

FIGURA 4.20 - Curva de tempo de exposição característica do filme ektaspeed, Kodak.

De acordo com a curva apresentada na FIG. 4.20 pode-se observar que a região de maior contraste está entre os tempos 0,1 a $0,5 \mathrm{~s}$. Sendo assim, o objeto teste foi irradiado com estes tempos e os filmes revelados de acordo com as instruções do fabricante.

Com base nas radiografias obtidas, FIG. 4.21, pode-se observar que a imagem exposta a 0,2 segundos apresentou o maior número de "orifícios" observáveis em relação aos demais filmes. Nesta imagem (em 0,2 segundos) foi possível, utilizando-se um negatoscópio, observar praticamente as sete linhas de furos nas três últimas colunas, sendo que nas duas primeiras pode-se observar claramente cinco linhas, a sexta linha é vista com certa dificuldade. A sétima linha não é visível na última coluna. 


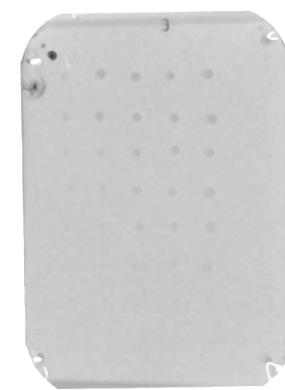

$0,1 \mathrm{~s}$

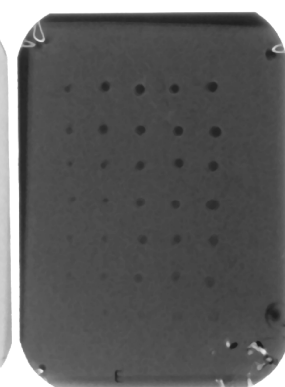

$0,2 \mathrm{~s}$

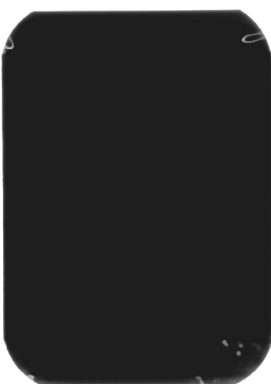

$0,3 \mathrm{~s}$

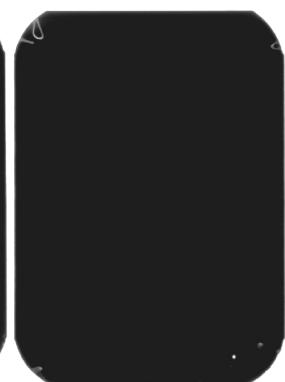

$0,4 \mathrm{~s}$

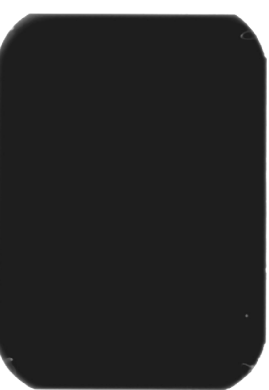

$0,5 \mathrm{~s}$

FIGURA 4.21 - Imagens do objeto teste irradiado em intervalos de tempo de 0,1 a 0,5 segundos.

$\mathrm{Na}$ imagem da radiografia exposta a 0,1 segundos foi possível observar até a sexta linha e com dificuldades.

É importante destacar que os filmes irradiados com tempos de 0,3 a 0,5 segundos apresentam densidades ópticas muito elevadas, apesar de estarem dentro do intervalo de maior contraste, o que mostra a importância de utilização deste objeto teste. 


\section{8 Integridade das vestimentas de proteção individual}

Os aventais de chumbo e os protetores de tireóide são utilizados como vestimentas de proteção individual de pacientes nos consultórios odontológicos $^{10,27,30}$; para tanto, eles devem estar em perfeitas condições para uma proteção efetiva às regiões adjacentes àquelas irradiadas ${ }^{43,52,53}$.

O avental deve possuir dimensões mínimas de $76 \mathrm{~cm}$ de comprimento por $60 \mathrm{~cm}$ de largura ${ }^{28}$ e $0,25 \mathrm{~mm}$ de espessura de chumbo.

Para a verificação da integridade destas vestimentas, neste trabalho sugere-se que inicialmente seja realizada uma inspeção visual e em seguida uma de contato, procurando alguma deformação no chumbo, ou seja, uma possível trinca. Caso alguma deformação seja encontrada, deve-se colocar um filme radiográfico atrás do avental de chumbo, na área deformada e realizar uma exposição.

Neste trabalho foram testados dois aventais ilustrados na FIG. 4.22 sendo um de borracha plumbífera (a) e um de chumbo (b) largamente utilizados.

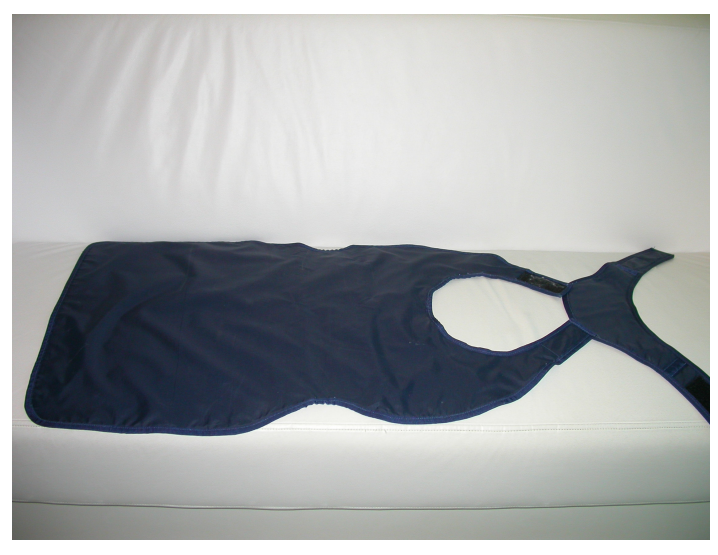

(a)

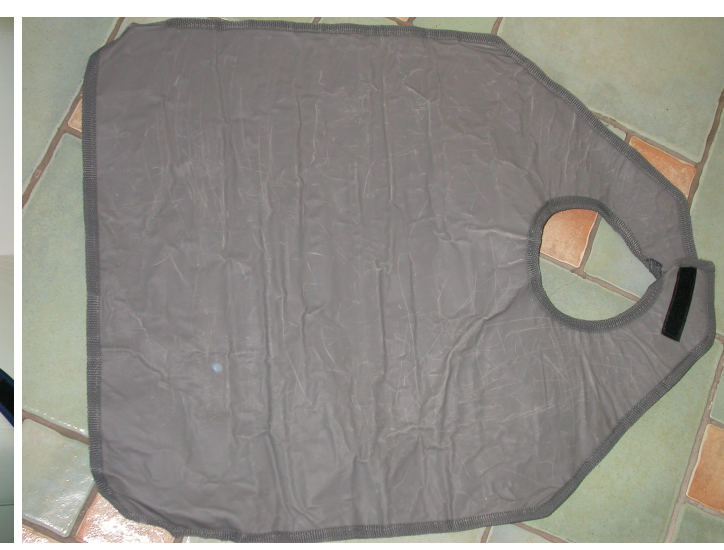

(b)

FIGURA 4.22 - Aventais de proteção individual testados: (a) avental de borracha plumbífera e (b) avental de chumbo.

Após observar-se que no avental de chumbo (b) havia deformações pelo método visual e de contato, foi realizada uma exposição à radiação-X conforme FIG. 4.23, colocando-se um filme radiográfico atrás do avental. 


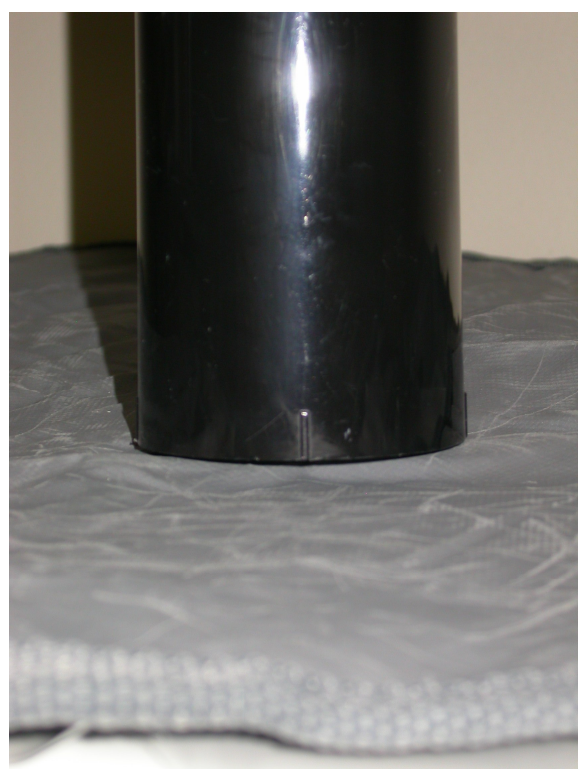

FIGURA 4.23 - Arranjo utilizado para detecção de trincas em vestimentas plumbífera.

Após a revelação do filme radiográfico pode-se fazer uma avaliação da trinca encontrada, bem como sua dimensão. Desta forma pode-se confirmar se há ou não uma transmissão da radiação através desta vestimenta, avaliando a eficiência do avental (FIG. 4.24).

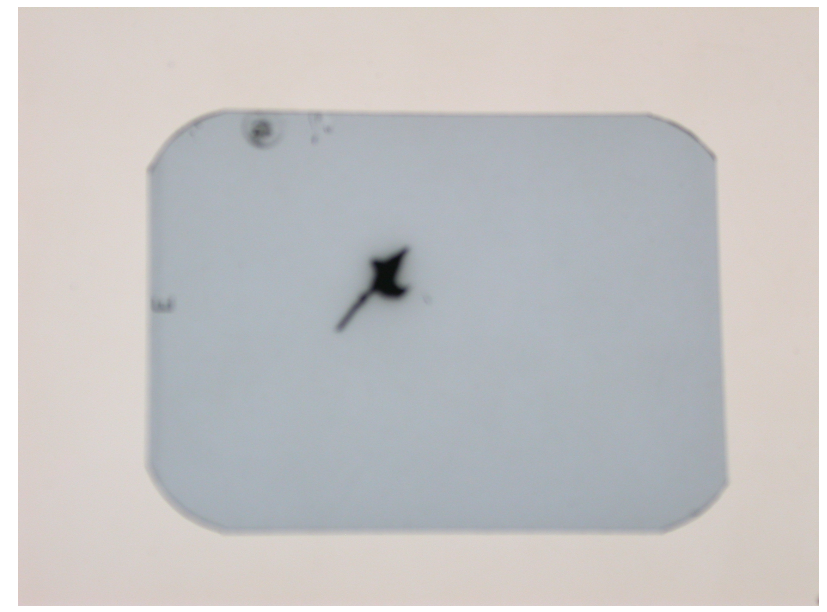

FIGURA 4.24 - Imagem da uma trinca detectada na inspeção da vestimenta. 
O resultado deste teste mostrou uma imagem radiolúcida no filme radiográfico, confirmando a presença de uma trinca no avental de chumbo da FIG. 4.22b. Este modelo de avental é confeccionado com uma lâmina de chumbo, de no mínimo 0,25 mm, e requer armazenamento adequado, sem dobras, para que não apareçam trincas durante sua vida útil.

Atualmente as novas vestimentas são confeccionadas a partir de uma borracha plumbífera, com espessura equivalente em chumbo de 0,25 mm. Neste caso é mais difícil encontrar deformações ou trincas, devido ao seu armazenamento inadequado. No entanto, o avental de chumbo mostrado na FIG. 4.22b ainda é amplamente comercializado. 


\section{CONCLUSÕES}

Os procedimentos sugeridos neste trabalho para 0 atendimento dos requisitos da $\mathrm{PF} 453^{10}$, para a realização de controle de qualidade de aparelhos de raios $\mathrm{X}$ odontológicos, demonstraram no instrumento testado, atenderem satisfatoriamente este documento.

O equipamento de raios $X$ utilizado para realização destes procedimentos é um aparelho moderno, com recursos não existentes na maioria dos utilizados pela classe odontológica, como por exemplo, a visualização simultânea do tempo nominal e tempo real de exposição, devido a um sistema de compensação automática da variação de corrente elétrica do local. Portanto, os testes de constância apresentados são de suma importância para a elaboração de procedimentos para a realização do controle de qualidade nos consultórios odontológicos, uma vez que outros modelos de aparelhos de raios $X$ fabricados podem apresentar resultados diferenciados, e os mais antigos provavelmente poderão estar em desacordo com a norma vigente.

Entretanto, é importante destacar que na utilização de posicionadores para fixar os filmes e alinhar o feixe de raios $X$ a dose de entrada na pele diminui, mas o tamanho do campo aumenta e ultrapassa o valor máximo de $6 \mathrm{~cm}$ descrito nesta portaria. Neste caso sugere-se que haja uma avaliação mais detalhada do custo-benefício no uso dos posicionadores.

Os resultados obtidos da CSR estão de acordo com a Portaria Federal $453^{10}$, porém diferem entre os arranjos apresentados. No segundo arranjo, o resultado obtido foi menor, devido à não contribuição dos fótons espalhados do feixe, o que sugere a sua utilização. No caso da utilização do primeiro arranjo, o valor da CSR poderá ser maior que o real e num eventual teste de qualidade 0 aparelho poderá ser aprovado erroneamente.

A utilização da radiografia odontológica como um exame complementar é de suma importância para um bom diagnóstico, para isso deve-se garantir a sua qualidade. As imagens obtidas por meio da exposição do objeto teste, desenvolvido neste trabalho, confirmaram a boa qualidade do aparelho de raio $\mathrm{X}$ utilizado; no entanto, demonstraram a importância mais uma vez de um dos 
princípios básicos de radioproteção, a otimização do uso da radiação ionizante, uma vez que a melhor radiografia foi obtida com um tempo de exposição menor $(0,2 \mathrm{~s})$ dentro do intervalo indicado pela curva característica do filme utilizado, diminuindo portanto a dose de radiação ao paciente e ao trabalhador.

A importância do controle de qualidade em sistemas de radiodiagnóstico odontológico é evidenciada pelo uso rotineiro da radiação- $X$ nos consultórios odontológicos. A PF $453^{10}$ recomenda a realização dos testes de constância com freqüência mínima de dois anos, porém sugere-se que o próprio profissional, cirurgião-dentista, implemente seu controle interno da qualidade das radiografias obtida em seu aparelho. Isto poderá ser executado através de exposições mensais de um objeto teste (simulador) do tipo desenvolvido neste trabalho acumulando um histórico de informações sobre seu equipamento, e se necessário realizando os testes de controle de qualidade antes dos prazos definidos pela PF $453^{10}$. 


\section{6 - REFERÊNCIAS}

1 POTIENS, M.P.A. Metodologia dosimétrica e sistema de referência para radiação $\boldsymbol{X}$ nível diagnóstico. 1999. Tese (Doutorado) - Instituto de Pesquisas Energéticas e Nucleares, São Paulo.

2 INTERNATIONAL ATOMIC ENERGY AGENCY. Safety Standards Series: Radiological Protection for Medical Exposure to lonizing Radiation. Vienna: IAEA, 2002. (Safety Guide N RS-G-1.5).

3 Radiological protection of patients in diagnostic and interventional radiology, nuclear medicine and radiotherapy: Proceedings of an International Conference Held in Malaga. In: INTERNATIONAL CONFERENCE ON RADIOLOGICAL PROTECTION OF PATIENTS IN DIAGNOSTIC AND INTERVENTIONAL RADIOLOGY, NUCLEAR MEDICINE AND RADIOTHERAPY, Mar 26-30, 2001, Spain. Proceedings series IAEA, ISSN 0074-1884.

4 SOUZA, D.N.; AZEVEDO, J.P.A.; DE OLIVEIRA, M.G. Desenvolvimento de módulos dosimétricos para radiologia. In: II seminário de Pesquisa FAPSE, out., 2004, Aracaju.

5 INTERNATIONAL ATOMIC ENERGY AGENCY. Radiation dose in diagnostic radiology and methods for doses reduction. Vienna: IAEA, 1995. (IAEATECDOC-786).

6 SOCIEDAD ESPAÑOLA DE FÍSICA MÉDICA E SOCIEDAD ESPAÑOLA DE PROTECCIÓN RADIOLÓGICA. Protocolo Español de Control de Calidad en Radiodiagnóstico, revisión 1. Madri, 2002.

7 EUROPEAN COMMISSION. European guidelines on radiation protection in dental radiology: The safe use of radiographs in dental practice, Issue $\mathrm{N}^{\circ}$ 136, Victoria University of Manchester, United Kingdom, 2004.

8 NATIONAL COUNCIL ON RADIATION PROTECTION AND MEASUREMENTS. Radiation Protection in Dentistry. Bethesda, MD, USA, 2003 (Publication 145).

9 ANDRADE, P.S.; POTIENS, M.P.A. Avaliação da necessidade de radiografias intra-orais antes e após tratamentos odontológicos. In: I Congresso Americano del IRPA 2006 / I American IRPA Congress 2006, Sep. 3-8, 2006, Acapulco, México. Proceedings IJM Acapulco 2006.

10 MINISTÉRIO DA SAÚDE, Portaria Federal 453. Diretrizes básicas de proteção radiológica em radiodiagnóstico médico e odontológico. Brasília: Diário Oficial da União. 02 Jun., 1998. 
11 MAIA. A.F. Padronização de feixes e metodologia dosimétrica em tomografia computadorizada. 2005. Tese (Doutorado) - Instituto de Pesquisas Energéticas e Nucleares, São Paulo.

12 INTERNATIONAL ELETROTECHNICAL COMISSION. Medical diagnostic $\boldsymbol{x}$ ray equipment - radiation conditions for use in the determination of characteristics. (FDIS), Geneva, 2005. (IEC 61267).

13 LECOMBER, A.R.; FAUKNER, K. Dose and risk in dental radiography. Radiat. Prot. Dosim., v. 80, n 1-3, p. 249-252, 1998.

14 NAPIER, I.D. Reference doses for dental radiography. British Dent. J., v.186, n. 8, p. 392-396, 1999.

15 GORI, C. STECCO, A.; VILLARI, N .; ZTELLI, G. Dose evaluation and quality criteria in dental radiology. Radiat. Prot. Dosim., v. 90, n. 1-2, p. 225-227, 2000.

16 WATT, J.; DAVIDSON, D.W.; JOHNSTON, C.; et al. Dose reductions in dental X-ray imaging using Medipix. Nucl. Instrum. Methodos Phys. Res., v. 513, n. 1-2, p. 65-69, 2003.

17 ALONSO, T.C.; PEREIRA, E.G.; SILVA,T.A.; GUEDES, E. Proteção radiológica em radiodiagnóstico odontológico em Minas Gerais. In. Encontro Nacional de Aplicações Nucleares, 11-16 ago., 2002, Rio de Janeiro. Anais do IV ENAN, Rio de Janeiro, 2002.

18 MELO, F.A.; KHOURY, H.J. Medidor não invasivo de $k V p$ para raios $X$ odontológico. - In. Encontro Nacional de Aplicações Nucleares, 11-16 ago., 2002, Rio de Janeiro. Anais do VI ENAN, Rio de Janeiro, 2002.

19 AGÊNCIA NACIONAL DE VIGILÂNCIA SANITÁRIA, Resolução RE ㄲo 64. Guia de procedimentos para segurança e qualidade de imagem em radiodiagnóstico médico. Brasília: Diário Oficial da União, 10 abr., 2003.

20 INTERNATIONAL ATOMIC ENERGY AGENCY. Dosimetry in diagnostic radiology. An international code of practice, Vienna: IAEA, 2005 (Draft).

21 Física Moderna: Descoberta dos raios X. Desenvolvido pelo Instituto de Física da Universidade Federal do Rio Grande do Sul. Disponível em: $<$ http://www.if.ufrgs.br/tex/fis142/fismod/mod05/m s01.html>. Acesso em: 20 jul. 2006.

22 FREITAS, A.; ROSA, J.E.; SOUZA, I.F. Radiologia Odontológica. Artes Médicas, São Paulo, 1998.

23 DE PAULA, M.V.Q; TAUHATA, L. Manual de Radioproteção Radiodiagnóstico Intra Bucal. Editora UFJF, Juiz de Fora, 2005. 
24 ROSENTHAL, E. Cem anos da descoberta dos raios $X$ (1895-1995), São Paulo, Brasil, IMOSP, 1995.

25 U.S. DEPARTMENT OF HEALTH AND HUMAN SERVICES FOOD AND DRUG ADMINISTRATION - CENTER FOR DEVICES AND RADIOLOGICAL HEALTH. Routine compliance testing procedures for diagnostic $x$-ray systems. Rockville, Maryland, 2000.

26 U.S. DEPARTMENT OF HEALTH AND HUMAN SERVICES FOOD AND DRUG ADMINISTRATION - CENTER FOR DEVICES AND RADIOLOGICAL HEALTH. Code of federal regulations: title 21(8). Rockville, Maryland, revised Apr. 2004.

27 ARGUIRÓPULO, A.Y. Desenvolvimento e implantação de um sistema de garantia da qualidade em radiologia odontológica. 1999. Tese (Doutorado) - Instituto de Radioproteção e Dosimetria, Rio de Janeiro.

28 SECRETARIA DO ESTADO DE SÃO PAULO - CENTRO DE VIGILÂNCIA SANITÁRIA, Resolução SS-625. Norma técnica que disciplina o uso de radiação ionizante nos serviços de saúde no Estado de São Paulo. São Paulo: Diário Oficial da União, 12 dez., 1994.

29 COMISSÃO NACIONAL DE ENERGIA NUCLEAR. Norma NN 3.01: Diretrizes Básicas de Proteção Radiológica. Resolução 27: Diário Oficial da União, 06 jan., 2005.

30 OKUNO, E.; CALDAS, I.L.; CHOW, C. Física para ciências biológicas e biomédicas. Harper \& Row do Brasil, São Paulo, 1982.

31 JOHNS, H.E., CUNNINGHAM, J.R. Physics of Radiology. American lecture series, 1054, $4^{\mathrm{a}}$ edition, 1983.

32 BITELLI, T. Física e Dosimetria das Radiações. Atheneu, $2^{\mathrm{a}}$ ed., São Paulo, 2006.

33 Informativo de divulgação Dabi Atlante, $\mathrm{n}^{\circ}$ 4, abril 2005. Disponível em: $<$ http://www.dabiatlante.com.br/br/produto mostra.php?id=3\&idp=18 $>$. Acesso em: 20 jan. 2007.

34 Periapical Radiography. NRPB/RCR in their document Guidelines on Radiology Standards in Primary Dental Care and in the new 2001 Guidance Notes (see Ch. 6). Disponível em: <www.fleshandbones.com/readingroom/pdf/229.pdf>. Acesso em: 30 jul. 2006.

35 DE FREITAS, L. Radiologia Bucal - Técnicas e interpretações. Pancast editora, $2^{\mathrm{a}}$ edição, 2000.

36 INTERNATIONAL COMMISSION ON RADIATION UNITS AND MEASUREMENTS. Fundamental quantities and units for ionizing radiation. Bethesda, MD, 1998 (Publication 60). 
37 CERQUEIRA, E.M.M.; GOMES-FILHO, I.S.; TRINDADE, S.; et al, Genetic damage in exfoliated cells from oral mucosa of individuals exposed to X-rays during panoramic dental radiographies, Mutat. Res., v. 562, p.111-117, 2004.

38 ANDRADE, M.L.G. Caracterização de sistemas filme-conversor para radiografia com nêutrons. 2002. Dissertação (Mestrado) - Instituto de Pesquisas Energéticas e Nucleares, São Paulo.

39 HUDA, W.; SLONE, R.M. Review of radiologic physics. Williams \& Wilkins, USA, 1995.

40 MOTA, H.C.; ARAÚJO, A.M.C.; PEIXOTO, J.E.; DREXLER, G.G. Proteção radiológica e controle de qualidade em radiologia dentária: utilização segura da radiografia na prática odontológica. Instituto de Radioproteção e Dosimetria/CNEN, Rio de Janeiro, 1994.

41 ANDRADE, P.S.; POTIENS M.P.A. Evaluation of the field size in dental diagnostic radiology system. In: II European IRPA Congress on Radiation Protection, May. 15-19, 2006, Paris, France. Proceedings IRPA, Paris, 2006.

42 CAMPOS, A.A.; WATANABE, P.C.A., PARDINI, L.C.; TAMBURUS, J.R. Avaliação do diâmetro do feixe útil de radiação de aparelhos de raios $X$ odontológicos. Rev. Odontol. Univ. São Paulo, v. 9, n. 4, p. 293-297, out/dez. 1995.

43 SOARES, F.C.S. Avaliação de dispositivos de proteção individual utilizados em radiologia diagnóstica. 2006. Dissertação (Mestrado) Instituto de Pesquisas Energéticas e Nucleares, São Paulo.

44 YAKOMAKIS, E.N.; TIERRIS, C.E; STEFANOU, E.P.; et al. Image quality assessment and radiation doses in intraoral radiography. Oral Surg. Oral Med. Oral Pathol. Oral Radiol. Endod. V. 91, n. 3, p. 362-368, 2001.

45 KUNZEL, A.; SCHERKOWSKI, D.; WILLERS, R.; BECKER, J. Visually detectable resolution of intraoral dental films. Dentomaxillofac. Radiol., v. 32, p. 385-389, 2003.

46 SERVOMAA, A. Design criteria for and evaluation of phantoms for dental radiography. Radiat. Prot. Dosim. v. 49, n. 1/3, p. 113-116, 1993.

47 Descrição do fantoma: Artinis Contrast-Detail Dental Phantom CDDENT 1.0. Disponível em: <http://www.artinis.com/cddent description.htm>. Acesso em: 12 mai. 2006.

48 ASSOCIAÇÃO BRASILEIRA DE NORMAS TÉCNICAS. Guia para a expressão da incerteza de medição. 3. ed. Rio de Janeiro: ABNT, 2003 (ABNT-INMETRO).

49 Tabela de tempo e temperatura para revelação de filmes periapicais. Disponível em:

$<$ http://www.kodakdental.com/en/film/intraoralFilm/productLiterature/intllntraora IProcessingGuidelines.html?pID=2384|>. Acesso em: 20 jan. 2007. 
50 Ministério da Saúde - Agência Nacional de Vigilância Sanitária. Radiodiagnóstico Médico: Desempenho de Equipamentos e Segurança. Brasília: Ministério da Saúde, 2005.

51 SASAKI, P.S.A.; POTIENS, M.P.A. Implementação de procedimentos para avaliação de quilovoltagem aplicado em tubos de raios X odontológicos. In: VII Encontro Nacional de Energia Nuclear, 29 ago.- 02 set. 2005, Santos, Anais do INAC 2005, Santos, 2005.

52 LAMBRECHT, J.T.; ROTH, J.; KIEFER, H.P. Dose exposition from intra - and extraoral dental radiography. International Congress Series, 1268, 11471151, 2004.

53 OGUNDARE, F.O.; ONI, O.M.; BALOGUN, F.A. Measurements of X-ray absorbed doses to dental patients in two dental X-ray units in Nigeria. Radiat. Prot. Dosim., v. 104, n. 4, p. 355-358, 2002. 